Juliana Takitane

\title{
Drogas de abuso em vítimas de mortes violentas no município de São Paulo
}

Tese apresentada à Faculdade de Medicina da Universidade de São Paulo para obtenção do título de Doutor em Ciências

Programa de Fisiopatologia Experimental Orientadora: Profa. Dra. Vilma Leyton Co-orientador: Dr. Gabriel Andreuccetti

(Versão corrigida. Resolução CoPGr 6018, de 03 de outubro de 2011. A versão original está disponível na Biblioteca FMUSP)

São Paulo 
Juliana Takitane

\section{Drogas de abuso em vítimas de mortes violentas no município de São Paulo}

Tese apresentada à Faculdade de Medicina da Universidade de São Paulo para obtenção do título de Doutor em Ciências

Programa de Fisiopatologia Experimental Orientadora: Profa. Dra. Vilma Leyton Co-orientador: Dr. Gabriel Andreuccetti

(Versão corrigida. Resolução CoPGr 6018, de 03 de outubro de 2011. A versão original está disponível na Biblioteca FMUSP)

São Paulo 
Dados Internacionais de Catalogação na Publicaçăo (CIP)

Preparada pela Biblioteca da

Faculdade de Medicina da Universidade de Săo Paulo

Creprodução autorizada pelo autor

Takitane, Juliana

Drogas de abuso em vitimas de mortes violentas no

municipio de São Paulo / Juliana Takitane. -- São

Paulo, 2019.

Tese (doutorado)--Faculdade de Medicina da

Universidade de São Paulo.

Programa de Fisiopatologia Experimental.

Orientadora: Vilma Leyton.

Coorientador: Gabriel Andreuccetti.

Descritores: 1.Causas externas 2.Drogas ilicitas 3. Toxicologia forense 4 . Sangue

USP/FM/DBD-142/19

Responsável: Erinalva da Conceiçăo Batista, CRB-8 6755 


\section{AGRADECIMENTOS}

Aos meus pais, Luiz e Mariko, pelo amor incondicional. Essa conquista é para vocês.

Aos meus irmãos, Mariana e Roberto, pelo companheirismo, amizade e carinho.

Ao Thales, que surgiu na reta final deste trabalho e se tornou meu grande companheiro e incentivador. Amo você!

À Professora Vilma Leyton, por ser mais do que uma orientadora. Muito obrigada pela paciência, pelo amor e pelo cuidado que tem conosco.

Ao Professor Daniel Romero Muñoz pelo apoio e incentivo às pesquisas desenvolvidas no Departamento de Medicina Legal, Ética Médica e Medicina Social e do Trabalho da FMUSP.

Ao meu co-orientador Gabriel Andreuccetti, por ter aceitado este papel e dividido comigo todo conhecimento.

Aos amigos do Departamento de Ciências Forenses, do Hospital Universitário de Oslo, que fizeram parte de uma das experiências mais incríveis que vivenciei. Eleninha e Doffen, obrigada por me acolher com tanto carinho e dividir a família e amigos de vocês comigo. Thomas, serei eternamente grata pela paciência que teve comigo neste período e por todo aprendizado que me proporcionou. Hallvard, Vigdis e Stig Tore, obrigada por tornarem tudo aquilo possível e por me receberem tão bem.

Às amigas mais "Good Vibes" que eu poderia desejar. Dani, Li (colega), Malu e Tali, a amizade de vocês é uma das coisas mais preciosas que São Paulo me deu. Amo vocês!

À Dani (sim, vou repetir), porque como eu já te disse, apesar dos nossos gênios tão diferentes, você é quem me vem à mente quando algo acontece na minha vida e eu quero compartilhar. Obrigada por ser a melhor companheira de (ex-) sala!

À Ana Miguel, que foi, sem dúvidas, a melhor pessoa que conheci nos últimos anos. Amiga, muito muito obrigada por ser parte da minha vida. Meu, sério, se todos tivessem uma Ana em suas vidas, as pessoas seriam infinitamente mais felizes. Sinto falta de você todos os dias, mas já sabemos que nossa amizade será para sempre.

Aos amigos da minha "Família da Vida". Clari, Fer, Julitos e Rachel, vocês são, sim, os melhores amigos que o IOF poderia ter me dado. Que venham muitos cafés e Natais juntos!

Aos amigos queridos do Laboratório de Toxicologia. Ana Flávia, Ju Mag(r)a, Helena, Henrique, Mari e Ana Mielli, para mim é uma felicidade enorme poder 
contar com a amizade de vocês. Obrigada por todas as nossas conversas e desabafos, idas ao bandejão, gordices e ajuda para quebrar a cabeça com as análises.

Às funcionárias do Departamento de Medicina Legal, Ética Médica e Medicina Social e do Trabalho: Branca, Paula, Dirce, Rô, Sol e Fátima. E ao Valtair, pela presteza em nos ajudar.

A todos os funcionários da pós-graduação, em especial à Chefe do Serviço de Pós-Graduação da FMUSP, Ângela Guedes, por ter sido sempre muito atenciosa e solícita quando necessitei.

Ao Marcelo Filonzi, pela amizade e disposição em sempre nos ajudar.

Às amigas de infância e do coração, Camila, Melina e Sassa, por essa amizade tão linda que cultivamos ao longo desses anos. Obrigada pelos puxões de orelha e pelas palavras de conforto. Amo vocês, para sempre!

À Sassa (sim, vou repetir de novo), por estar presente em todos os momentos. Amiga, saber que posso contar sempre com você (e a recíproca é verdadeira!) torna tudo mais fácil e leve.

Àquele que (res)surgiu há pouco tempo, mas que se tornou um bom amigo: BRUNO, obrigada pela força, pelas piadas de gosto duvidoso (brincadeira) e pelos cafés à distância.

À Superintendência da Polícia Técnico-Científica, por permitir com que a pesquisa fosse realizada.

A todos os funcionários das Equipes de Perícias Médico Legais da cidade de São Paulo pela compreensão com o estudo e por torná-lo possível.

Ao LIM-40 do Hospital das Clínicas da Faculdade de Medicina da USP.

À Coordenação de Aperfeiçoamento de Pessoal de Nível Superior (CAPES), pela bolsa e pelo auxílio financeiro concedidos. Programa de Demanda Social. Programa de Doutorado Sanduíche no Exterior/Processo no 88881.133873/2016-01. Programa Ciências Forenses - Edital 25/2014/Processo ำ 88882.160442/2017-01. 


\section{NORMALIZAÇÃO ADOTADA}

Esta tese está de acordo com as seguintes normas em vigor no momento desta publicação:

Referências: adaptado de International Committee of Medical Journals Editors (Vancouver).

Universidade de São Paulo. Faculdade de Medicina. Divisão de Biblioteca e Documentação. Guia de apresentação de dissertações, teses e monografias. Elaborado por Anneliese Carneiro da Cunha, Maria Julia de A. L. Freddi, Maria F. Crestana, Marinalva de Souza Aragão, Suely Campos Cardoso, Valéria Vilhena. 3a ed. São Paulo: Divisão de Biblioteca e Documentação; 2011.

Abreviaturas dos títulos dos periódicos de acordo com List of Journals Indexed in Index Medicus. 


\section{SUMÁRIO}

Lista de Siglas
Lista de Figuras
Lista de Tabelas
Lista de Quadros
Resumo
Abstract
1 INTRODUÇÃO

1.1 Uso de drogas no mundo

1.2 Uso de drogas ilícitas no Brasil .....

1.3 Mortes decorrentes de causas externas e a associação entre violência e o consumo de drogas

1.3.1 Mortes por causas externas (acidentes e violências).

1.3.2 Drogas de abuso e a precipitação de episódios de violência............... 8

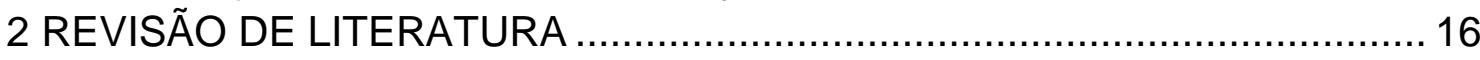

2.1 Aspectos gerais das substâncias pesquisadas .................................... 16

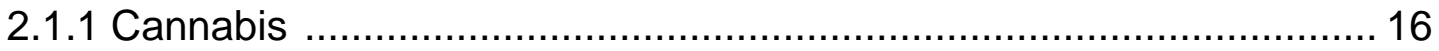

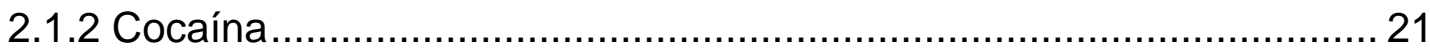

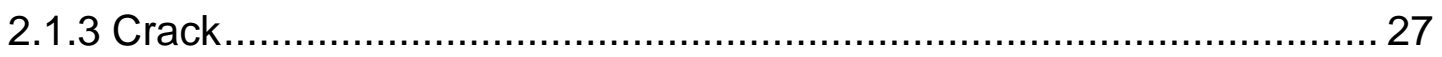

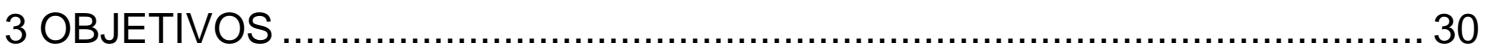

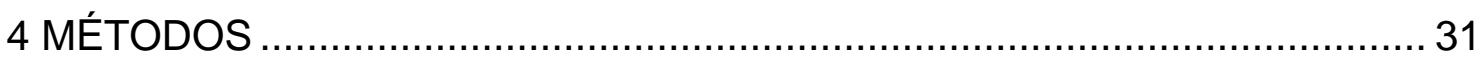

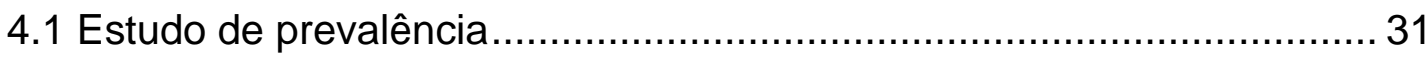

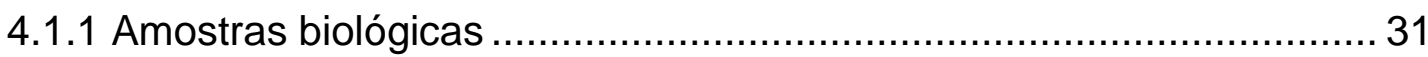

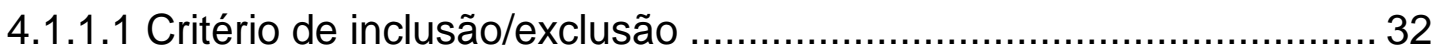

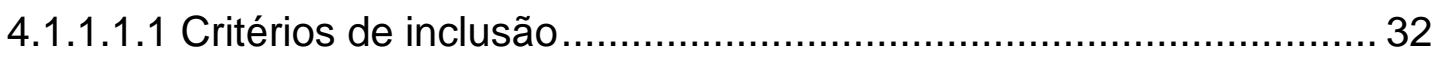

4.1.1.1.2 Critérios de exclusão .............................................................. 32

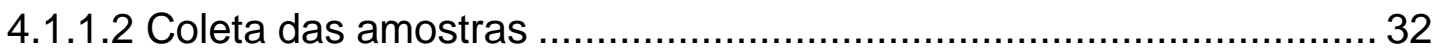

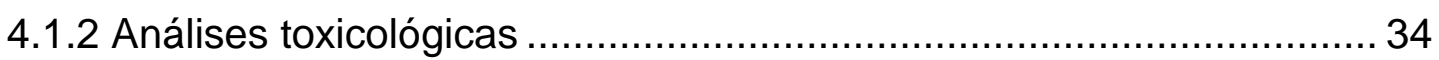

4.1.3 Coleta dos dados do contexto da lesão e sociodemográficos das vítimas.

4.2 Desenvolvimento e validação de metodologia em UHPLC-MS/MS para quantificação de cocaína, benzoilecgonina, cocaetileno e anidroecgonina metil éster.

4.2.1 Material para análises toxicológicas.................................................. 36

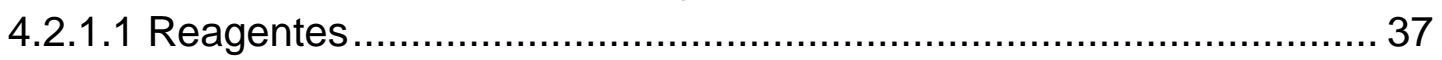

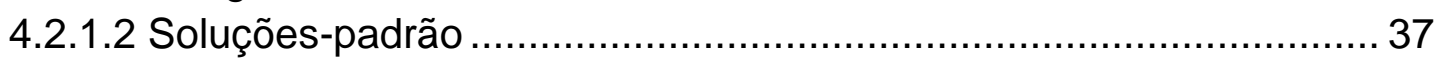

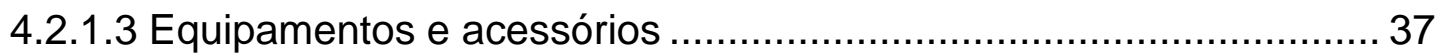

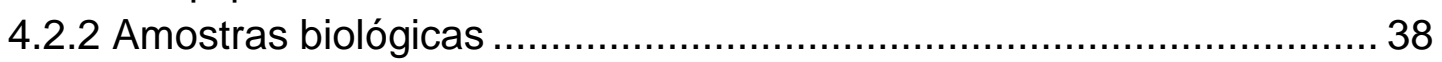

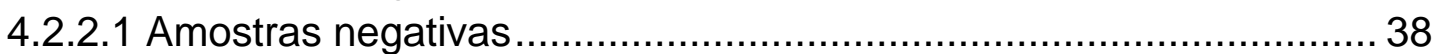

4.2.2.2 Amostras de sangue postmortem .............................................. 38 
4.2.3 Preparo dos calibradores, controles de qualidade e padrões internos

4.2.4 Procedimento de extração/Preparo das amostras ............................. 39

4.2.5 Condições UHPLC-MS/MS .......................................................... 40

4.2.6 Validação do método para determinação de cocaína e produtos de biotransformação em amostras de sangue total ........................................ 42

4.2.6.1 Curva de calibração e linearidade ................................................ 42

4.2.6.2 Limite de detecção (LD) e limite de quantificação (LQ) ................... 42

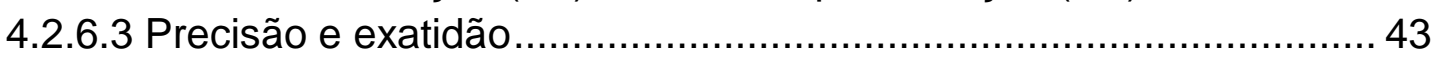

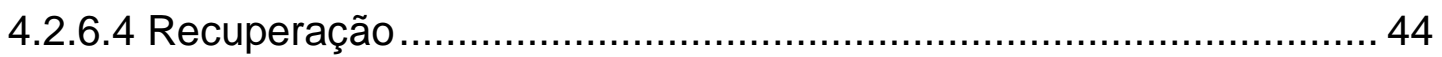

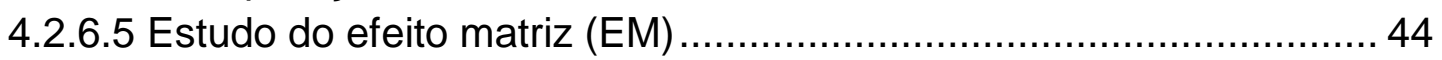

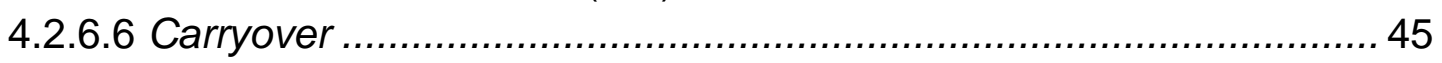

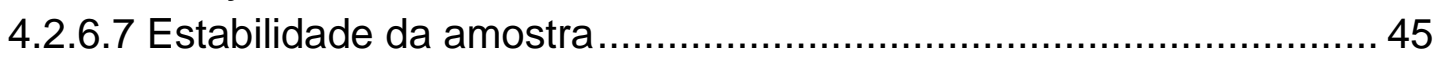

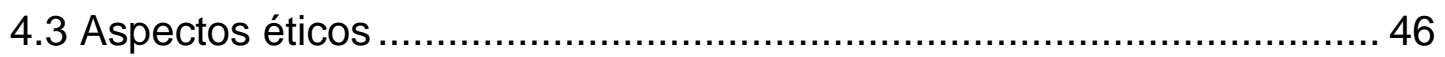

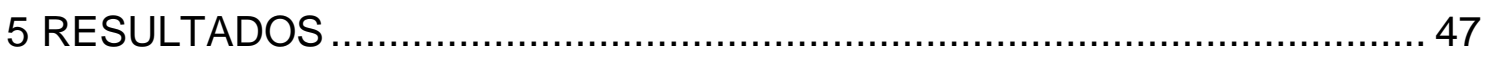

5.1 Estudo de prevalência....................................................................... 47

5.2 Desenvolvimento e validação de metodologia em UHPLC-MS/MS para quantificação de cocaína, benzoilecgonina, cocaetileno e anidroecgonina

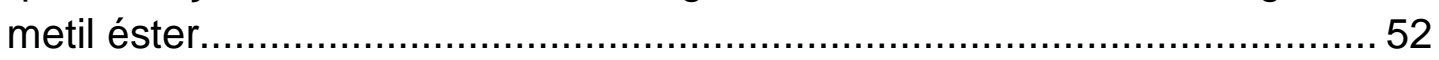

5.2.1 Otimização do procedimento de extração ……………………........ 52

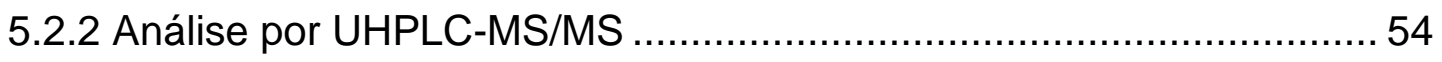

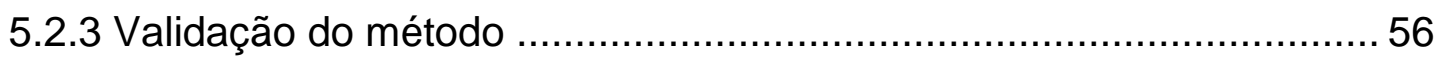

5.2.3.1 Curva de calibração e linearidade .................................................. 56

5.2.3.2 Limite de detecção (LD) e limite de quantificação (LQ) ................... 56

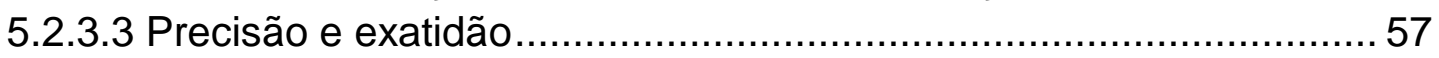

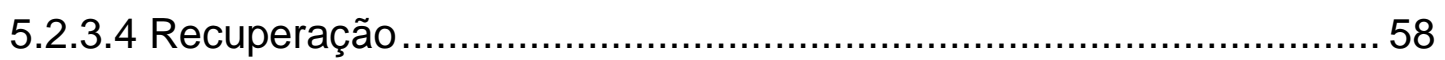

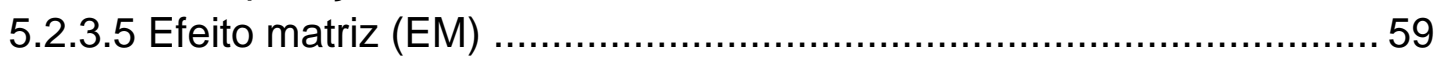

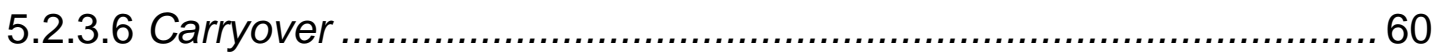

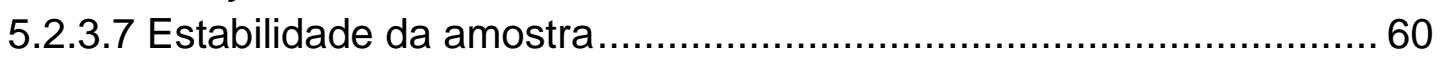

5.2.4 Aplicação do método em amostras de sangue postmortem e cálculo de

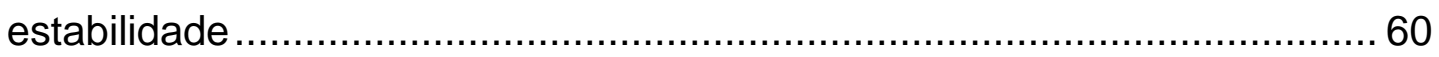

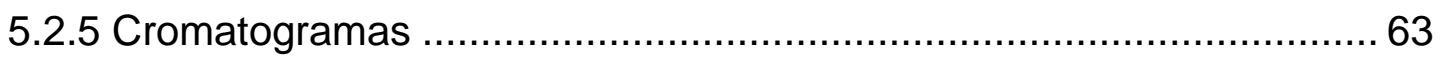

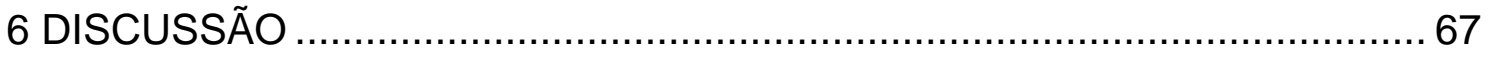

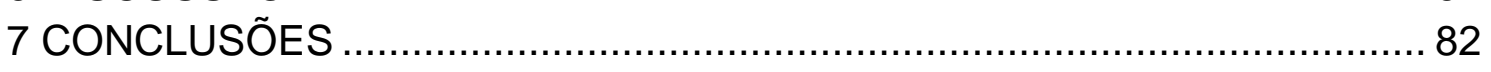

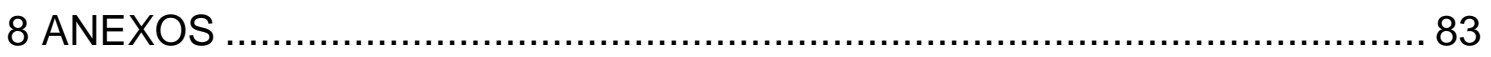

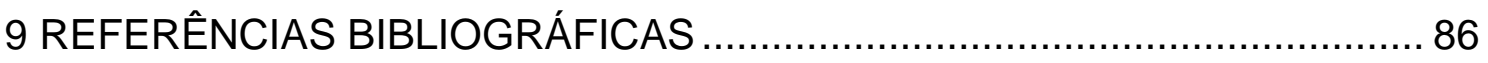




\section{LISTA DE SIGLAS}

\begin{tabular}{|c|c|}
\hline$\Delta^{9}-\mathrm{THC}$ & delta-9-tetrahidrocanabinol \\
\hline 11-OH-THC & 11-hidroxitetrahidrocanabinol \\
\hline AEME & Anidroecgonina metil éster \\
\hline BChE & Butirilcolinesterase \\
\hline $\mathrm{BO}$ & Boletim de Ocorrência \\
\hline BZE & Benzoilecgonina \\
\hline CAPES & $\begin{array}{l}\text { Coordenação de Aperfeiçoamento de Pessoal de Nível } \\
\text { Superior }\end{array}$ \\
\hline $\mathrm{CB}_{1}$ & Receptores canabinoides do tipo 1 \\
\hline $\mathrm{CB}_{2}$ & Receptores canabinoides do tipo 2 \\
\hline CBD & Canabidiol \\
\hline CBN & Canabinol \\
\hline CE & Cocaetileno \\
\hline CEP-FMUSP & $\begin{array}{l}\text { Comitê de Ética em Pesquisa da Faculdade de Medicina } \\
\text { da Universidade de São Paulo }\end{array}$ \\
\hline CQ & Controle de Qualidade \\
\hline DPR & Desvio Padrão Relativo \\
\hline EDTA & $\begin{array}{l}\text { Ethylenediamine tetraacetic acid (ácido etilenodiamino } \\
\text { tetra-acético) }\end{array}$ \\
\hline ELISA & $\begin{array}{l}\text { Enzyme-Linked Immunosorbent Assay (ensaio de } \\
\text { imunoabsorção enzimática) }\end{array}$ \\
\hline EM & Efeito Matriz \\
\hline EME & Ecgonina Metil Éster \\
\hline EPML & Equipe de Perícia Médico Legal \\
\hline ESI & Electrospray lonization (ionização por "electrospray") \\
\hline FAB & Ferimento por Arma Branca \\
\hline FAF & Ferimento por Arma de Fogo \\
\hline GC-MS & $\begin{array}{l}\text { Gas Chromatography-Mass Spectrometry (cromatografia } \\
\text { gasosa acoplada à espectrometria de massas) }\end{array}$ \\
\hline HIV & $\begin{array}{l}\text { Human Immunodeficiency Virus (vírus da imunodeficiência } \\
\text { humana) }\end{array}$ \\
\hline IML & Instituto Médico Legal \\
\hline
\end{tabular}



IML-SP
Instituto Médico Legal do Estado de São Paulo
LC-MS
Liquid Chromatography-Mass Spectrometry (cromatografia líquida com espectrômetro de massas)
LC-MS/MS
Liquid Chromatography tandem Mass Spectrometry (cromatografia líquida com espectrômetro de massas em tandem)
LD
Limite de Detecção
LENAD
Levantamento Nacional de Álcool e Drogas
LLE
Liquid-Liquid Extraction (extração líquido-líquido)
LPME
Liquid-Phase Microextraction (microextração em fase sólida)
LQ
Limite de Quantificação
LT-FMUSP Laboratório de Toxicologia da Faculdade de Medicina da Universidade de São Paulo
MRM
Multiple Reaction Monitoring (monitoramento de reações múltiplas)
MTBE
NPS
OBID
Methyl Tert - Butyl Ether (éter metil terc-butílico)
New Psychoactive Substances (novas substâncias psicoativas)
PDSE
Observatório Brasileiro de Informações sobre Drogas
PI
Programa de Doutorado Sanduíche no Exterior
PIB
Padrão Interno
PPT
Produto Interno Bruto
Protein Precipitation Technique (técnica de precipitação de proteínas)
SDS
Severity Dependence Scale (escala de severidade de dependência)
SENAD Secretaria Nacional de Políticas sobre Drogas
SLE
Solid Liquid Extraction (extração sólido-líquido)
SPE
Solid Phase Extraction (extração em fase sólida)
SPTC
Superintendência da Polícia Técnico-Científica
$\mathrm{THC}-\mathrm{COOH}$ ácido 11-nor-delta-9-tetrahidrocanabinol carboxílico
TR Tempo de Retenção 
TRR

Tempo de Retenção Relativo

UHPLC-MS/MS Ultra-High Performance Liquid Chromatography-tandem Mass-Spectrometry (cromatografia líquida de ultra-alta eficiência acoplada à espectrometria de massas em tandem)

UNODC United Nations Office on Drugs and Crime (escritório das Nações Unidas sobre drogas e crime)

$\mathrm{Vd}$

Volume de distribuição 


\section{LISTA DE FIGURAS}

Figura 1 - Distribuição dos casos não incluídos na amostra final, conforme critério de exclusão

Figura 2 - (a) Separação cromatográfica de AEME, benzoilecgonina, cocaína, cocaetileno e 23 drogas e produtos de biotransformação utilizando-se 0 método desenvolvido e (b) separação dos 27 analitos, com apresentação do gradiente de eluição

Figura 3 - Fragmentos monitorados e cromatogramas referentes a uma amostra adicionada dos padrões de drogas na concentração de $1,0 \mathrm{ng} / \mathrm{mL}$. Os respectivos padrões internos foram adicionados na concentração de $100 \mathrm{ng} / \mathrm{mL}$

Figura 4 - Fragmentos monitorados e cromatogramas referentes a uma amostra de sangue postmortem submetida ao método desenvolvido. As concentrações obtidas respectivamente para AEME, benzoilecgonina, cocaína e cocaetileno foram: $0,3 \mathrm{ng} / \mathrm{mL}, 11 \mathrm{ng} / \mathrm{mL}, 0,7 \mathrm{ng} / \mathrm{mL}$ e $1,1 \mathrm{ng} / \mathrm{mL}$. Os respectivos padrões internos foram adicionados na concentração de 100 $\mathrm{ng} / \mathrm{mL}$

Figura 5 - Fragmentos monitorados e cromatogramas referentes a uma amostra de sangue "branco", isenta de quaisquer analitos pesquisados. Não foram adicionados padrões internos também. 


\section{LISTA DE TABELAS}

Tabela 1 - Valores de cutoffs $(\mathrm{ng} / \mathrm{mL})$ adotados nas etapas de triagem e confirmação para cocaína e canabinoides

Tabela 2 - Fragmentos monitorados para os analitos e respectivos padrões internos, voltagem de ionização, energia de colisão e tempo de monitoramento

Tabela 3 - Parâmetros cromatográficos adotados nas análises.

Tabela 4 - Número de óbitos por causas externas registrados na cidade de São Paulo, em 2013, e a amostra incluída no estudo $(n=365)$ de acordo com o tipo de lesão.

Tabela 5 - Uso de substâncias (cocaína e/ou cannabis) por vítimas de causas externas e informações sociodemográficas e do contexto da lesão

Tabela 6 - Teste de solventes orgânicos (composição e volume) e recuperação dos analitos

Tabela 7 - Valores dos coeficientes de determinação $\left(R^{2}\right)$, desvio padrão relativo e faixa de linearidade dos analitos.

Tabela 8 - Limites de detecção (LD) e limites de quantificação (LQ) para os analitos pesquisados

Tabela 9 - Resultados dos estudos de precisão e exatidão do método

Tabela 10 - Valores de recuperação obtidos com a aplicação do método proposto em amostras de sangue

Tabela 11 - Estudo de efeito matriz

Tabela 12 - Análise de amostras de sangue postmortem, estabilidade e dados das vítimas e ocorrências.

Tabela 13 - Tempo de retenção e tempo de retenção relativo dos analitos em estudo 


\section{LISTA DE QUADROS}

Quadro 1 - Início, intensidade e duração dos efeitos do consumo da cocaína e a via de administração

Quadro 2 - Concentrações plasmáticas da cocaína e seus produtos de biotransformação. 


\section{RESUMO}

Takitane J. Drogas de abuso em vítimas de mortes violentas no município de São Paulo [tese]. Faculdade de Medicina da Universidade de São Paulo; 2019.

Aproximadamente 5,6\% da população mundial, entre 15 e 64 anos de idade, usaram algum tipo de droga pelo menos uma vez, no ano de 2016. Estimativas indicam que no ano de 2015 aproximadamente 450 mil pessoas morreram em todo o mundo por motivos diversos, porém todos relacionados de alguma forma às drogas. Além disso, o consumo de cannabis e cocaína estão entre os mais associados aos prejuízos advindos dos transtornos relacionados ao uso de drogas ilícitas na América Latina. Dessa forma, este trabalho teve como objetivos avaliar a prevalência do consumo de cannabis e cocaína por vítimas de causas externas (acidentes e violências), necropsiadas no Instituto Médico Legal de São Paulo (IML-SP). Além disso, foi proposto também o desenvolvimento e validação de um método em Cromatografia Líquida de Ultra Eficiência acoplada à Espectrometria de Massas sequencial (UHPLC-MS/MS) para quantificação de cocaína, benzoilecgonina, cocaetileno e anidroecgonina metil éster (AEME) em sangue, empregando-se a técnica de extração líquido-líquido com solventes não clorados, que permite a distinção das diferentes vias de administração da cocaína. Foi utilizado um método de amostragem probabilística para a coleta das amostras de sangue postmortem, entre os meses de junho de 2014 a dezembro de 2015. A etapa de triagem das análises toxicológicas foi feita por Ensaio de Imunoabsorção Enzimática e as amostras positivas foram confirmadas pelas técnicas de Cromatografia Líquida acoplada à Espectrometria de Massas sequencial e Cromatografia Gasosa acoplada à Espectrometria de Massas. Ao longo de 19 meses consecutivos, foram coletadas 365 amostras de sangue postmortem, as quais apresentaram positividade de quase um terço para cannabis e/ou cocaína. Indivíduos do sexo masculino, jovens $(\leq 30$ anos de idade) e que apresentavam algum registro de antecedentes criminais foram os mais prováveis $(P \leq 0,05)$ de terem feito uso de alguma substância pesquisada. Entre as causas do óbito estudadas, o uso de cannabis foi mais prevalente entre as vítimas de acidentes de trânsito, enquanto o consumo de cocaína ou de pelo menos uma das drogas foi maior entre as vítimas de homicídio. Utilizou-se uma mistura de éter metil terc-butílico e 2-propanol como solventes orgânicos para a extração da cocaína e produtos de biotransformação e detecção por UHPLCMS/MS, método que se mostrou preciso, exato, robusto e sensível para a determinação dos analitos de interesse. Acredita-se que o estudo dos resultados toxicológicos em ocorrências com desfechos fatais é de grande importância pois fornece informações que podem auxiliar políticas de prevenção e o combate ao uso de substâncias psicoativas.

Descritores: Causas externas, Drogas ilícitas, Toxicologia forense, Sangue 


\begin{abstract}
Takitane J. Drugs of abuse in victims of violent deaths in the city of Sao Paulo [thesis]. Faculdade de Medicina da Universidade de São Paulo; 2019.

Approximately $5.6 \%$ of the world's population aged 15-64 years used some type of drug at least once in 2016. Estimates indicate that in 2015 approximately 450,000 people died worldwide for different reasons, but all of them related in some way to drugs. In addition, the consumption of cannabis and cocaine are among the most associated with the damages resulting from illicit drug use disorders in Latin America. The aim of this study was to evaluate the prevalence of consumption of cannabis and cocaine by victims of external causes (accidents and violence), necropsied at the Legal Medical Institute in the city of Sao Paulo (IML/SP). In addition, the aim of this study was to develop and validate an UltraHigh-Performance Liquid Chromatography-tandem Mass Spectrometry (UHPLC-MS/MS) for quantification of cocaine, benzoylecgonine, cocaethylene and anhydroecgonine methyl ester (AEME) in blood, using Liquid-Liquid Extraction with non-chlorinated solvents, which allows distinguishing among different routes of administration of cocaine. A probabilistic sampling method was used to collect postmortem blood samples from June 2014 to December 2015. The screening step of the toxicological analyzes was done by Enzyme-Linked Immunosorbent Assay and the positive samples were confirmed by Liquid Chromatography-tandem Mass Spectrometry and Gas Chromatography coupled to Mass Spectrometry. Over a period of 19 consecutive months, 365 postmortem blood samples were collected, which were positive for almost one third for cannabis and / or cocaine. Males, young ( $\leq 30$ years old) and those who had some criminal history record were the most likely $(P \leq 0.05)$ to have used any substance searched. Among the causes of death, the use of cannabis was more prevalent among victims of traffic accidents, while cocaine use or the consumption of at least one of the drugs was higher among homicide victims. A mixture of methyl tert-butyl ether and 2-propanol as organic solvents for the extraction of cocaine and metabolites and detection by UHPLC-MS/MS was used and the developed method was precise, accurate, robust and sensitive for the determination of analytes of interest. The study of toxicological results in occurrences with fatal outcomes is of great importance because it provides information that can aid in prevention policies and in the fight against the use of psychoactive substances.
\end{abstract}

Descriptors: External causes, Street drugs, Forensic toxicology, Blood 


\section{INTRODUÇÃO}

\subsection{Uso de drogas no mundo}

De acordo com levantamento feito pelo Escritório das Nações Unidas sobre Drogas e Crimes (UNODC), o mundo se depara atualmente com uma variedade de drogas ilícitas como jamais vista e a expansão no mercado fornecedor dessas substâncias (sendo, inclusive, facilitado pelas transações online através da chamada darknet) para regiões até então não habituais (UNODC, 2018).

Aproximadamente $5,6 \%$ da população mundial (uma a cada 18 pessoas), entre 15 e 64 anos de idade, usaram algum tipo de droga (substâncias psicoativas, ilícitas e/ou fármacos de uso médico controlado, quando produzidos e comercializados sem controle dos órgãos sanitários ou se consumidos sem prescrição médica) pelo menos uma vez, no ano de 2016. Este consumo, que é maior entre a população jovem, pode chegar a níveis tão prejudiciais (a ponto de causar dependência e/ou requerer tratamento) para cerca de 31 milhões de pessoas, além de ter levado a óbito aproximadamente 450 mil pessoas em 2015, sendo $37,3 \%$ destes diretamente associados ao consumo de drogas (principalmente por overdose) e o restante atribuído a fatores indiretos como, por exemplo, mortes por complicações decorrentes do HIV (do inglês, "Human Immunodeficiency Virus") ou Hepatite C adquiridos através da administração não segura dessas substâncias (UNODC, 2018).

Muito embora tenha havido um decréscimo na apreensão de cannabis, particularmente na América do Norte (provavelmente em virtude do uso medicinal e da legalização do uso recreativo em muitos estados), ela continuou 
sendo a substância mais consumida mundialmente em 2016, com 192 milhões de usuários naquele ano (3,9\% da população global, entre 15 e 64 anos de idade); além disso, dados coletados de 130 países sugerem que o uso tem se destacado também entre os mais jovens (estudantes, em sua maioria, entre 15 e 16 anos). Apesar disso, é o consumo indevido de opiáceos (substâncias naturais, derivadas da papoula, como a morfina e a codeína) e de opióides (classe que inclui tanto as drogas naturais como as sintéticas relacionadas, tais como a heroína, oxicodona, meperidina, o propoxifeno e a metadona e que atuam nos receptores opióides neuronais) que tem sido motivo de grande preocupação por serem os maiores causadores de danos à saúde dos que consomem drogas. A exemplo, em 2015, $76 \%$ das mortes decorrentes de distúrbios relacionados ao uso de drogas estiveram relacionadas ao uso de opióides e, naquele mesmo ano, 34,3 milhões de pessoas $(0,7 \%$ da população mundial entre 15 e 64 anos de idade) afirmaram terem feito uso dessas substâncias. A produção global total de ópio aumentou em 65\% de 2016 para 2017, a maior já registrada desde o início dos levantamentos feitos pelo UNODC, com destaque para o Afeganistão (UNODC, 2018).

Após uma queda observada entre os anos de 2005 e 2013, a produção de cocaína aumentou em 56\% no período compreendido entre 2013 e 2016, atingindo 1410 toneladas neste último ano do levantamento. A maior parte da droga que circula no mundo vem da Colômbia, que possui $69 \%$ da área total de cultivo no mundo. O maior aumento observado na apreensão da droga, em 2016, se deu na Ásia e na África, refletindo a expansão do tráfico e consumo para mercados emergentes. O consumo de cocaína permanece concentrado na 
América do Norte e na América do Sul, onde, respectivamente, 1,9\% e 0,95\% da população entre 15 e 64 anos de idade fizeram uso em 2016 e na Oceania (1,7\%) e Europa Ocidental e Central (1,2\%) (UNODC, 2015; UNODC, 2018).

Nos últimos anos, centenas de Novas Substâncias Psicoativas (NPS, do inglês "New Psychoactive Substances") pertencentes a diferentes classes de drogas (estimulantes, agonistas dos receptores canabinoides, alucinógenos, etc.) foram sintetizadas e incorporadas ao mercado. Apesar da quantidade global apreendida ter sofrido uma queda em 2016, verificou-se que essas substâncias estão presentes em um maior número de países ao redor do mundo o que, somado aos desafios analíticos inerentes a elas, dificulta ainda mais sua detecção e controle (UNODC, 2018).

Com relação a diferenças entre gêneros, foi verificado que o consumo não prescrito de opióides e tranquilizantes por mulheres se equipara (ou é até mesmo discretamente maior) aos homens. Por outro lado, indivíduos do sexo masculino são muito mais propensos a utilizarem cannabis, cocaína e opiáceos. Interessante observar que o primeiro contato das mulheres com as drogas geralmente é mais tardio quando comparado aos homens, porém uma vez iniciado, as mulheres tendem a aumentar as taxas de consumo de álcool, cannabis, cocaína e opióides muito mais rapidamente que eles. Outra diferença é que as mulheres geralmente associam o consumo de drogas a um parceiro íntimo, enquanto os homens tendem a compartilhar este momento com amigos do mesmo sexo. Apesar da falta de dados mais consistentes em termos epidemiológicos e, principalmente, acerca dos fatores determinantes, sabe-se que as mulheres têm ocupado importantes papeis dentro da cadeia de 
fornecimento de drogas, seja na presidência de organizações de tráfico internacionais, no cultivo da papoula no Afeganistão ou da coca na Colômbia e no tráfico de drogas, como as chamadas "mulas" (UNODC, 2018).

\subsection{Uso de drogas ilícitas no Brasil}

Seguindo a tendência mundial, a substância ilícita com maior prevalência de uso na população brasileira é a cannabis, seguida da cocaína. Em uma pesquisa conduzida no país nos anos de 2011 e 2012, do total da população adulta, 5,8\% declararam já ter usado a substância alguma vez na vida (7,8 milhões de brasileiros adultos). Entre os adolescentes esse número é de 597 mil indivíduos (4,3\%) dentre quase 14 milhões de adolescentes brasileiros. Analisando o uso nos últimos 12 meses anteriores ao levantamento, 2,5\% dos brasileiros adultos declararam ter usado e $3,4 \%$ dos adolescentes representando mais de 3 milhões de adultos e 478 mil adolescentes em todo país (Laranjeira, 2014).

O Brasil foi identificado pela UNODC como uma das nações emergentes na qual o uso de cocaína (tanto na forma intranasal como fumada) tem aumentado, em contraste com países onde o consumo tem declinado, como é o caso dos Estados Unidos, ou se mantido estável, como ocorre na maioria dos países europeus (UNODC, 2018). Algumas das razões apontadas como causas da elevada taxa de consumo de cocaína no Brasil são: (i) a posição geográfica que o país ocupa, ao fazer fronteira com os maiores produtores mundiais da droga - Peru, Colômbia e Bolívia, (ii) população jovem (quase 35\% da população se encontra na faixa etária compreendida entre 15 e 34 anos de idade), (iii) crescimento econômico vivenciado na última década no país, o qual reflete no 
aumento do poder aquisitivo da população e (iv) o baixo custo da droga no Brasil (cerca de US\$21,28/grama. Para efeitos de comparação, nos EUA ela chega a custar US\$ 87,82/grama e, na Europa, entre US\$ 95,28 a 127,04/grama) (IBGE, 2010; Abdalla et al., 2014).

Dados do II Levantamento Nacional de Álcool e Drogas (LENAD), conduzido no Brasil entre novembro de 2011 e março de 2012, revelaram que no ano anterior à pesquisa, 2,2\% dos entrevistados fizeram uso de cocaína e/ou crack, o que representa cerca de 3 milhões e 200 mil pessoas. As prevalências de uso da forma em pó (administração intranasal) em algum momento da vida e no ano anterior à pesquisa foram de 3,9\% e 1,7\%, respectivamente. Já para a forma inalada (fumada), as porcentagens foram de 1,5\% (algum momento da vida) e $0,8 \%$ (no ano anterior), sendo que a forma de apresentação da droga difere de acordo com a região do país, sendo o crack mais comum no Sul e Sudeste e a merla, no Norte (Galduróz et al., 2000; Carlini et al., 2002; Laranjeira, 2014). A dependência foi avaliada utilizando-se a Escala SDS (do inglês, "Severity Dependence Scale"), a qual revelou uma taxa de dependência entre os usuários de 41,4\%. Vários estudos demonstraram que quanto mais cedo se inicia o contato com a droga, maiores são as chances de desenvolver dependência e outras doenças psiquiátricas. Neste estudo, verificou-se que quase metade (45\%) dos usuários de cocaína experimentaram-na pela primeira vez antes dos 18 anos de idade. Em consonância com outros estudos, o consumo de cocaína foi maior entre indivíduos do sexo masculino, enquanto as mulheres se demonstraram mais vulneráveis a desenvolver síndrome de abstinência (Laranjeira, 2014). 
Outras substâncias citadas pelos entrevistados do estudo brasileiro foram tranquilizantes, estimulantes tipo anfetaminas e solventes (como cola de sapateiro, por exemplo), cujas prevalências de uso alguma vez na vida foram, respectivamente, $9,6 \%, 2,7 \%$ e $2,2 \%$ da população com 18 anos ou mais (Laranjeira, 2014).

\subsection{Mortes decorrentes de causas externas e a associação entre violência e o consumo de drogas}

\subsubsection{Mortes por causas externas (acidentes e violências)}

Anualmente, mais de cinco milhões de pessoas no mundo perdem suas vidas em decorrência das causas externas, as quais podem ser provocadas por lesões não intencionais (acidentes de trânsito, envenenamentos, quedas, incêndios, afogamentos, exposição a forças mecânicas, desastres naturais e outros) ou lesões intencionais (autoprovocadas voluntariamente, interpessoal e intervenções legais e operações de guerra (WHO, 2018a). Este número é cerca de 1,7 vezes maior que o número de mortes resultante do somatório das fatalidades atribuídas ao HIV/AIDS, tuberculose e malária. Aproximadamente 25\% das mortes nesta categoria são decorrentes de suicídio e homicídio, enquanto os acidentes de trânsito respondem por outra parcela de $25 \%$ dessas mortes (WHO, 2014).

No Brasil, as causas externas (acidentes e violência) são a terceira causa de óbitos na população geral e somaram aproximadamente 155 mil casos em 2016, sendo que as três principais foram: homicídio, óbitos relacionados ao trânsito e suicídio. Estimativas de custos econômicos dos homicídios e suicídios 
mostraram que eles foram equivalentes a 1,2\% do Produto Interno Bruto (PIB) do Brasil (WHO, 2014; Brasil, 2018a).

A violência interpessoal correspondeu a $40,1 \%$ dos casos de lesões em 2015 para homens, em grande parte motivados por agressão com armas de fogo, responsáveis pela maioria dos homicídios (a taxa de homicídios por arma de fogo no país é de 19,3 a cada 100 mil habitantes; a título de comparação, em países desenvolvidos como França, Canadá e Estados Unidos essas taxas foram de 0,2, 0,5 e 3,6/100 mil habitantes, respectivamente, no ano de 2010) (Grinshteyn \& Hemenway, 2016; França et al., 2017). Segundo dados mais recentes, o Brasil apresenta uma taxa de homicídios de 31,3 a cada 100 mil habitantes, número 4,9 vezes maior que a taxa mundial, que é de 6,4 homicídios a cada 100 mil habitantes (WHO, 2018b). As regiões Norte, Nordeste e Centro Oeste foram as que apresentaram as maiores taxas de mortalidade por homicídio em 2015 no Brasil, sendo impulsionados pela rápida urbanização e migração da população da zona rural para a zona urbana, desorganização social e pobreza, associada ao tráfico de drogas, elevado consumo de álcool, posse de armas de fogo e, especificamente na região Norte, conflitos por posse de terras (Beato Filho \& Marinho, 2007; Cano \& Ribeiro, 2007; França et al., 2017). Estudo feito no estado do Rio de Janeiro mostrou que a violência está intimamente relacionada ao contexto social na qual se insere: as taxas de homicídio reportadas nas áreas mais pobres foram três vezes maiores que nas áreas de maior poder aquisitivo (Barcellos \& Zaluar, 2014).

Apesar das taxas de mortalidade no país devido a ferimentos em acidentes de trânsito terem reduzido de 36,9 para 23,8 a cada 100 mil habitantes, 
de 1990 a 2015, ainda continuam altas se comparadas à média mundial de 18,3 mortes/100 mil habitantes. Os pedestres ainda representam as maiores vítimas fatais no trânsito, porém foi observado um aumento bastante acentuado entre motociclistas e ciclistas em todos os estados brasileiros e no Distrito Federal, entre o período estudado (França et al., 2017). As maiores vítimas fatais no trânsito brasileiro são os indivíduos do sexo masculino, principalmente entre os ciclistas, motociclistas e ocupantes de veículos pesados e ônibus. Já os pedestres idosos ( $\geq 60$ anos de idade) compõem a maior parcela das vítimas fatais de atropelamento (Reichenheim et al., 2011). Alguns dos fatores de risco para a ocorrência de acidentes de trânsito incluem: consumo de substâncias psicoativas, excesso de velocidade, estresse, fadiga, tontura, falta de manutenção das vias (má iluminação, deficiência na pavimentação, sinalização inadequada) e do veículo (Camara, 1999; Lima \& Garcia, 2001; Moreno et al., 2001; Matielo et al., 2002; Souza \& Minayo, 2005).

No Brasil, de 2010 a 2015, foram registrados 60440 óbitos por suicídio entre pessoas adultas (20 anos ou mais), com média anual de 10945 suicídios. A taxa de mortalidade por 100 mil habitantes foi 7,5, sendo o risco de suicídio no sexo masculino quatro vezes maior que no feminino. Independente do sexo, os maiores riscos de suicídio foram observados entre os idosos com 70 ou mais anos e considerando-se a raça/cor da pele, os indígenas apresentaram uma taxa duas vezes maior do que a observada na população branca. O enforcamento foi principal meio utilizado para cometer o suicídio (Brasil, 2018b).

\subsubsection{Drogas de abuso e a precipitação de episódios de violência}


O abuso de drogas está associado não somente a elevados índices de comorbidades físicas e psiquiátricas, mas também à degradação progressiva de fatores sociais, tais como relações interpessoais e com o ambiente, incluindo a violência. Usuários de drogas apresentam taxa de mortalidade que pode ser de três a 20 vezes maior em relação à população geral, dependendo do tipo de substância considerada e da metodologia empregada (Tunving, 1988; Engström et al., 1991; Gossop et al., 2002; Hickman et al., 2003; Arendt et al., 2011; EMCDDA, 2011).

Goldstein, em seu trabalho publicado em 1985, propôs três possíveis modelos (os quais podem se sobrepor) para justificar o nexo existente entre $o$ consumo de substâncias psicoativas e a precipitação de violência: (i) o psicofarmacológico; (ii) o compulsivo econômico; (iii) o modelo sistêmico.

O modelo psicofarmacológico sugere que alguns indivíduos, como resultado direto do consumo a curto ou longo prazo de certas substâncias, podem apresentar um estado de excitação exacerbado, por vezes irracional, e podem exibir comportamento violento. As substâncias mais relevantes neste contexto seriam o álcool, estimulantes, barbitúricos e fenciclidina. Porém, outros episódios de violência podem surgir durante crises de abstinência de certas drogas, como por exemplo os opiáceos. Nesses casos, portanto, o desfecho "violência" não seria decorrente do consumo da droga em si, mas sim da irritabilidade e agitação verificadas durante a síndrome de abstinência. Nestes casos de violência que têm como causa principal os efeitos psicofarmacológicos das substâncias envolvidas o consumo da droga pode ter sido feito pelo agressor ou pela vítima. Ou seja, a droga pode contribuir para que uma pessoa se 
comporte de forma violenta ou pode alterar o comportamento de uma pessoa de forma a provocar a vitimização violenta da mesma (como acontece em muitos casos de estupro, por exemplo, em que a vítima ingere alguma substância cujo efeito possibilita ou facilita o cometimento daquele crime). No modelo psicofarmacológico, a vítima pode ser qualquer pessoa e a violência pode ocorrer no ambiente de trabalho, nas ruas, em bares, ou até mesmo dentro da própria residência do agressor (Goldstein, 1985). O álcool é a substância psicoativa mais consumida no mundo e, portanto, a mais extensamente estudada e associada ao aumento nas chances dos que a consomem sofrerem ou cometerem atos de violência. Algumas explicações teóricas para tal relacionam a desinibição observada durante a intoxicação aguda pelo álcool, o qual provoca também intensas alterações no humor, aumento da agressividade, reduz o estado de autoconsciência e torna o indivíduo mais inconsequente dos seus atos (Hoaken \& Stewart, 2003; Abdalla et al., 2018). Assim sendo, essa desinibição induzida pelo álcool aumenta o risco de envolvimento em episódios de violência, seja na condição de executor de tais atos, ou de vítima. Outro grupo de substâncias amplamente utilizado e cujo uso de maneira regular está fortemente associado ao risco aumentado de crises de paranoia, delírios e atos de violência são os estimulantes, como por exemplo cocaína e metanfetamina (Anderson \& Bokor, 2012). Há evidências experimentais que indicam que o uso crônico aumenta o comportamento agressivo e que a intoxicação aguda pode exacerbar respostas agressivas, além de estar associada a psicose paranoica, a qual frequentemente vem acompanhada de comportamentos violentos (Licata et al., 1993; McEllistren, 2004; Sokolov et al., 2004; Sokolov \& Cadet, 2006). 
O modelo compulsivo econômico sugere que o episódio de violência surja de uma tentativa de se obter dinheiro para a aquisição de drogas (por meio de um roubo, por exemplo). O objetivo primário, portanto, não é agir de forma violenta, mas sim obter dinheiro para comprar drogas. A violência, nesse caso, decorre geralmente de algum fator no contexto social em que o crime com objetivo econômico foi executado. Heroína e cocaína, por serem drogas de alto custo e apresentarem padrão de uso repetitivo, são substâncias que se destacam nessa categoria. Sabe-se que a ocorrência de atos de violência em circunstâncias que envolvem grandes somas de dinheiros é bastante alta e que a prática de crimes e prostituição para a manutenção do vício é recorrente (Goldstein, 1985). Assim como ocorre no modelo anterior, a vítima da violência do modelo compulsivo econômico pode ser qualquer pessoa. Estudos prévios mostraram que frequentemente a vítima residia na mesma vizinhança que o agressor e que não raramente ela própria se encontrava envolvida em atividades ilícitas (Goldstein \& Johnson, 1983; Johnson et al., 1985).

Por fim, no modelo sistêmico, a violência é intrínseca ao envolvimento com qualquer substância ilícita e se refere aos já tradicionais padrões agressivos observados dentro do sistema de distribuição e consumo de drogas. Alguns exemplos de violência sistêmica seriam aqueles decorrentes de: disputa por território entre traficantes rivais; agressões e homicídios cometidos dentro de uma hierarquia, como forma de imposição de códigos normativos; roubo de traficantes de drogas e a retaliação geralmente violenta por parte do próprio traficante ou dos chefes; eliminação de informantes; punição pela venda de drogas falsas ou adulteradas; punição pelo não pagamento de dívidas; punição 
de um traficante que não oferece ao seu superior o retorno monetário esperado; disputa por áreas de cultivo de drogas. Muitos usuários acabam se envolvendo no processo de distribuição da droga, o que aumenta o risco de se tornarem vítimas ou causadores da violência sistêmica. Neste modelo, portanto, a grande maioria das vítimas são aqueles que usam drogas, que as comercializam, ou que estão relacionadas de alguma forma ao comércio/negócio em torno delas (Goldstein, 1985).

Estudos de prevalência mostram uma clara correlação entre o uso de substâncias e as chances aumentadas de provocar ou vir a ser vítima de episódios de violência com o emprego de arma de fogo (Wintemute, 2015; McGinty et al., 2016; McGinty \& Webster, 2017). O risco de lesões, principalmente aquelas resultantes de violência interpessoal, está fortemente associado ao uso de cocaína (Hoaken \& Stewart, 2003; MacDonald et al., 2003; MacDonald et al., 2008; Phillips, 2011), a qual teve, inclusive, sua forma de administração estudada neste contexto: as chances de usuários de ambas as formas, intranasal (aspirada) e inalatória (fumada na forma de crack) já terem sido presos ao longo da vida foram maiores quando comparados ao grupo de usuários exclusivamente da forma de apresentação em pó (Guindalini et al., 2006). Hatsukami \& Fischman (1996) observaram que os usuários de crack estiveram relacionados a crimes em uma proporção maior do que os usuários de cloridrato de cocaína, com muitos desses crimes sendo associados à própria manutenção do consumo da droga.

Já no caso da cannabis, os dados encontrados na literatura são mais controversos (Liakoni et al., 2018), porém um estudo de revisão demonstrou que 
mais da metade das vítimas de homicídio possuem alguma substância ilícita presente no sangue no momento da morte, sendo a cannabis uma das mais comumente detectadas (Darke, 2010).

O consumo de álcool foi citado como fator contribuinte para $40 \%$ de todos os crimes violentos nos Estados Unidos e duas meta-análises, as quais incluíram diferentes países, verificaram a presença de álcool em aproximadamente 50\% dos criminosos e em 48\% das vítimas (Kuhns et al., 2011; Kuhns et al., 2014). O consumo agudo de álcool também pode ser relacionado a comportamento suicida: quase um terço das vítimas de suicídio nos Estados Unidos se encontrava intoxicada, sendo que alcoolemias maiores foram associadas a métodos de suicídio mais violentos (Kaplan et al., 2013). Além disso, estudo toxicológico conduzido em 16 estados norte-americanos com vítimas de suicídio revelou positividade de 2\% para anfetaminas, 5\% para cocaína, 10\% para cannabis e $20 \%$ para opiáceos (McGinty et al., 2016). Vítimas de homicídio em Trinidade e Tobago, de 2001 a 2007, apresentaram resultados toxicológicos positivos para cannabis (32\%), álcool (29\%), cocaína (7\%) e opióides $(1,5 \%)$ (Kuhns \& Maguire, 2012).

Devido à importância dentre os casos de mortalidade por causas externas no Brasil, o entendimento acerca dos prejuízos atribuídos ao uso de outras drogas (exceto o álcool) na direção de veículos automotores também é de suma importância. Estudos têm sugerido que muitas drogas ilícitas e medicamentos prescritos causam danos à coordenação exigida para a condução de veículos, podendo assim aumentar o risco de acidentes de trânsito (UNODC, 2013; Vearrier et al., 2016). A análise toxicológica de 391 amostras de vítimas fatais de 
acidentes de trânsito na cidade de Vitória, no Espírito Santo, apresentou positividade de $12 \%$ para cocaína, $4,3 \%$ para cannabis e $4,1 \%$ para anfetaminas. Dentre os casos positivos para cocaína, $27,7 \%$ das vítimas haviam feito uso de crack (Pelição et al., 2016). Um estudo retrospectivo conduzido na Suécia que incluiu motoristas vítimas fatais de acidentes de trânsito entre os anos de 2008 e 2011 ( $n=895$ ) identificou o consumo de drogas ilícitas em 7\% dos casos, sendo as principais cannabis $(n=31)$, anfetaminas $(n=30)$ e cocaína $(n=8)$, e medicamentos prescritos (benzodiazepínicos, sedativos e opióides) em 7,6\% dos casos levantados (Ahlner et al., 2014).

Acredita-se que o estudo dos resultados toxicológicos em ocorrências com desfechos fatais é de grande importância pois fornece informações que podem auxiliar políticas de prevenção e o combate ao uso de substâncias psicoativas. Dessa forma, o presente trabalho teve como objetivo estimar a prevalência de cannabis e cocaína entre vítimas de mortes violentas ou mortes suspeitas necropsiadas no Instituto Médico Legal (IML) da cidade de São Paulo através da análise toxicológica em amostras de sangue. Além disso, devido à alta prevalência do consumo de crack no Brasil e às peculiaridades deste grupo de usuários, quando comparados aos usuários das outras formas de apresentação da cocaína, um método para quantificação de cocaína e produtos de biotransformação, inclusive anidroecgonina metil éster (AEME), cuja presença em amostras biológicas é um marcador diferencial para o consumo de crack, foi desenvolvido e validado utilizando-se a técnica de Cromatografia Líquida de Ultra Eficiência acoplada à Espectrometria de Massas sequencial (UHPLC-MS/MS, do inglês "Ultra-High Performance Liquid Chromatography- 
tandem Mass-Spectrometry') (Kintz et al., 1997; Cone et al., 1994; Toennes et al., 1999; Ferreira Filho et al., 2003; Guindalini et al., 2006; Carvalho \& Seibel, 2009; Kessler et al., 2012; Bastos \& Bertoni, 2014; Toledo et al., 2017). 


\section{REVISÃO DE LITERATURA}

\subsection{Aspectos gerais das substâncias pesquisadas}

\subsubsection{Cannabis}

O termo cannabis, de modo genérico, denota as várias preparações com efeitos psicoativos das plantas do gênero Cannabis (Cannabis sativa, Cannabis indica e Cannabis ruderalis), sendo os canabinoides, que compõem uma classe de diversos compostos químicos que agem nos receptores canabinoides das células, um dos responsáveis por esses efeitos (Gloss, 2015; WHO, 2016).

As plantas contêm pelo menos 750 compostos químicos e cerca de 100 diferentes tipos de canabinoides, sendo que os principais são o delta-9tetrahidrocanabinol $\left(\Delta^{9}-\mathrm{THC}\right)$, canabidiol (CBD) e canabinol (CBN) (Izzo et al., 2009; Radwan et al., 2015). Praticamente toda atividade psicomimética está associada ao teor de $\Delta^{9}$-THC, uma vez que o CBD, apesar de figurar como 0 segundo canabinoide mais prevalente e ser capaz de modular os efeitos psicoativos do $\Delta^{9}$-THC, é um composto que isoladamente não produz tal efeito (Mechoulam \& Hanus, 2012). Novos compostos químicos naturais ainda são identificados nas plantas; mas o que preocupa as autoridades são as melhorias nas técnicas de cultivo e a utilização de linhagens geneticamente selecionadas que, além de proporcionarem aumento no rendimento da colheita, leva ao desenvolvimento de extratos ainda mais concentrados e potentes o que, até mesmo para consumidores experientes, torna difícil estimar uma dose segura podendo levar a casos de intoxicação (UNODC, 2016; WHO, 2016).

As formas mais comuns de preparo da cannabis e algumas de suas denominações são: 
• "Marijuana", "Marihuana", "Bongo", "Ganja", "Grass", "Hemp", "Sinsemilla", "Thai-sticks": as inflorescências e as folhas do topo são ressecadas e trituradas originando um material esverdeado/acastanhado, semelhante ao tabaco, que pode ser compactado e geralmente é introduzido pela via inalatória com o emprego de cigarros convencionais, ou então os chamados "vaporizadores" e os "purificadores" ou "bong" (UNODC, 2003; WHO, 2016). Por esta via, o pico de concentração plasmática é atingido em 15 a 30 minutos, podendo durar de duas a três horas, sendo que a farmacocinética do $\Delta^{9}$-THC e os efeitos variam em função da quantidade de material utilizada (em torno de 0,5 a um grama por cigarro), da forma de preparo, da potência do $\Delta^{9}$-THC, da concentração de outros canabinoides, da taxa de inalação, da intensidade da inspiração da fumaça, do volume inalado e da capacidade vital (Azorlosa et al., 1992; Azorlosa et al., 1995). A denominação "Sinsemilla" ("sem semente", em espanhol) referese à planta não polinizada, na qual a planta fêmea converte sua energia na produção de mais canabinoides, ao invés de sementes, elevando assim o seu potencial (Potter, 2014).

- "Haxixe", "Charas", "H", "Hash", "Hashish": trata-se da resina solidificada secretada pelas inflorescências do topo da planta, de cor castanha ou preta, que pode ser fumada misturada ou não ao tabaco (UNODC, 2003). O haxixe pode ainda ser introduzido via oral, através do preparo de alimentos e, na Índia, preparação de hastes e folhas, conhecida como "bhang", é tradicionalmente 
empregada como bebida ou então mascada, como parte de rituais religiosos (WHO, 2016).

• "Óleo de haxixe", "Óleo de Cannabis", "Hash Oil", "Honey Oil", "Red Oil": líquido viscoso escuro, obtido a partir da resina por um processo de filtração. Com elevada concentração de $\Delta^{9}$-THC, pode ser administrado pela via inalatória ou então pela via oral, adicionando-o a alimentos ou bebidas (UNODC, 2003).

O principal componente psicoativo da Cannabis sativa é o $\Delta^{9}$-THC, que age em receptores específicos do cérebro, os receptores canabinoides. Já foram identificados dois tipos de receptores (tipo $1-\mathrm{CB}_{1}$ e tipo $2-\mathrm{CB}_{2}$ ), sendo que os primeiros desempenham importante papel nos efeitos psicoativos e estão localizados em regiões responsáveis pela memória (hipocampo), respostas emocionais (amídala), cognição (córtex cerebral), motivação (área pré-frontal do sistema límbico) e a coordenação motora (cerebelo) (Iversen, 2012; Hu \& Mackie, 2015). CB2, por sua vez, são encontrados principalmente em tecidos periféricos, especialmente no sistema imunológico, além de atuar no trato gastrointestinal, fígado, coração, músculos, pele e órgão reprodutores (Iversen, 2012; Madras, 2015).

Efeitos imediatos do consumo de cannabis incluem o sentimento de bemestar, relaxamento e aumento das experiências sensoriais. A curto prazo, o indivíduo experimenta o aumento do apetite e da pulsação, vermelhidão dos olhos e enquanto os efeitos durarem, os desempenhos físicos e intelectuais poderão ficar prejudicados. Posteriormente, o usuário se torna silencioso, reflexivo e sonolento. Com doses maiores, as percepções de sons e cores 
podem ficar distorcidas e o pensamento se torna lento e confuso. Doses muito elevadas produzem efeitos similares aos alucinógenos, tais como confusão, inquietação, excitação e alucinações, os quais podem causar ansiedade ou pânico ou até mesmo precipitar episódios psicóticos (UNODC, 2003; Volkow et al., 2014).

Já os efeitos a longo prazo são observados principalmente entre aqueles usuários que consomem cannabis diariamente ou quase diariamente. Cerca de $16 \%$ daqueles que iniciam o uso ainda durante a adolescência desenvolvem dependência (Anthony, 2006); essa fração sobe para $33-50 \%$ entre os consumidores diários (van der Pol et al., 2013). Foram identificados também entre usuários crônicos déficits de aprendizado, memória e atenção, os quais puderam ser relacionados ao tempo e à frequência de uso (Grant et al., 2003; Solowij \& Battisti, 2008; Schreiner \& Dunne, 2012; Crane et al., 2013). Exames de imagem como de ressonância magnética nuclear revelaram mudanças estruturais (redução no volume, por exemplo) em áreas como hipocampo, córtex pré-frontal e cerebelo de usuários crônicos (Yucel et al., 2008; Lorenzetti et al., 2013). Estudos também já verificaram relação entre o uso de cannabis e o desenvolvimento de esquizofrenia, surtos psicóticos, episódios de ansiedade, distúrbios alimentares e, em menor proporção, depressão (WHO, 2016). Por fim, foi detectado um teor $50 \%$ maior de alcatrão na fumaça de cigarros de cannabis quando comparado a cigarros de tabaco; assim, o uso regular aumenta o risco de desenvolvimento de câncer de pulmão, bronquite crônica e outras doenças pulmonares, por exemplo (UNODC, 2003). 
Após administração por via oral, o $\Delta^{9}$-THC é absorvido pelo trato gastrointestinal de forma lenta e irregular, sendo que a concentração plasmática máxima nesse caso é atingida entre uma a duas horas após o consumo (Sharma et al., 2012). Por outro lado, quando introduzido pela via inalatória, dentro de alguns segundos já é possível a sua mensuração no plasma, sendo que o pico plasmático se dá dentro de três a dez minutos e sua meia vida é de cerca de duas horas (Moffat et al., 2011; WHO, 2016). Devido à sua alta lipossolubilidade, é prontamente distribuído para o tecido adiposo e outros órgãos e tecidos ricamente vascularizados, como o cérebro e os músculos, o que resulta na rápida diminuição da concentração plasmática (Haggerty et al., 1986; Huestis, 2005).

Através de reações de hidroxilação, oxidação e conjugação com ácido glicurônico ou glutationa, o $\Delta^{9}$-THC é biotransformado por intermédio de enzimas hepáticas, pulmonares e cerebrais (Cerro, 1998). Os principais produtos de biotransformação são o 11-hidroxitetrahidrocanabinol (11-OH-THC), o ácido 11nor-delta-9-tetrahidrocanabinol carboxílico (THC-COOH) e o ácido 11-nor-delta9-tetrahidrocanabinol carboxílico conjugado com ácido glicurônico (Moffat et al., 2011). Enquanto o primeiro se refere a um produto de biotransformação psicoativo, os outros são inativos, sendo que a fração conjugada é excretada na urina (cerca de $20 \%$ ), podendo ser detectada por até quatro dias após o consumo de um único cigarro ou por até quatro semanas nos casos de uso frequente (Moffat et al., 2011). A principal via de excreção se dá pelas fezes, com mais de $65 \%$ da dose sendo eliminada em cinco dias, principalmente sob as formas de 11-OH-THC e dos ácidos carboxílicos conjugados. Ainda, $\Delta^{9}-\mathrm{THC}$ atravessa a 
barreira placentária e já pôde ser detectado no leite materno (Perez-Reyes \& Wall, 1982; Garry et al., 2009).

\subsubsection{Cocaína}

A cocaína é o principal alcaloide psicoativo das plantas do gênero Erythroxylon, as quais se desenvolvem em climas tropicais (500 a 2000 metros acima do nível do mar), como arbustos ou árvores, sendo que suas folhas, que podem ser mascadas ou usadas na forma de chá, podem ser colhidas por cerca de 20 anos (UNODC, 2003).

A pasta de coca ou pasta base de cocaína é obtida das folhas do arbusto, de aspecto que pode variar de um material pegajoso castanho a um pó grosseiro de cor amarelada ou bege, úmido, de odor característico e que geralmente contém impurezas. É consumida normalmente fumada (de forma isolada ou associada ao tabaco ou maconha) ou ingerida oralmente numa dose média de 50 a 300 mg, sendo que da sua purificação resulta a cocaína (UNODC, 2003).

Esta, por sua vez, foi quimicamente isolada pela primeira vez em 1855 e no início dos anos 90 era o principal ingrediente ativo de muitos tônicos e elixires usados para tratar uma série de doenças, além de ter feito parte da composição da bebida Coca-Cola ${ }^{\circledR}$ por algum tempo. Na medicina, foi amplamente usada para o bloqueio da dor em procedimentos cirúrgicos antes do descobrimento dos anestésicos sintéticos e do seu alto poder de adição (UNODC, 2003; NIDA, 2016).

De forma ilegal, a cocaína é comercializada na forma de um fino pó branco cristalino, o cloridrato de cocaína, sofrendo muitas vezes adulteração visando ao 
aumento da toxicidade ou a um lucro maior pelo incremento do volume com substâncias de aparência semelhante tais como talco, farinha, amido de milho, bicarbonato de sódio ou até mesmo outras drogas, como por exemplo procaína (anestésico local) e anfetamina (outro estimulante psicoativo) (Goldstein et al., 2009; NIDA, 2016). Este sal, solúvel em água, é utilizado de forma injetável (endovenoso) ou então aspirado (intranasal) em doses diárias que variam em média de 100-200 mg e 100-350 mg, respectivamente (UNODC, 2003; NIDA, 2016). Para ser inalado (fumado), é necessário que o sal de cocaína retorne à forma de base (cocaína alcaloide ou base livre), neutralizando-se a parte ácida ou o cloridrato através da sua reação com uma solução aquosa de um álcali (amônio ou bicarbonato de sódio) aquecido (NIDA, 2016). O produto gerado é conhecido popularmente como "crack", devido ao som produzido quando do aquecimento das pedras para serem fumadas, sendo que a dose média consumida nesta forma é de 50-200 mg (Goldstein et al., 2009).

O Quadro 1 apresenta, de forma simplificada, as diferenças com relação ao início da ação e duração dos efeitos, pico plasmático e biodisponibilidade, de acordo com as diferentes vias de administração da cocaína. 
Quadro 1 - Início, intensidade e duração dos efeitos do consumo da cocaína e a via de administração

\begin{tabular}{|c|c|c|c|c|c|}
\hline \multicolumn{2}{|c|}{ Administração } & \multirow{2}{*}{$\begin{array}{l}\text { Início da } \\
\text { ação } \\
\text { (segundos) }\end{array}$} & \multirow{2}{*}{$\begin{array}{c}\text { Duração } \\
\text { dos } \\
\text { efeitos } \\
\text { (minutos) }\end{array}$} & \multirow{2}{*}{$\begin{array}{c}\text { Pico } \\
\text { plasmático } \\
(\mathrm{ng} / \mathrm{mL})\end{array}$} & \multirow{2}{*}{$\begin{array}{l}\text { Biodisponibilidade } \\
\text { (\% absorvida) }\end{array}$} \\
\hline Via & Apresentação & & & & \\
\hline Oral & $\begin{array}{c}\text { Folhas de coca } \\
\text { mascadas }\end{array}$ & $300-600$ & $45-90$ & 150 & 20 \\
\hline Intranasal & $\begin{array}{c}\text { Cocaína } \\
\text { refinada ("pó") }\end{array}$ & $120-180$ & $30-45$ & 150 & $20-30$ \\
\hline Endovenosa & $\begin{array}{c}\text { Cocaína } \\
\text { refinada diluída } \\
\text { em água }\end{array}$ & $30-45$ & $10-20$ & $300-400$ & 100 \\
\hline Inalatória & $\begin{array}{l}\text { Pasta de coca } \\
\text { crack }\end{array}$ & $8-10$ & $5-10$ & $300-800$ & $60-70$ \\
\hline
\end{tabular}

Fonte: Gold, 1993 (adaptado)

A cocaína é menos tóxica quando administrada por via oral devido à hidrólise no trato gastrointestinal (Moffat et al., 2011). Os principais produtos de biotransformação (75-90\%) são ecgonina metil éster (EME) e benzoilecgonina (BZE), ambos inativos e que são formados por ação das colinesterases hepáticas e plasmáticas e hidrólise não enzimática, respectivamente (Moffat et al., 2011). Norcocaína, um produto de biotransformação biologicamente ativo, também pode ser produzido, assim como ecgonina, etilecgonina, hidroxicocaína e metilecgonidina (Carrera et al., 2004). Uma pequena fração da cocaína inalterada é excretada na urina, ao contrário do que ocorre nas fezes, sendo que essa fração será aumentada quando da acidificação da urina. Importante ressaltar também que a cocaína é capaz de atravessar a barreira placentária, tendo sido detectada inclusive no leite materno (Moffat et al., 2011).

O efeito anestésico provocado pela cocaína se deve à interrupção da condução do estímulo nervoso por bloquear a condutância dos canais de sódio 
e consequentemente impedir a deflagração do potencial de ação (Carvalho, 1994). Além disso, a cocaína se liga aos transportadores da dopamina (principalmente), noradrenalina e serotonina responsáveis pela recaptura destes na fenda sináptica, dificultando tal ação e assim provocando acúmulo dos neurotransmissores, o que gera uma amplificação do sinal nos neurônios póssinápticos, a qual se manifesta pela euforia comumente experimentada imediatamente após o consumo da droga (NIDA, 2016).

Pequenas doses de cocaína provocam no usuário sensações como euforia, aumento da eloquência, do estado de alerta e das percepções sensoriais (sexuais, auditivas, táteis e visuais), anorexia leve e insônia (Romano et al., 2002). Alguns acreditam ainda que a droga os permitem realizar tarefas físicas e intelectuais mais rapidamente, embora outros relatem o efeito oposto. A duração dos efeitos depende da via de administração utilizada: quanto mais rápida a absorção, mais intensos e de início imediato serão os efeitos, porém mais rápida será sua duração (NIDA, 2016). Com relação aos efeitos fisiológicos a curto prazo, podem-se citar vasoconstrição, midríase e aumento da temperatura corporal, frequência cardíaca e pressão sanguínea (UNODC, 2003).

O consumo de doses maiores e a longo prazo não apenas intensifica os efeitos supracitados como também pode levar a um comportamento errático, bizarro e violento, além de provocar episódios de ansiedade, irritabilidade, pânico, paranoia, tremores, vertigens e contrações musculares (UNODC, 2003; Goldstein et al., 2009). Algumas consequências podem inclusive relacionar-se à via de administração (NIDA, 2016): 
- Intranasal: perda do sentido do olfato, perfuração do septo nasal, sangramento, coriza e problemas de deglutição;

- Oral: isquemia mesentérica devido ao fluxo sanguíneo reduzido;

- Endovenosa: o principal risco envolve a aquisição de doenças infecciosas como hepatite e AIDS, ainda que estas também estão sujeitas a serem adquiridas por aqueles que empregam outras vias, por conta do comportamento sexual de risco geralmente observado nesta população;

- Inalatória: edema pulmonar, esofagite, broncopneumonias, asma, lesões térmicas.

A intoxicação aguda de cocaína provoca efeitos sobre o sistema cardiovascular tais como arritmias, infarto do miocárdio e colapso cardiovascular e sobre o Sistema Nervoso Central como agitação, convulsões, acidente vascular cerebral, psicose e coma (Heard et al., 2008). Há ainda o risco de overdose pelo consumo excessivo (crônico, eventual ou iniciante) de cocaína, que provoca uma reação tóxica seguida da falência de um ou mais órgãos por excesso de estimulação do Sistema Nervoso Simpático por meio do bloqueio da recaptação de catecolaminas (Perri \& Dunn, 1999). A dose letal mínima estimada é de $1,2 \mathrm{~g}$, porém há relatos de pessoas mais suscetíveis que morreram com doses de $30 \mathrm{mg}$, quando administradas via membranas mucosas; farmacodependentes são capazes de tolerar uma dose diária de 5 a 10 gramas da droga. O Quadro 2 apresenta faixas de concentrações terapêuticas, tóxicas e letais para cocaína e produtos de biotransformação (benzoilecgonina e ecgonina metil éster). As concentrações variam de acordo com a dose 
administrada, via de administração, período de sobrevivência e armazenamento da amostra. Além disso, a interpretação de concentrações de drogas em amostras postmortem é complexa e influenciada por diversos fatores, tais como variações individuais na resposta às substâncias, tolerância, compleição física e patologias associadas; a presença de outras drogas e os fenômenos que ocorrem após a morte e que podem alterar a concentração das substâncias.

Quadro 2 - Concentrações plasmáticas da cocaína e seus produtos de biotransformação

\begin{tabular}{|l|c|c|c|}
\hline Substância & $\begin{array}{c}\text { Concentração não } \\
\text { tóxica }(\mathbf{n g} / \mathbf{m L})\end{array}$ & $\begin{array}{c}\text { Concentração } \\
\text { tóxica }(\mathbf{n g} / \mathbf{m L})\end{array}$ & $\begin{array}{c}\text { Concentração } \\
\text { letal }(\mathbf{n g} / \mathbf{m L})\end{array}$ \\
\hline COC, BZE, EME & $50-1000$ & $100-5000$ & $>900$ \\
\hline
\end{tabular}

Abreviações: $\mathrm{COC}$ = cocaína; $\mathrm{BZE}$ = benzoilecgonina; $\mathrm{EME}=$ ecgonina metil éster

Fonte: NC-OCME, 2017 (Adaptado)

Álcool e cocaína são comumente utilizados concomitantemente; entre 50 e 90\% dos usuários de cocaína também ingerem bebidas alcoólicas quando do consumo da substância ilícita (Jatlow, 1993). A presença do etanol altera a biotransformação da cocaína, resultando na transesterificação para um produto de biotransformação ativo, o cocaetileno (Bosron et al., 1997). Segundo os usuários, essa combinação minimiza os sentimentos disfóricos associados ao uso da cocaína e prolonga a duração dos efeitos eufóricos, provavelmente devido ao maior tempo de meia-vida do cocaetileno (150 minutos) quando comparado ao da cocaína (cerca de 90 minutos) (Boghdadi \& Henning, 1997; Goldstein et al., 2009). Entretanto, o cocaetileno é neurotóxico e cardiotóxico e foi associado a um risco maior para morte repentina se comparado ao uso isolado de cocaína (Andrews, 1997; Hoffman, 2006). Dependentes de cocaína estão sujeitos ainda aos sinais e sintomas característicos de condições como tolerância, dependência e abstinência da droga (Leite et al., 1999). 


\subsubsection{Crack}

Enquanto a cocaína em pó (cloridrato) já vinha sendo usada há décadas, o crack emergiu como um subtipo e uma nova forma de consumo por volta de 1980. Observa-se que o consumo ocorre principalmente entre populações urbanas, compostas em sua maioria por homens jovens (abaixo de 30 anos de idade), solteiros, socioeconomicamente marginalizados, com baixo nível de escolaridade, sem emprego formal e no continente americano, principalmente (Duailibi et al., 2008; Chaves et al., 2011; Fischer et al., 2016).

O crack chegou ao Brasil na década de 90, no estado de São Paulo, e rapidamente se espalhou pelos centros urbanos do país. O baixo custo da droga, seu modo de consumo não invasivo, a rápida absorção a partir dos pulmões e a consequente rapidez com que provoca os efeitos de euforia e excitação facilitaram a expansão e popularização da droga em diferentes segmentos sociais (Alves \& Lima, 2013). O Brasil possui o maior mercado consumidor de crack no mundo: estima-se que em 2015, um milhão de brasileiros fizeram uso da droga, sendo 370 mil usuários regulares, dos quais $80 \%$ a consomem em lugares públicos (Abdalla et al., 2014; Ribeiro et al., 2016). Na região metropolitana de São Paulo, a maior do país com mais de 20 milhões de habitantes e composta por 39 municípios, são identificados alguns desses locais espalhados por todas as regiões, sendo o mais antigo (desde 1989) e o mais densamente povoado (com 500 moradores fixos e mais de 2000 "visitantes" regulares) conhecido como "Cracolândia" e localizado na região central da cidade de São Paulo (Moreira et al., 2015). A economia e a organização da região da Cracolândia são controladas principalmente pelo tráfico de drogas local e atividades ligadas ao consumo de drogas, tais como bares sem licença 
para funcionamento, comércio de objetos roubados e prostituição (Watts, 2013). Apesar de iniciativas do Governo do Estado de São Paulo envolvendo profissionais das mais diversas áreas (enfermagem, assistência social, agentes comunitários de saúde, psicologia, direito), tratamento em clínicas de desintoxicação, comunidades terapêuticas, oportunidades de emprego e moradia e até mesmo tentativas de intervenções compulsórias, muitos usuários se recusam a abandonar a área ou então retornam após algum tempo, situação que, invariavelmente, acaba criando um ambiente com altos índices de violência e criminalidade (Fischer et al., 2013; Watts, 2013; São Paulo, 2014; Bansal, 2014).

Um estudo de coorte conduzido no Brasil com 131 usuários dependentes de crack admitidos em clínicas de reabilitação revelou que, ao final de 12 anos de acompanhamento, $20 \%$ vieram a óbito, sendo o homicídio a causa mais comum (Dias et al., 2011). No Brasil, o uso de crack representa uma importante questão de saúde pública e está fortemente associado a diversos problemas como evasão escolar, desemprego, pessoas em situação de moradia de rua, exposição à violência, déficit cognitivo, transtornos psiquiátricos, prostituição, infecção pelo HIV, hepatite $B$, hepatite $C$, sífilis, envolvimento em atividades ilegais, prisão e mortalidade (Dunn \& Laranjeira, 1999; Ribeiro et al., 2004; Santos Cruz et al., 2013; Narvaez et al., 2014). Diante deste cenário, fica evidente que o país carece de uma política pública nacional de saúde voltada especificamente ao usuário de crack e que haja, inclusive, consenso na legislação brasileira e entre especialistas no que diz respeito ao tratamento para os dependentes (Ribeiro et al., 2016; Moreira et al., 2017). 
Entende-se que formulação de políticas públicas referentes a estas e outras populações deve ter por base evidências empíricas consistentes, conforme descrito em modelos de tomada de decisão, na interface entre a epidemiologia e a análise de políticas públicas. 


\section{OBJETIVOS}

3.1 Avaliar a prevalência do consumo de cannabis e cocaína por vítimas de causas externas necropsiadas pelas Equipes de Perícias Médico Legais (EPMLs) do Instituto Médico Legal, situadas no município de São Paulo, no período de junho de 2014 a dezembro de 2015;

3.2 Desenvolver uma nova metodologia analítica para identificação e quantificação de cocaína, benzoilecgonina, cocaetileno e anidroecgonina metil éster em sangue, com análise por UHPLC-MS/MS, a qual permita, inclusive, identificar e diferenciar a via de administração da cocaína. 


\section{MÉTODOS}

\subsection{Estudo de prevalência}

O Instituto Médico Legal do Estado de São Paulo (IML-SP), órgão subordinado à Superintendência da Polícia Técnico-Científica (SPTC), foi criado com o intuito de fornecer bases técnicas em Medicina Legal para o julgamento de causas criminais. A necropsia é conduzida no IML nos casos de óbitos por causas externas (decorrentes de traumatismos, lesões ou quaisquer outros agravos à saúde - intencionais ou não - de início súbito e como consequência imediata de violência ou outra causa exógena, qualquer que tenha sido o tempo entre o evento lesivo e a morte propriamente dita), nos cadáveres cuja identidade seja desconhecida e naqueles cujos óbitos ocorreram enquanto estavam sob custódia do Estado qualquer que seja a causa (natural ou violenta) (Brasil, 2011). Para que haja a completa elucidação dos fatos, toda e qualquer informação disponível (investigação da cena, relatórios policiais, prontuário de eventual atendimento médico prévio, achados necroscópicos, resultados anatomopatológicos, histológicos e toxicológicos (quando for o caso), etc.) é de grande valia. O questionamento se uma determinada substância -álcool, drogas ilícitas ou outros agentes tóxicos, por exemplo - causou ou contribuiu para a ocorrência do óbito deverá ser sempre respondido (Hearn \& Walls, 2008).

\subsubsection{Amostras biológicas}

Foi utilizado um método de amostragem probabilística utilizando a cidade de São Paulo, a mais populosa do país com mais de 12,2 milhões de habitantes, como população alvo. Os casos incluídos corresponderam a indivíduos adultos 
vítimas de morte súbita, violenta ou de qualquer causa não-natural, os quais somam aproximadamente 7000 e são submetidos ao exame necroscópico no IML-SP anualmente.

\subsubsection{Critérios de inclusão/exclusão}

\subsection{Critérios de inclusão}

Foram incluídos no estudo:

- Indivíduos maiores de 18 anos idade;

- Vítimas cujo tempo decorrido entre a morte (ou o encontro do cadáver) e a necrópsia tenha sido igual ou menor a 12 horas.

\subsection{Critérios de exclusão}

Os critérios de exclusão foram:

- Casos em que não havia amostra em volume suficiente pelo tipo de trauma sofrido, levando à perda expressiva de sangue;

- Casos em que houve atendimento hospitalar e/ou internação prévia à morte, ou ainda, que a vítima tenha sobrevivido por período igual ou superior a seis horas;

- Casos que poderiam oferecer risco à saúde dos pesquisadores, principalmente em virtude da contaminação do sangue com agentes patogênicos (HIV, tuberculose, hepatite).

\subsubsection{Coleta das amostras}


As amostras incluídas neste estudo foram coletadas no período de junho de 2014 a dezembro de 2015. Os locais de coleta foram as EPMLs do IML-SP, aqui definidas como postos de coleta, localizadas em diferentes regiões geográficas da cidade de São Paulo (Central, Sul e Leste). As unidades localizadas nas Zonas Norte e Oeste não foram incluídas, pois no período do estudo a primeira encontrava-se fechada para reforma e os casos eram encaminhados para a unidade Central (incluída no estudo), e a segunda tem como função primária realizar exame necroscópico em cadáveres putrefeitos (ou em avançado estado de decomposição).

Seguindo o método de amostragem probabilística padrão, adotado em estudos conduzidos em unidades de emergência, as vítimas foram selecionadas durante um período de oito horas durante o plantão diurno de um dado dia da semana para a primeira semana, no plantão vespertino do mesmo dia da semana para a segunda semana e no plantão noturno também correspondente ao mesmo dia da semana, na terceira semana - este esquema foi então repetido para cada dia da semana, em cada localidade, a cada três semanas. A adoção dessa estratégia garantiu uma igual representação de todos os três turnos de um dia para um determinado dia da semana a cada três semanas de coleta de amostras, em cada localidade (Cherpitel, 2010).

Foram coletadas amostras de todas as vítimas que atenderam aos critérios de inclusão mencionados no item 4.1.1.1.1. As amostras de sangue cardíaco, em volume aproximado de $20 \mathrm{~mL}$, foram coletadas utilizando-se seringas descartáveis de $20 \mathrm{~mL}$ e tubos tipo Vacutainer ${ }^{\circledR}$ de $4 \mathrm{~mL}$ com fluoreto de sódio ( $\mathrm{NaF}$ ) e ácido etilenodiamino tetra-acético (EDTA), acondicionados em 
caixas térmicas refrigeradas e conduzidos ao final de cada plantão ao Laboratório de Toxicologia da Faculdade de Medicina da Universidade de São Paulo (LT-FMUSP). Tão logo se deu a chegada ao LT-FMUSP, os tubos foram armazenados em freezer a $-20 \stackrel{\circ}{ } \mathrm{C}$.

\subsubsection{Análises toxicológicas}

Os analitos pertencentes às classes da cocaína e cannabis foram pesquisados. As análises toxicológicas das amostras de sangue postmortem foram realizadas por instituição colaboradora no projeto de pesquisa.

Para a triagem das drogas nas amostras foi utilizada a técnica de imunoensaio por ELISA (do inglês, Enzyme-Linked Immunosorbent Assay) (Venture Laboratories, Inc., Redwood City, CA, USA).

Os casos identificados como positivos na etapa de triagem foram submetidos à etapa de confirmação utilizando-se as técnicas de Cromatografia Líquida acoplada à Espectrometria de Massas em tandem (LC-MS/MS, do inglês "Liquid Chromatography tandem Mass Spectrometry"), no caso do $\Delta^{9}$-THC e produtos de biotransformação (THC-OH, canabidiol, THC-COOH e canabinol), e Cromatografia Gasosa acoplada à Espectrometria de Massas (GC-MS, do inglês “Gas Chromatography-Mass Spectrometry"), para a quantificação de cocaína, benzoilecgonina e cocaetileno. Os valores de cutoffs adotados estão apresentados na Tabela 1. 
Tabela 1 - Valores de cutoffs $(\mathrm{ng} / \mathrm{mL})$ adotados nas etapas de triagem e confirmação para cocaína e canabinoides

\begin{tabular}{|c|c|c|c|}
\hline \multicolumn{2}{|c|}{ Cutoffs (triagem) } & \multicolumn{2}{|c|}{ Cutoffs (confirmação) } \\
\hline Classe & LD (ng/mL) & Compostos & $\mathrm{LQ}(\mathrm{ng} / \mathrm{mL})$ \\
\hline \multirow[t]{4}{*}{ Cocaína } & 20 & & \\
\hline & & Cocaína & 50 \\
\hline & & Benzoilecgonina & 20 \\
\hline & & Cocaetileno & 20 \\
\hline \multirow[t]{6}{*}{ Canabinoides } & 5 & & \\
\hline & & THC-OH & 1 \\
\hline & & Canabidiol & 1 \\
\hline & & THC-COOH & 5 \\
\hline & & Canabinol & 1 \\
\hline & & $\Delta^{9}-\mathrm{THC}$ & 1 \\
\hline
\end{tabular}

\subsubsection{Coleta dos dados do contexto da lesão e sociodemográficos das} vítimas

Visando um estudo completo do contexto do evento que ocasionou a morte das vítimas, os dados referentes à ocorrência foram coletados a partir da requisição do médico legista e de uma base de dados criminais da Polícia Civil do Estado de São Paulo. A classificação do evento que levou ao desfecho fatal se baseou em quatro grandes grupos: acidente de trânsito, $\underline{\text { homicídio, }}$ morte suspeita (este grupo incluiu todos os óbitos cuja causa permaneceu indeterminada e necessitaram de exames complementares para sua elucidação) e suicídio. As circunstâncias ou meios utilizados foram classificados em: atropelamento (choque entre veículo e pedestre), colisão (choque entre dois ou mais veículos ou entre veículo e objeto inanimado), enforcamento, arma branca (nesta categoria estão incluídos os objetos cortantes, perfurantes, 
perfurocortantes, contundentes, cortocontundentes, perfurocontundentes e/ou perfurocortocontundentes), arma de fogo, queda, intoxicação exógena e outros.

Foram coletados também dados referentes ao dia (dia da semana versus final de semana, sendo o primeiro considerado entre 00:00 da segunda-feira e 23:59 da sexta-feira e o segundo de 00:00 de sábado até 23:59 do domingo), período (classificado em manhã, tarde, noite e madrugada, considerando-se períodos de seis horas ao longo das 24 horas de um dia, iniciando-se o período da "manhã" às 06:00) e local da ocorrência (classificado em público (como por exemplo, via pública, estação ferroviária, estabelecimento comercial, igreja, motel, etc.) ou privado (residência, clínica de reabilitação, por exemplo). As características sociodemográficas das vítimas incluíram: sexo, idade (classificada entre $\leq 30$ anos e $>30$ anos), etnia (dividida entre brancos e nãobrancos, os quais englobavam os negros, pardos e amarelos) e grau de escolaridade (analfabeto ou $1^{\circ}$ grau, $2^{\circ}$ grau e $3^{\circ}$ grau, independente se completo ou incompleto). As análises foram realizadas com o auxílio do Software Stata ${ }^{\circledR}$, versão 13.1 .

\subsection{Desenvolvimento e validação de metodologia em UHPLC-MS/MS para quantificação de cocaína, benzoilecgonina, cocaetileno e anidroecgonina metil éster}

Esta etapa integrou o período do Programa de Doutorado Sanduíche no Exterior (PDSE), financiado pela Coordenação de Aperfeiçoamento de Pessoal de Nível Superior (CAPES) (Processo no 88881.133873/2016-01) sendo, portanto, desenvolvida na cidade de Oslo, Noruega. 


\subsubsection{Material para análises toxicológicas}

\subsubsection{Reagentes}

Metanol (MeOH) grau LC-MS foi adquirido da Honeywell (Seelze, Alemanha). Éter metil terc-butílico (MTBE), 2-propanol, acetato de etila, acetato de amônio, hidróxido de sódio e n-heptano foram comprados da Merck (Darmstadt, Alemanha). Ácido fórmico (98\%) e carbonato de amônio foram obtidos da VWR International (Oslo, Noruega). Água Tipo I (18.2 M $\Omega$ ) purificada com sistema Milli- $\mathrm{Q}^{\circledR}$ Synthesis $\mathrm{A} 10^{\circledR}$ da Millipore Corporation (Billerica, MA, USA) foi utilizada.

\subsubsection{Soluções-padrão}

Padrões de cocaína (COC) e benzoilecgonina (BZE) foram obtidos da Lipomed (Arlesheim, Suíça) ambos na concentração de $1 \mathrm{mg} / \mathrm{mL}$ em acetonitrila e metanol, respectivamente. Padrões de cocaetileno (CE), anidroecgonina metil éster (AEME) e os padrões internos cocaína- ${ }^{13} \mathrm{C}_{6}\left(\mathrm{COC}^{-13} \mathrm{C}_{6}\right)$, benzoilecgonina${ }^{13} \mathrm{C}_{6}\left(B Z E-{ }^{13} \mathrm{C}_{6}\right)$ e cocaetileno- $\mathrm{D}_{3}\left(C E-\mathrm{D}_{3}\right)$ na concentração de $1 \mathrm{mg} / \mathrm{mL}$ em acetonitrila foram adquiridos da Chiron AS (Trondheim, Noruega).

\subsubsection{Equipamentos e acessórios}

- Sistema de cromatografia líquida ACQUITY UPLC ${ }^{\circledR}$ I-Class SM-FTN acoplado a espectrômetro de massas Xevo TQ-S, da Waters ${ }^{\circledR}$ (Milford, MA, USA);

- Coluna Kinetex ${ }^{\mathrm{TM}}$ Bifenil, com tecnologia Core-Shell (100 mm x $2.1 \mathrm{~mm}$ ID, $1.7 \mu \mathrm{m})$, da Phenomenex ${ }^{\circledR}$ (Torrance, CA, USA); 
- MassLynx ${ }^{\mathrm{TM}}$ Mass Spectrometry Software, versão 4.1, da Waters ${ }^{\circledR}$ (Milford, MA, USA);

- Agitador de tubos;

- Centrífuga de tubos, da Beckman Coulter (Indianapolis, IN, USA);

- Concentrador de amostras com aquecimento e fluxo de nitrogênio, modelo Turbovap, da Biotage (Charlotte, NC, USA).

\subsubsection{Amostras biológicas}

\subsubsection{Amostras negativas}

Amostras de sangue total humano, isentas de quaisquer substâncias pesquisadas, utilizadas para o preparo dos calibradores, controles de qualidade e amostras "branco" foram obtidas do Banco de Sangue do Oslo University Hospital (Oslo, Noruega).

\subsubsection{Amostras de sangue postmortem}

O método desenvolvido e validado foi aplicado em um grupo selecionado de amostras de sangue postmortem.

\subsubsection{Preparo dos calibradores, controles de qualidade e padrões internos}

Soluções estoque dos calibradores, controles de qualidade e padrões internos foram preparadas em metanol ou acetonitrila, a depender do solvente de origem. Soluções de trabalho dos calibradores e controles de qualidade foram preparadas a partir da diluição das soluções estoque (respeitando-se as concentrações finais desejadas) em metanol/água Tipo I (1:1, v:v). Para os 
padrões internos, preparou-se uma solução de trabalho em metanol composta por um pool dos padrões adotados (cocaína- ${ }^{13} \mathrm{C}_{6}$, benzoilecgonina- ${ }^{13} \mathrm{C}_{6} \mathrm{e}$ cocaetileno- $\left.D_{3}\right)$ na concentração de $400 \mathrm{ng} / \mathrm{mL}$.

\subsubsection{Procedimento de extração/Preparo das amostras}

A técnica de extração empregada foi a extração líquido-líquido (LLE, do inglês "Liquid-Liquid Extraction"). Calibradores e controles de qualidade (25 $\mu \mathrm{L}$ das soluções de trabalho) foram adicionados a tubos contendo $100 \mu \mathrm{L}$ de sangue total branco. As amostras de sangue desconhecidas (em volume de $100 \mu \mathrm{L}$ ), por sua vez, foram acrescidas de $25 \mu \mathrm{L}$ de metanol/água Tipo I (1:1, v:v) para ajuste do volume final e composição. A todos os tubos (calibradores, controles de qualidade, amostras "branco" e amostras desconhecidas) foram adicionados 25 $\mu \mathrm{L}$ da solução de trabalho dos padrões internos, seguido de agitação. Foram

adicionados também $100 \mu \mathrm{L}$ de solução tampão de carbonato de amônio 0.2 $\mathrm{mol} / \mathrm{L}$ (pH 9.3) e $1000 \mu \mathrm{L}$ de MTBE/2-propanol (70:30, v:v). As amostras foram agitadas por cinco minutos e posteriormente centrifugadas a $4000 \mathrm{rpm}$, durante quatro minutos. O sobrenadante $(900 \mu \mathrm{L})$ foi transferido para tubos cônicos de vidro para evaporação do solvente com fluxo de nitrogênio (pressão 5-6 PSI) a 45ํㅡ e concentração dos analitos. Os resíduos foram então reconstituídos com $60 \mu \mathrm{L}$ da mistura de solução tampão de formato de amônio $5 \mathrm{mmol} / \mathrm{L}(\mathrm{pH}$ 3.1)/MeOH (95:5), agitados e transferidos para vials para serem analisados por UHPLC-MS/MS. 


\subsubsection{Condições UHPLC-MS/MS}

As análises UHPLC-MS/MS foram realizadas em sistema UPLC Waters ACQUITY I-Class SM-FTN acoplado ao espectrômetro de massas Xevo TQ-S. O sistema foi operado no modo MRM (do inglês, "Multiple Reaction Monitoring"), utilizando a técnica de ionização por electrospray no modo positivo (ESI+; $\left.[\mathrm{M}+\mathrm{H}]^{+}\right)$e argônio como gás de colisão. Os seguintes parâmetro foram adotados: tensão no capilar $1.0 \mathrm{kV}$; temperatura da fonte $150^{\circ} \mathrm{C}$; temperatura de dessolvatação $500^{\circ} \mathrm{C}$; fluxo do gás de colisão $300 \mathrm{~L} / \mathrm{h}$ e fluxo do gás de dessolvatação $1000 \mathrm{~L} / \mathrm{h}$.

A Tabela 2 apresenta os fragmentos monitorados para os analitos e respectivos padrões internos, voltagem de ionização, energia de colisão e tempo de monitoramento. Os parâmetros cromatográficos são mostrados na Tabela 3.

Tabela 2 - Fragmentos monitorados para os analitos e respectivos padrões internos, voltagem de ionização, energia de colisão e tempo de monitoramento

\begin{tabular}{|c|c|c|c|c|c|c|c|c|c|c|}
\hline \multirow{3}{*}{$\begin{array}{l}\text { Analito } \\
\text { Cocaína }\end{array}$} & \multirow{4}{*}{$\begin{array}{l}\text { Padrão Interno } \\
\text { Cocaína- }{ }^{13} \mathrm{C}_{6}\end{array}$} & \multicolumn{6}{|c|}{ Fragmentos monitorados } & \multicolumn{3}{|c|}{$\begin{array}{l}\text { Parâmetros espectrometria de } \\
\text { massas }\end{array}$} \\
\hline & & \multicolumn{3}{|c|}{ Analito } & \multicolumn{3}{|c|}{ Padrão Interno } & \multirow{2}{*}{$\begin{array}{c}\begin{array}{c}\text { Voltagem } \\
\text { de } \\
\text { ionização } \\
\text { (V) }\end{array} \\
30\end{array}$} & \multirow{2}{*}{$\begin{array}{c}\begin{array}{c}\text { Energia } \\
\text { de } \\
\text { colisão } \\
\text { (eV) }\end{array} \\
25\end{array}$} & \multirow{2}{*}{$\begin{array}{c}\begin{array}{c}\text { Tempo de } \\
\text { monitora- } \\
\text { mento } \\
\text { (ms) }\end{array} \\
18\end{array}$} \\
\hline & & 304 & $>150$ & Q & 310 & $>150$ & Q & & & \\
\hline & & 304 & $>182$ & & 310 & $>182$ & & 30 & 20 & 18 \\
\hline \multirow{2}{*}{$\begin{array}{l}\text { Benzoil- } \\
\text { ecgonina }\end{array}$} & Benzoilecgonina- & 290 & $>150$ & Q & 296 & $>150$ & Q & 30 & 25 & 18 \\
\hline & & 290 & $>168$ & & 296 & $>168$ & & 30 & 20 & 18 \\
\hline \multirow[t]{2}{*}{ Cocaetileno } & Cocaetileno- $\mathrm{D}_{3}$ & 318 & $>82$ & & 321 & $>85$ & & 25 & 30 & 18 \\
\hline & & 318 & $>196$ & Q & 321 & $>199$ & Q & 25 & 20 & $\begin{array}{c}18 \\
\text { continua }\end{array}$ \\
\hline
\end{tabular}


Tabela 2 - Fragmentos monitorados para os analitos e respectivos padrões internos, voltagem de ionização, energia de colisão e tempo de monitoramento (conclusão)

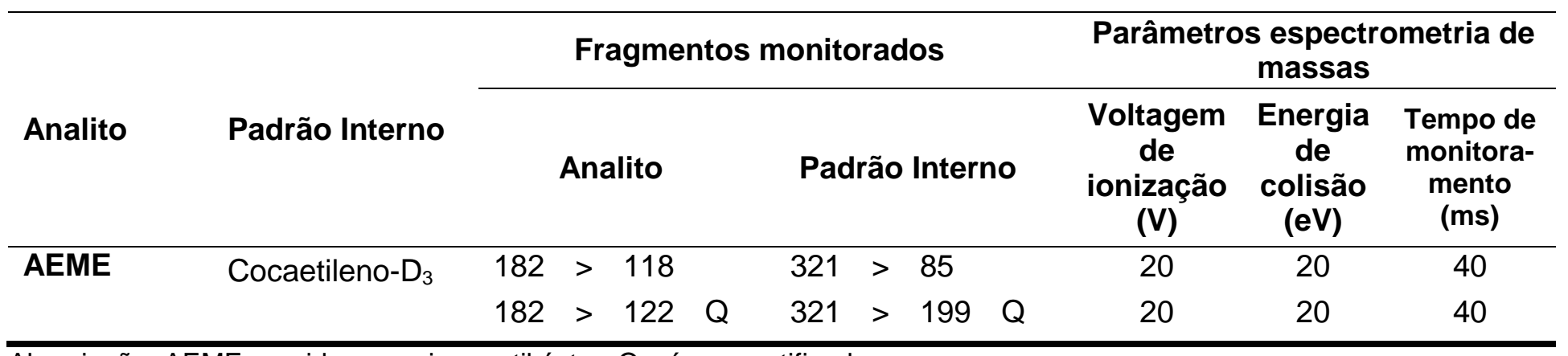

Abreviação: $\mathrm{AEME}$ = anidroecgonina metil éster; $\mathrm{Q}=$ íon quantificador

Tabela 3 - Parâmetros cromatográficos adotados nas análises

\begin{tabular}{|c|c|}
\hline \multicolumn{2}{|c|}{ Parâmetros cromatográficos } \\
\hline Coluna & $\begin{array}{l}\text { Kinetex }^{\circledR} \text { Biphenyl Core-Shell }(100 \mathrm{x} \\
2.1 \mathrm{~mm} \text { ID, } 1.7 \mu \mathrm{m})\end{array}$ \\
\hline Temperatura do forno da coluna & $60^{\circ} \mathrm{C}$ \\
\hline Fluxo da fase móvel & $0,5 \mathrm{~mL} / \mathrm{min}$ \\
\hline Volume de injeção & $0,4 \mu \mathrm{L}$ \\
\hline Tempo total de corrida & 6.40 minutos \\
\hline \multirow{2}{*}{ Fase Móvel } & $\begin{array}{l}\text { Solvente A: } 10 \mathrm{mmol} / \mathrm{L} \text { tampão } \\
\text { formato de amônio } \mathrm{pH} 3.1\end{array}$ \\
\hline & Solvente B: $\mathrm{MeOH}$ \\
\hline & $\begin{array}{l}\text { Inicial: } 98 \%(A) \mid 2 \%(B) \\
0.20 \text { min: } 98 \%(A) \mid 2 \%(B) \\
0.30 \text { min: } 90 \%(A) \mid 10 \%(B)\end{array}$ \\
\hline Gradiente de eluição & $\begin{array}{l}2.30 \mathrm{~min}: 45 \%(\mathrm{~A}) \mid 55 \%(\mathrm{~B}) \\
2.40 \mathrm{~min}: 2 \%(\mathrm{~A}) \mid 98 \%(\mathrm{~B}) \\
5.00 \mathrm{~min}: 2 \%(\mathrm{~A}) \mid 98 \%(\mathrm{~B}) \\
5.10 \mathrm{~min}: 98 \%(\mathrm{~A}) \mid 2 \%(B)\end{array}$ \\
\hline
\end{tabular}

Abreviação: $\mathrm{MeOH}=$ metanol

A aquisição e o processamento dos dados foram feitos utilizando-se o software Masslynx ${ }^{\text {TM }}$ (versão 4.1). 


\subsubsection{Validação do método para determinação de cocaína e produtos de biotransformação em amostras de sangue total}

A validação do método, utilizando-se sangue total humano como matriz, incluiu os seguintes parâmetros: curva de calibração e linearidade, limites de detecção e quantificação, precisão, exatidão, recuperação, efeito matriz, carryover e estabilidade da amostra (UNODC, 2009; SWGTOX, 2013).

\subsubsection{Curva de calibração e linearidade}

As curvas de calibração foram construídas com base em seis calibradores, cujas concentrações, para cada um dos quatro analitos, foram: 2, 5, 20, 100, 600 e 1250 ng/mL. As curvas de calibração (após a aplicação do coeficiente de ponderação $1 / x$ para todos os analitos) foram construídas plotando-se a razão da altura do pico contra a razão da altura do pico do correspondente padrão interno.

A linearidade se baseou em amostras de sangue extraídas, as quais foram adicionadas dos quatro analitos em 14 concentrações (pontos) diferentes: 2, 5, $20,100,200,400,600,800,1000,1250,1500,1750,2000$ e 2500 ng/mL. Três injeções de cada um dos 14 pontos foram realizadas.

\subsubsection{Limite de detecção (LD) e limite de quantificação (LQ)}

Com o intuito de evitar que limites muito baixos e, portanto, não condizentes com a realidade das análises, o desvio padrão de um controle de qualidade de baixa concentração foi utilizado ao invés do emprego do desvio padrão de uma amostra "branco". 
Os limites de detecção (LD) e quantificação (LQ) foram determinados a partir das equações 1 e 2 , respectivamente:

$L D=3,3 \times$ desvio padrão $C Q_{1 n g / m L}+$ concentração média da amostra "branco"

$\mathrm{LQ}=10 \times$ desvio padrão $\mathrm{CQ}_{1 \mathrm{ng} / \mathrm{mL}}+$ concentração média da amostra "branco"

Um requisito adicional para a determinação do $L D$ e $L Q$ era que o valor do sinal ruído dos íons quantificadores dos fragmentos monitorados fosse $\geq 3$ e 10, respectivamente. Para o limite de quantificação, é esperado também que os valores obtidos nos cálculos da precisão intermediária e da exatidão sejam $\leq 15 \%$.

\subsubsection{Precisão e exatidão}

A precisão intermediária e a exatidão foram determinadas a partir das concentrações calculadas de amostras controle de qualidade (CQ), que foram preparadas e analisadas em oito ensaios, em replicata para cada concentração, ao longo de 24 dias. As amostras controle foram preparadas em sangue total nas seguintes concentrações:

- Cocaína: 1, 2, 5, 25, 100, 200, 501 e 1001 ng/mL;

- Benzoilecgonina: 1, 2, 5, 25, 100, 200, 500, $1001 \mathrm{ng} / \mathrm{mL}$;

- Cocaetileno e AEME: 1, 2, 5, 25, 100, 200, 500 e $1000 \mathrm{ng} / \mathrm{mL}$.

A precisão intermediária foi determinada pelo cálculo do desvio padrão relativo (DPR) obtido em cada concentração de cada um dos analitos e a 
exatidão foi determinada pelo cálculo do desvio, em porcentagem, entre a média das concentrações obtidas nas amostras controle e a concentração teórica.

\subsubsection{Recuperação}

Para o estudo de recuperação do método, dois grupos de amostras de sangue humano foram analisados. No primeiro grupo, padrões de cocaína, benzoilecgonina, cocaetileno e AEME foram adicionados às amostras, as quais foram submetidas à extração conforme procedimento 4.2 .4 em seis replicatas para cada concentração. No segundo grupo, consistindo de quatro replicatas para cada concentração, os mesmos padrões mencionados anteriormente foram adicionados somente após a extração. Em ambos os casos os padrões internos foram adicionados após a etapa de extração. Uma mistura de MeOH/água Tipo I (1:1, v:v, 25 ou $50 \mu \mathrm{L})$ foi adicionada às amostras antes da LLE, para garantir que a composição das amostras (sangue, solventes orgânicos e água Tipo I) fosse a mesma para todas. A recuperação foi calculada pela concentração média calculada das amostras cujos analitos foram adicionados antes da etapa de extração em comparação com a concentração média calculada das amostras que tiveram os analitos adicionados após esta etapa.

\subsubsection{Estudo do efeito matriz (EM)}

Alguns componentes inerentes à matriz biológica podem coeluir com os analitos de interesse interferindo, assim, na eficiência de ionização dos mesmos. Esta interferência pode resultar na diminuição (supressão) ou no aumento da eficiência de formação desses íons, o que poderia acarretar na interpretação errônea dos resultados. 
Neste caso, o efeito matriz foi investigado em dois níveis de concentração de acordo com o procedimento descrito por Matuszewski e colaboradores (2003). Dois conjuntos de amostras foram analisados em cada nível de concentração. No primeiro conjunto $(n=8)$, amostras de sangue total humano de quatro fontes distintas foram submetidas ao processo de extração descrito no item 4.2.4, evaporadas e $60 \mu \mathrm{L}$ do solvente de reconstituição foi adicionado. Os extratos obtidos ( $50 \mu \mathrm{L}$ do volume total de $60 \mu \mathrm{L}$ ) foram então transferidos para vials, aos quais foram adicionados os analitos ( $25 \mu \mathrm{L}$ da solução de trabalho) e padrões internos ( $25 \mu \mathrm{L}$ da solução de trabalho). No segundo conjunto ( $n=8), 50$ $\mu \mathrm{L}$ do solvente de reconstituição foi adicionado a vials vazios, aos quais também foram adicionados os analitos e padrões internos. A composição e o volume final das amostras nos conjuntos um e dois eram os mesmos. Todas as amostras foram analisadas pelo método UHPLC-MS/MS desenvolvido e o efeito matriz foi calculado pela equação 3 :

$E M=($ altura do pico do conjunto $1 /$ altura do pico do conjunto 2) $\times 100 \quad$ (eq. 3), sendo que $E M=100$ indica que não ocorreu efeito matriz, $E M>100$ indica a possível ocorrência de efeito matriz com enriquecimento iônico e $E M<100$ indicando a possível ocorrência de efeito matriz com supressão iônica.

\subsubsection{Carryover}

A possível ocorrência do fenômeno de carryover entre as análises foi avaliada em todos os oito ensaios utilizados para o cálculo da precisão e da exatidão. Em cada ensaio, duas amostras "branco" foram analisadas após o controle de qualidade (CQ) correspondente a $1000 \mathrm{ng} / \mathrm{mL}$. 


\subsubsection{Estabilidade da amostra}

A estabilidade da cocaína em solventes pode ser aumentada pela acidificação e refrigeração da solução, enquanto no sangue o analito aumenta a sua estabilidade pela adição de conservantes (como por exemplo fluoreto) e pelo acondicionamento em freezer (Baselt, 1983; Giorgi \& Meeker, 1995; Fandino et al., 2002a; Rees et al., 2012). A estabilidade dos analitos incluídos no estudo foi investigada através da análise de amostras de sangue postmortem coletadas em tubo Vacutainer ${ }^{\circledR}$ contendo fluoreto de sódio e EDTA e que foram mantidas congeladas $\mathrm{a}-20^{\circ} \mathrm{C}$. As amostras foram analisadas duas vezes, sendo que 0 intervalo de tempo entre a primeira análise e a segunda foi de 63 dias.

\subsection{Aspectos éticos}

O presente protocolo de pesquisa foi aprovado pelo Comitê de Ética em Pesquisa da Faculdade de Medicina da Universidade de São Paulo (CEPFMUSP) em 08 de dezembro de 2014 (Anexo A), como parte do projeto de pesquisa intitulado "Determinação de lesões relacionadas ao uso de drogas: unindo achados toxicológicos e dados criminais", aprovado pelo mesmo órgão em 22 de abril de 2014 sob protocolo nº 096/14 (Anexo B). Os pesquisadores obtiveram autorização da Superintendência da Polícia Técnico Científica para a realização do estudo (Anexo $\mathrm{C}$ ) e reafirmam o compromisso de preservar o anonimato e a confidencialidade dos dados coletados. 


\section{RESULTADOS}

\subsection{Estudo de prevalência}

Os dados foram coletados ao longo de 135 turnos de oito horas de duração cada, conduzidos durante 19 meses. Um total de 656 vítimas foram admitidas no IML-SP durante o período do estudo, sendo que 365 (55,6\%) delas preencheram os critérios de inclusão. Os motivos que levaram à exclusão dos demais casos encontram-se distribuídos na Figura 1.

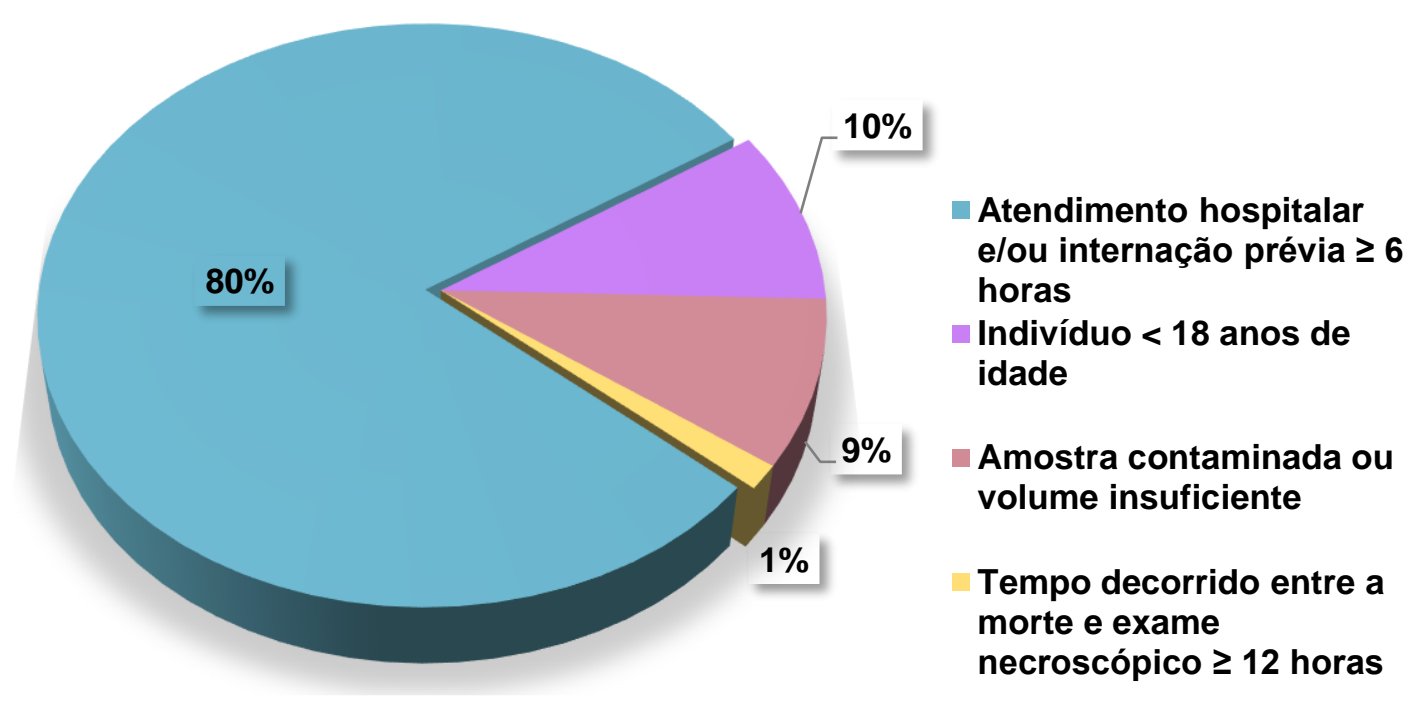

Figura 1 - Distribuição dos casos não incluídos na amostra final, conforme critério de exclusão

A amostra final considerada neste estudo teve uma distribuição das causas de óbito com porcentagens similares em relação ao registrado ao longo do ano de 2013, na cidade de São Paulo, conforme mostrado na Tabela 4. 
Tabela 4 - Número de óbitos por causas externas registrados na cidade de São Paulo, em 2013, e a amostra incluída no estudo $(n=365)$ de acordo com o tipo de lesão

\begin{tabular}{lccc}
\hline & $\begin{array}{c}\text { Estatística anual } \\
(\mathbf{2 0 1 3})^{\mathbf{a}} \mathbf{n}(\%)\end{array}$ & $\begin{array}{c}\text { Amostra final do } \\
\text { estudo } \mathbf{n}(\%)\end{array}$ & $\mathbf{P}^{\mathbf{b}}$ \\
\hline Homicídios & $1354(26,0)$ & $104(28,5)$ & \\
Acidente de trânsito & $1054(20,3)$ & $56(15,3)$ & \\
Suicídio & $524(10,1)$ & $44(12,1)$ & \\
Outros & $2267(43,6)$ & $161(44,1)$ & \\
Total & 5199 & 365 & 0.08 \\
\hline
\end{tabular}

a Foram excluídos os menores e aqueles que vieram a óbito em decorrência de complicações de assistência médica e cirúrgica (Y40-Y84) ou em virtude de sequelas de causas externas de morbidade e de mortalidade (Y85-Y89).

b teste qui-quadrado

Os resultados das análises toxicológicas revelaram que quase um terço $(29,9 \%)$ das vítimas de morte por causas externas havia feito uso recente de pelo menos uma das substâncias ilícitas pesquisadas, sendo o consumo de cocaína $(21,9 \%)$ maior que o consumo de cannabis (14\%).

A maior parte das vítimas era do sexo masculino $(82,2 \%)$ e o consumo de cannabis e/ou cocaína por eles foi maior quando comparado às mulheres. Com relação à idade das vítimas no momento do óbito, foi verificado que a maioria possuía mais de 30 anos de idade (63,0\%); apesar disso, os indivíduos mais jovens ( $\leq 30$ anos de idade) foram os que mais haviam feito uso tanto de cannabis, quanto de cocaína, no momento do evento fatal (Tabela 5).

A proporção de brancos e não-brancos (negros, pardos, amarelos) na amostra geral foi similar; porém, quando analisado o consumo de drogas, verificou-se que os não-brancos apresentaram maior positividade para o consumo de pelo menos uma das substâncias pesquisadas e também para 0 
uso de cocaína. Para o consumo de cannabis, a diferença observada não foi estatisticamente significativa $(P=0.056)($ Tabela 5$)$.

Com relação ao grau de escolaridade das vítimas, $61,1 \%$ pertencia ao grupo dos analfabetos ou daqueles que possuíam até o $1^{\circ}$ grau (completo ou incompleto). O consumo de cocaína, ou de pelo menos uma das drogas, foi maior entre este grupo, ao passo que entre aqueles que possuíam algum grau de instrução de $3^{\circ}$ grau $(10,1 \%)$, não foi detectada nenhuma das substâncias (Tabela 5).

Dentre as causas que levaram ao óbito, os homicídios ocuparam a segunda posição (depois do grupo das mortes suspeitas), seguidos pelos acidentes de trânsito, os quais apresentaram a maior positividade de vítimas que haviam feito uso de cannabis em relação às demais causas. Já entre aqueles que consumiram pelo menos uma das substâncias pesquisadas ou cocaína, a maior prevalência observada foi entre as vítimas de homicídio. Apesar da arma de fogo ter sido um importante meio empregado na ocorrência que resultou no desfecho fatal, o consumo maior de pelo menos uma das drogas ou de cocaína foi encontrado entre as vítimas que sofreram intoxicação exógena (Tabela 5).

A maior parte dos óbitos ocorreu em local público (64,9\%), principalmente na via pública e o consumo de drogas (cannabis e pelo menos uma das substâncias) também foi maior entre as vítimas que vieram a óbito em espaço público quando comparado às vítimas que morreram em local privado (residência ou clínica de reabilitação). Buscou-se também informações acerca de antecedentes criminais das vítimas e verificou-se que apesar da minoria (15,9\%) apresentar algum registro, a diferença com relação ao consumo de cannabis 
e/ou cocaína foi estatisticamente significativa entre este grupo quando comparado aos indivíduos que não possuíam antecedentes criminais (Tabela 5).

Por fim, observou-se uma maior ocorrência de mortes por causas externas em dias úteis (segunda-feira a sexta-feira) e no período noturno; entretanto, apesar da diferença não ter sido estatisticamente significativa, o consumo de pelo menos uma das substâncias consideradas no estudo foi maior entre as vítimas que vieram a óbito no final de semana e durante a madrugada (Tabela 5).

Tabela 5 - Uso de substâncias (cocaína e/ou cannabis) por vítimas de causas externas e informações sociodemográficas e do contexto da lesão

\begin{tabular}{|c|c|c|c|c|c|}
\hline & $\begin{array}{l}\text { Total } \\
\text { n (\%) }\end{array}$ & $\begin{array}{c}\text { Positivo para } \\
\text { pelo menos } \\
\text { uma das } \\
\text { drogas }(\%)\end{array}$ & $\begin{array}{l}\text { Positivo } \\
\text { para } \\
\text { cocaína } \\
(\%)\end{array}$ & $\begin{array}{c}\text { Positivo } \\
\text { para } \\
\text { cannabis } \\
(\%)\end{array}$ & $\begin{array}{c}\text { Dados } \\
\text { omissos ou } \\
\text { faltantes }\end{array}$ \\
\hline \multicolumn{6}{|l|}{ Total } \\
\hline & 365 & 29,9 & 21,9 & 14,0 & $0 \%$ \\
\hline \multicolumn{6}{|l|}{ Sexo } \\
\hline Masculino & $300(82,2)$ & $34,3^{*}$ & $25,0^{*}$ & $16,7^{*}$ & \\
\hline Feminino & $65(17,8)$ & 9,2 & 7,7 & 1,5 & $0 \%$ \\
\hline \multicolumn{6}{|l|}{ Idade (anos) } \\
\hline$\leq 30$ & $120(37,0)$ & $49,2^{*}$ & $34,2^{*}$ & $25,0^{*}$ & \\
\hline$>30$ & $204(63,0)$ & 14,7 & 12,3 & 5,4 & $11,2 \%$ \\
\hline \multicolumn{6}{|l|}{ Etnia } \\
\hline Brancos & $172(50,3)$ & 23,3 & 16,9 & 10,5 & \\
\hline Não-brancos & $170(49,7)$ & $36,5^{\star}$ & $27,7^{*}$ & 17,7 & $6,3 \%$ \\
\hline \multicolumn{6}{|l|}{ Grau de escolaridade } \\
\hline 1 grau ou analfabeto & $157(61,1)$ & $30,6^{*}$ & $23,6^{*}$ & 14,0 & \\
\hline $2^{\circ}$ grau & $74(28,8)$ & 24,3 & 14,9 & 10,8 & \\
\hline $3^{\circ} \mathrm{grau}$ & $26(10,1)$ & 0,0 & 0,0 & 0,0 & $29,6 \%$ \\
\hline \multicolumn{6}{|l|}{ Causa do óbito } \\
\hline Acidente de trânsito & $56(15,3)$ & 30,4 & 21,4 & $19,6^{*}$ & \\
\hline Homicídio & $104(28,5)$ & $43,3^{*}$ & $30,8^{*}$ & 19,2 & \\
\hline Morte suspeita & $161(44,1)$ & 26,1 & 19,9 & 11,8 & \\
\hline Suicídio & $44(12,1)$ & 11,4 & 9,1 & 2,3 & $0 \%$ \\
\hline
\end{tabular}


Tabela 5 - Uso de substâncias (cocaína e/ou cannabis) por vítimas de causas externas e informações sociodemográficas e do contexto da lesão (conclusão)

\begin{tabular}{|c|c|c|c|c|c|}
\hline & $\begin{array}{l}\text { Total } \\
\text { n (\%) }\end{array}$ & $\begin{array}{c}\text { Positivo para } \\
\text { pelo menos } \\
\text { uma das } \\
\text { drogas }(\%)\end{array}$ & $\begin{array}{l}\text { Positivo } \\
\text { para } \\
\text { cocaína } \\
(\%)\end{array}$ & $\begin{array}{c}\text { Positivo } \\
\text { para } \\
\text { cannabis } \\
(\%)\end{array}$ & $\begin{array}{c}\text { Dados } \\
\text { omissos ou } \\
\text { faltantes }\end{array}$ \\
\hline \multicolumn{6}{|l|}{ Circunstância do óbito } \\
\hline Atropelamento & $31(8,5)$ & 19,4 & 16,1 & 16,1 & \\
\hline Colisão & $27(7,4)$ & 37,0 & 25,9 & 18,5 & \\
\hline Enforcamento & $14(3,8)$ & 14,3 & 7,1 & 7,1 & \\
\hline Arma branca ${ }^{a}$ & $23(6,3)$ & 30,4 & 26,1 & 13,0 & \\
\hline Arma de fogo & $83(22,7)$ & 43,4 & 30,1 & 19,3 & \\
\hline Queda & $34(9,3)$ & 5,9 & 5,9 & 0,0 & \\
\hline Intoxicação exógena & $25(6,9)$ & $52,0^{*}$ & $40,0^{*}$ & 24,0 & \\
\hline Outros & $128(35,1)$ & 25,8 & 18,8 & 11,7 & $0 \%$ \\
\hline \multicolumn{6}{|l|}{ Local da ocorrência } \\
\hline Privado & $112(35,1)$ & 21,4 & 17,9 & 6,3 & \\
\hline Público & $207(64,9)$ & $33,8^{*}$ & 25,1 & $17,4^{*}$ & $12,6 \%$ \\
\hline \multicolumn{6}{|l|}{ Antecedentes criminais } \\
\hline Sim & $50(15,9)$ & $66,0^{*}$ & $48,0^{*}$ & $34,0^{*}$ & \\
\hline Não & $264(84,1)$ & 20,8 & 15,9 & 8,3 & $14,0 \%$ \\
\hline \multicolumn{6}{|l|}{ Dia da ocorrência } \\
\hline Dia da semana & $270(74,0)$ & 29,3 & 22,2 & 13,3 & \\
\hline Final de semana & $95(26,0)$ & 31,6 & 21,1 & 15,8 & $0 \%$ \\
\hline \multicolumn{6}{|l|}{ Período da ocorrência } \\
\hline Manhã & $64(17,6)$ & 31,3 & 25,0 & 10,9 & \\
\hline Tarde & $80(21,9)$ & 27,5 & 22,5 & 13,8 & \\
\hline Noite & $137(37,5)$ & 26,3 & 18,3 & 12,4 & \\
\hline Madrugada & $84(23,0)$ & 36,9 & 25,0 & 19,1 & $0 \%$ \\
\hline
\end{tabular}


5.2 Desenvolvimento e validação de metodologia em UHPLC-MS/MS para quantificação de cocaína, benzoilecgonina, cocaetileno e anidroecgonina metil éster

Um método sensível, preciso e robusto para determinação de cocaína, benzoilecgonina, cocaetileno e anidroecgonina metil éster em sangue total, utilizando-se a técnica de extração líquido-líquido com MTBE/2-propanol (70:30, v:v) e análise por UHPLC-MS/MS, foi desenvolvido e validado.

\subsubsection{Otimização do procedimento de extração}

A extração líquido-líquido baseia-se na separação dos analitos tendo por base as suas solubilidades, sendo que a extração ocorre entre duas fases líquidas imiscíveis (uma aquosa e outra orgânica) através da adição de solventes adequados. Diferentes misturas de solventes de MTBE/2-propanol e heptano/acetato de etila foram testadas e os resultados da recuperação dos analitos de interesse são apresentados na Tabela 6.

Tabela 6 - Teste de solventes orgânicos (composição e volume) e recuperação dos analitos

\begin{tabular}{|c|c|c|c|c|c|c|c|c|c|c|c|c|}
\hline \multirow[b]{2}{*}{$\mathbf{n}$} & \multicolumn{4}{|c|}{ Solventes orgânicos } & \multicolumn{2}{|c|}{ Cocaína } & \multicolumn{2}{|c|}{ BZE } & \multicolumn{2}{|c|}{ CE } & \multicolumn{2}{|c|}{ AEME } \\
\hline & $\begin{array}{c}\text { MTBE } \\
(\%)\end{array}$ & $\begin{array}{c}2- \\
\text { propanol } \\
(\%)\end{array}$ & $\begin{array}{l}\text { AE } \\
(\%)\end{array}$ & $\begin{array}{c}\text { Hep. } \\
(\%)\end{array}$ & $\begin{array}{l}\text { Rec. } \\
(\%)\end{array}$ & $\begin{array}{c}\text { DPR } \\
(\%)\end{array}$ & $\begin{array}{c}\text { Rec. } \\
(\%)\end{array}$ & $\begin{array}{l}\text { DPR } \\
(\%)\end{array}$ & $\begin{array}{l}\text { Rec. } \\
(\%)\end{array}$ & $\begin{array}{c}\text { DPR } \\
(\%)\end{array}$ & $\begin{array}{l}\text { Rec. } \\
(\%)\end{array}$ & $\begin{array}{c}\text { DPR } \\
(\%)\end{array}$ \\
\hline 4 & 100 & 0 & 0 & 0 & 91 & 8 & 0,2 & 46 & 98 & 9 & 59 & 3 \\
\hline 4 & 90 & 10 & 0 & 0 & 79 & 6 & 2,2 & 32 & 84 & 3 & 48 & 14 \\
\hline 4 & 80 & 20 & 0 & 0 & 78 & 4 & 14 & 13 & 75 & 1 & 86 & 5 \\
\hline 4 & 70 & 30 & 0 & 0 & 74 & 5 & 39 & 9 & 75 & 3 & 82 & 4 \\
\hline 4 & 60 & 40 & 0 & 0 & 74 & 5 & 54 & 9 & 75 & 4 & 73 & 2 \\
\hline 4 & 0 & 0 & 100 & 0 & 85 & 4 & 4,0 & 24 & 82 & 2 & 125 & 31 \\
\hline 4 & 0 & 0 & 90 & 10 & 89 & 7 & 1,7 & 27 & 90 & 3 & 67 & 27 \\
\hline 4 & 0 & 0 & 80 & 20 & 91 & 2 & 0,5 & 62 & 92 & 2 & 35 & 40 \\
\hline
\end{tabular}


Tabela 6 - Teste de solventes orgânicos (composição e volume) e recuperação dos analitos (conclusão)

\begin{tabular}{|c|c|c|c|c|c|c|c|c|c|c|c|c|}
\hline \multirow[b]{2}{*}{ n } & \multicolumn{4}{|c|}{ Solventes orgânicos } & \multicolumn{2}{|c|}{ Cocaína } & \multicolumn{2}{|c|}{ BZE } & \multicolumn{2}{|c|}{ CE } & \multicolumn{2}{|c|}{ AEME } \\
\hline & $\begin{array}{c}\text { MTBE } \\
(\%)\end{array}$ & $\begin{array}{c}2- \\
\text { propanol } \\
(\%)\end{array}$ & $\begin{array}{l}\mathrm{AE} \\
(\%)\end{array}$ & $\begin{array}{c}\text { Hep. } \\
(\%)\end{array}$ & $\begin{array}{l}\text { Rec. } \\
(\%)\end{array}$ & $\begin{array}{c}\text { DPR } \\
(\%)\end{array}$ & $\begin{array}{l}\text { Rec. } \\
(\%)\end{array}$ & $\begin{array}{l}\text { DPR } \\
\text { (\%) }\end{array}$ & $\begin{array}{l}\text { Rec. } \\
(\%)\end{array}$ & $\begin{array}{c}\text { DPR } \\
\text { (\%) }\end{array}$ & $\begin{array}{l}\text { Rec. } \\
(\%)\end{array}$ & $\begin{array}{c}\text { DPR } \\
(\%)\end{array}$ \\
\hline 4 & 0 & 0 & 70 & 30 & 88 & 3 & 0,7 & 53 & 94 & 3 & 108 & 10 \\
\hline 4 & 0 & 0 & 60 & 40 & 93 & 5 & 0,3 & 93 & 95 & 2 & 104 & 19 \\
\hline 2 & 0 & 0 & 0 & 100 & 93 & 2 & 0,1 & 92 & 90 & 3 & 97 & 19 \\
\hline
\end{tabular}

Para a extração, os analitos na concentração de $25 \mathrm{ng} / \mathrm{mL}$ foram adicionados a $100 \mu \mathrm{L}$ de sangue e realizado o procedimento conforme descrito no item 4.2.3. Os padrões internos foram adicionados após a extração em todas as amostras.

A recuperação em cada conjunto foi calculada de acordo com a Equação 4.

Rec. $(\%)=($ concentração média calculada das amostras cujos analitos foram adicionados antes da etapa de extração / concentração média calculada das amostras que tiveram os analitos adicionados após a etapa de extração) x 100

(eq. 4)

Cocaína, cocaetileno e AEME obtiveram resultados satisfatórios de recuperação ( $\geq 35 \%$ ) para todas as combinações de solventes orgânicos testadas, porém a recuperação da benzoilecgonina se mostrou altamente dependente dos solventes. Assim, baixa recuperação $(<4 \%)$ do analito foi observada empregando-se heptano/acetato de etila, em todas as faixas de concentrações. Apesar da recuperação de benzoilecgonina utilizando-se $40 \%$ de 2-propanol (60\% MTBE) ter sido maior (54\%), optou-se pela proporção MTBE/2- 
propanol (70:30, v:v) pois o tempo de evaporação se mostrou menor e os extratos, em inspeção visual, apresentaram-se mais límpidos.

\subsubsection{Análise por UHPLC-MS/MS}

Foram testadas duas colunas para a separação dos analitos de interesse: ACQUITY UPLC ${ }^{\circledR}$ HSS T3 (100 mm x $2.1 \mathrm{~mm}$ ID, partículas de $\left.1.8 \mu \mathrm{m}\right)$, da Waters Inc., e Kinetex ${ }^{\mathrm{TM}}$ Bifenil com tecnologia Core-Shell (100 mm x $2.1 \mathrm{~mm}$ ID, partículas de $1.7 \mu \mathrm{m})$, da Phenomenex ${ }^{\circledR}$. Ambas forneceram picos simétricos e estreitos e a mesma ordem de eluição da cocaína e produtos de biotransformação; entretanto, devido à menor pressão da coluna, a segunda foi escolhida.

A Figura 2 mostra o gradiente de eluição e a separação cromatográfica dos quatro analitos (COC, BZE, CE e AEME) e de outras 23 substâncias obtida com o método desenvolvido. As 23 substâncias adicionais incluem algumas drogas e produtos de biotransformação que poderiam apresentar o mesmo tempo de retenção e assim coeluir com os analitos de interesse. Não foi possível obter comercialmente o padrão interno $(\mathrm{PI})$ específico para o AEME (por esta razão, utilizou-se Cocaetileno- $\mathrm{D}_{3}$ como $\mathrm{PI}$ ). Ao final da corrida cromatográfica, o gradiente de eluição foi mantido durante 2,6 minutos com uma concentração de 98\% de solvente B (MeOH) para a eluição de fosfolipídios e outros compostos apolares que porventura não tivessem sido removidos durante a extração líquido-líquido e que poderiam causar interferência na análise. Após testes, o volume de injeção de $0,4 \mu \mathrm{L}$ foi escolhido com o intuito de se injetar baixas quantidades de componentes da matriz no sistema, porém mantendo-se ainda 
um volume suficiente que permitisse uma detecção satisfatória de todos os analitos.

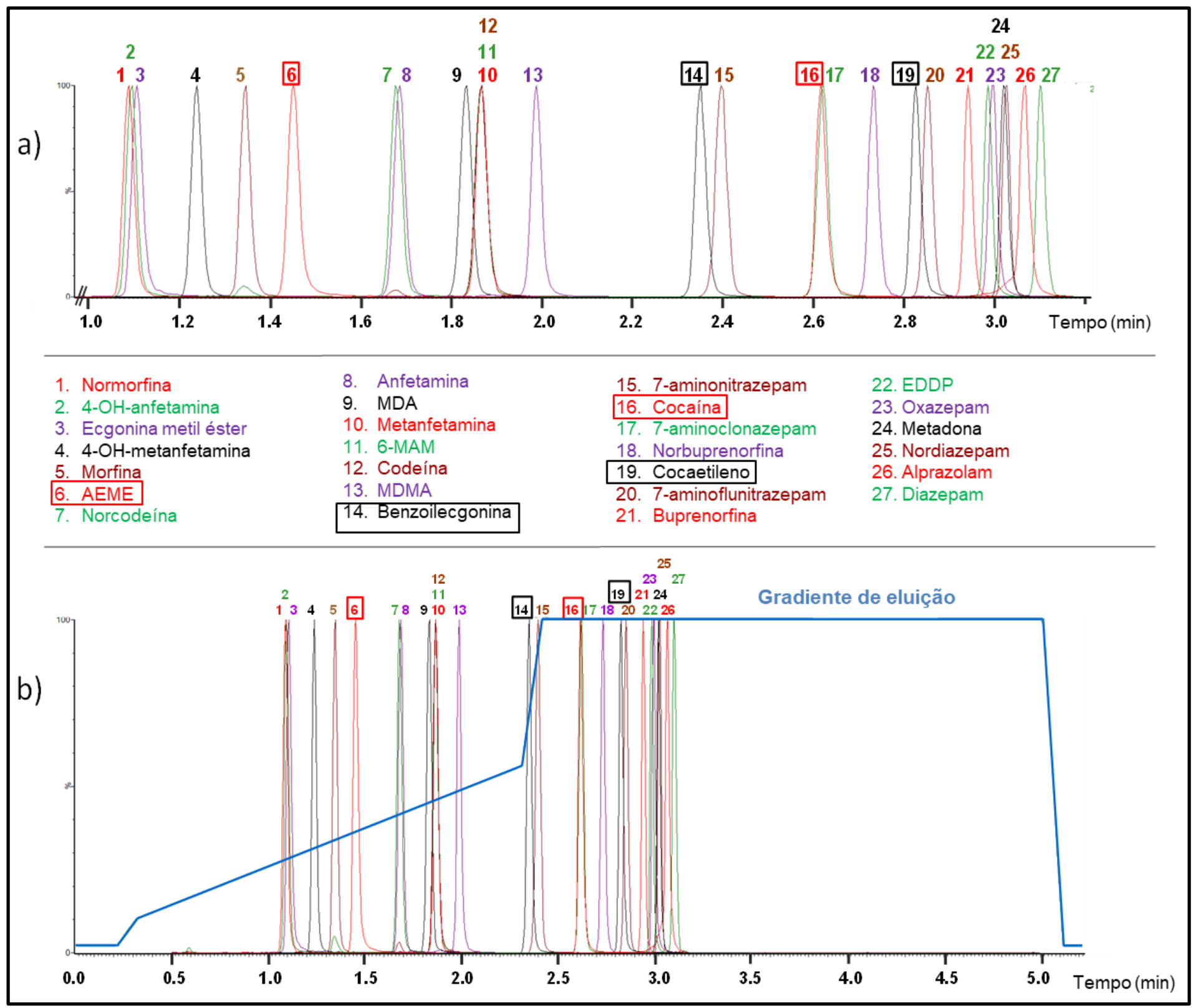

Figura 2 - (a) Separação cromatográfica de AEME, benzoilecgonina, cocaína, cocaetileno e 23 drogas e produtos de biotransformação utilizando-se o método desenvolvido e (b) separação dos 27 analitos, com apresentação do gradiente de eluição 


\subsubsection{Validação do método}

\subsubsection{Curva de calibração e linearidade}

Os valores dos coeficientes de determinação $\left(R^{2}\right)$ para as curvas de calibração, os respectivos desvios padrões relativos e a faixa de linearidade para cada analito estão apresentados na Tabela 7.

Tabela 7 - Valores dos coeficientes de determinação $\left(R^{2}\right)$, desvio padrão relativo e faixa de linearidade dos analitos

\begin{tabular}{lccc}
\hline Analito & $\mathbf{R}^{2}$ & DPR (\%) & $\begin{array}{c}\text { Faixa de } \\
\text { linearidade } \\
(\mathbf{n g} / \mathbf{m L})\end{array}$ \\
\hline Cocaína & 0,99955 & 0,05 & $2-2000$ \\
Benzoilecgonina & 0,99966 & 0,03 & $2-1750$ \\
Cocaetileno & 0,99979 & 0,03 & $2-2500$ \\
AEME & 0,99970 & 0,03 & $2-2000$ \\
\hline
\end{tabular}

Abreviações: $\mathrm{DPR}=$ desvio padrão relativo; $\mathrm{AEME}$ = anidroecgonina metil éster

\subsubsection{Limite de detecção (LD) e limite de quantificação (LQ)}

Os limites de detecção (LD) e quantificação (LQ) obtidos com o método proposto para determinação de cocaína, benzoilecgonina, cocaetileno e anidroecgonina metil éster em amostras de sangue estão apresentados na Tabela 8. 
Tabela 8 - Limites de detecção (LD) e limites de quantificação (LQ) para os analitos pesquisados

\begin{tabular}{lcc}
\hline Analito & LD $(\mathbf{n g} / \mathbf{m L})$ & LQ $(\mathbf{n g} / \mathbf{m L})$ \\
\hline Cocaína & 0,3 & 0,7 \\
Benzoilecgonina & 0,5 & 1,5 \\
Cocaetileno & 0,3 & 0,8 \\
AEME & 0,4 & 1,0 \\
\hline
\end{tabular}

Abreviações: $\mathrm{AEME}=$ anidroecgonina metil éster; $\mathrm{LD}=$ limite de detecção; $L Q$ = limite de quantificação

\subsubsection{Precisão e exatidão}

Para todas as oito concentrações avaliadas, o desvio padrão relativo calculado para o teste de precisão foi $\leq 15 \%$ e o desvio entre a média das concentrações obtidas nas amostras controle e a concentração teórica foi $\leq 12 \%$, o que atesta a precisão e exatidão do método (Tabela 9).

Tabela 9 - Resultados dos estudos de precisão e exatidão do método

\begin{tabular}{lcccc}
\hline Analito & $\begin{array}{c}\text { Concentração } \\
\text { teórica } \\
(\mathbf{n g} / \mathbf{m L})\end{array}$ & $\begin{array}{c}\text { Média das } \\
\text { concentrações } \\
\text { obtidas } \\
(\mathbf{n g} / \mathbf{m L})\end{array}$ & $\begin{array}{c}\text { Precisão } \\
(\% \mathrm{DPR}) \\
(\mathbf{n}=\mathbf{8})\end{array}$ & $\begin{array}{c}\text { Exatidão } \\
\text { (\%desvio) } \\
(\mathbf{n}=\mathbf{8})\end{array}$ \\
\hline Cocaína & 1,0 & 1,1 & 5 & 6 \\
& 2,0 & 1,9 & 5 & -4 \\
& 5,0 & 4,6 & 4 & -8 \\
& 25 & 24 & 3 & -4 \\
Benzoilecgonina & 100 & 69 & 2 & -4 \\
& 200 & 198 & 4 & -1 \\
& 501 & 497 & 1 & -1 \\
& 1001 & 1025 & 3 & 2 \\
& 1,0 & 1,0 & 15 & -2 \\
& 2,0 & 2,0 & 10 & -2 \\
& 5,0 & 4,6 & 6 & -9 \\
& 25 & 24 & 4 & -4
\end{tabular}


Tabela 9 - Resultados dos estudos de precisão e exatidão do método (conclusão)

\begin{tabular}{lcccc}
\hline Analito & $\begin{array}{c}\text { Concentração } \\
\text { teórica } \\
(\mathbf{n g} / \mathbf{m L})\end{array}$ & $\begin{array}{c}\text { Média das } \\
\text { concentrações } \\
\text { obtidas } \\
(\mathbf{n g} / \mathbf{m L})\end{array}$ & $\begin{array}{c}\text { Precisão } \\
(\% \mathrm{DPR}) \\
(\mathbf{n}=\mathbf{8})\end{array}$ & $\begin{array}{c}\text { Exatidão } \\
\text { (\%desvio) } \\
(\mathbf{n}=\mathbf{8})\end{array}$ \\
\hline Benzoilecgonina & 100 & 98 & 2 & -2 \\
& 200 & 199 & 3 & 0 \\
Cocaetileno & 500 & 513 & 2 & 2 \\
& 1001 & 1035 & 3 & 3 \\
& 1,0 & 1,02 & 8 & 2 \\
& 2,0 & 1,92 & 4 & -4 \\
& 5,0 & 4,59 & 2 & -8 \\
AEME & 25 & 23,4 & 4 & -6 \\
& 100 & 95,4 & 3 & -5 \\
& 200 & 192 & 2 & -4 \\
& 500 & 492 & 2 & -2 \\
& 1000 & 1039 & 2 & 4 \\
& 1,0 & 0,97 & 9 & -3 \\
& 2,0 & 1,81 & 4 & -10 \\
& 5,0 & 4,40 & 3 & -12 \\
25 & 22,8 & 4 & -9 \\
& 100 & 94,3 & 4 & -6 \\
200 & 188 & 3 & -6 \\
500 & 479 & 3 & -4 \\
& 1000 & 964 & 5 & -4 \\
\hline
\end{tabular}

Abreviações: DPR = desvio padrão relativo; AEME = anidroecgonina metil éster

\subsubsection{Recuperação}

A recuperação obtida com o método validado foi de aproximadamente 80\% para cocaína, cocaetileno e AEME e de cerca de $40 \%$ para benzoilecgonina (Tabela 10). Valores similares foram observados no teste de otimização dos solventes orgânicos quando se empregou a mesma composição utilizada para a validação do método (Tabela 6). 
Tabela 10 - Valores de recuperação obtidos com a aplicação do método proposto em amostras de sangue

\begin{tabular}{|c|c|c|c|}
\hline \multirow[b]{2}{*}{ Analitos } & \multirow{2}{*}{$\begin{array}{c}\text { Concentração } \\
\text { teórica } \\
(\mathrm{ng} / \mathrm{mL})\end{array}$} & \multicolumn{2}{|c|}{ Recuperação $(n=6)$} \\
\hline & & $\begin{array}{c}\text { Recuperação } \\
\text { média (\%) }\end{array}$ & DPR (\%) \\
\hline \multirow[t]{2}{*}{ Cocaína } & 25 & 76 & 9 \\
\hline & 100 & 80 & 4 \\
\hline \multirow[t]{2}{*}{ Benzoilecgonina } & 25 & 43 & 6 \\
\hline & 100 & 45 & 5 \\
\hline \multirow[t]{2}{*}{ Cocaetileno } & 25 & 82 & 6 \\
\hline & 100 & 81 & 2 \\
\hline \multirow[t]{2}{*}{ AEME } & 25 & 81 & 7 \\
\hline & 100 & 84 & 3 \\
\hline
\end{tabular}

\subsubsection{Efeito matriz (EM)}

A Tabela 11 apresenta os resultados obtidos para o teste de efeito matriz e revela a ocorrência de um discreto acréscimo de sinal, o qual foi corrigido pelo padrão interno marcado com isótopo estável.

Tabela 11 - Estudo de efeito matriz

\begin{tabular}{lcccc}
\hline Analitos & $\begin{array}{c}\text { Concentração } \\
\text { teórica } \\
(\mathbf{n g} / \mathbf{m L})\end{array}$ & Média EM & $\begin{array}{c}\text { DPR } \\
(\%)\end{array}$ & $\begin{array}{c}\text { Média EM } \\
\text { corrigida com PI }\end{array}$ \\
\cline { 3 - 5 } Cocaína & 5 & 130 & 10 & 99 \\
& 100 & 124 & 10 & 107 \\
Benzoilecgonina & 5 & 129 & 11 & 102 \\
& 100 & 122 & 8 & 106 \\
Cocaetileno & 5 & & & \\
& 100 & 131 & 11 & 99 \\
& & 125 & 10 & 106 \\
& & & & continua
\end{tabular}


Tabela 11 - Estudo de efeito matriz (conclusão)

\begin{tabular}{lcccc}
\hline Analitos & $\begin{array}{c}\text { Concentração } \\
\text { teórica } \\
(\mathbf{n g} / \mathbf{m L})\end{array}$ & Média EM & $\begin{array}{c}\text { DPR } \\
(\%)\end{array}$ & $\begin{array}{c}\text { Média EM } \\
\text { corrigida com PI }\end{array}$ \\
\cline { 3 - 5 } AEME & 5 & 121 & 7 & 92 \\
& 100 & 117 & 8 & 98 \\
\hline
\end{tabular}

Abreviações: $\mathrm{DPR}$ = desvio padrão relativo; $\mathrm{EM}$ = efeito matriz; $\mathrm{PI}$ = padrão interno;

$A E M E$ = anidroecgonina metil éster

\subsubsection{Carryover}

O método não apresentou a ocorrência do fenômeno de carryover. As médias calculadas, para os quatro analitos, da primeira amostra "branco" e da segunda (injetadas logo após o controle de qualidade mais alto, de concentração $1000 \mathrm{ng} / \mathrm{mL}$ ) foram, respectivamente, $\leq 0,05 \%$ e $\leq 0,01 \%$.

\subsubsection{Estabilidade da amostra}

Para tornar a exposição dos dados mais compreensível, os resultados das análises de estabilidade das amostras serão apresentados no item seguinte, juntamente com os resultados da aplicação do método em amostras de sangue postmortem.

\subsubsection{Aplicação do método em amostras de sangue postmortem e cálculo de estabilidade}

O método desenvolvido e validado, o qual incluiu a extração dos analitos utilizando-se extração líquido-líquido e a posterior detecção e quantificação por UHPLC-MS/MS, foi aplicado em 21 amostras de sangue postmortem, coletadas nos postos do Instituto Médico Legal para o estudo de prevalência do uso de cannabis e cocaína em vítimas de mortes violentas. Tais amostras foram 
analisadas duas vezes, com um intervalo de tempo de 63 dias entre as análises, e em duplicata em cada teste, sendo mantidas congeladas a $-20 \stackrel{\circ}{C}$ neste período.

A Tabela 12 apresenta os resultados das análises toxicológicas, sendo os resultados da segunda análise (decorridos os 63 dias) apresentados por meio do desvio (\%) observado entre as duas análises. Informações sociodemográficas das vítimas e do evento que levou ao desfecho fatal também são apresentados. 
Tabela 12 - Análise de amostras de sangue postmortem, estabilidade e dados das vítimas e ocorrências

\begin{tabular}{|c|c|c|c|c|c|c|c|c|c|c|c|c|}
\hline \multirow[b]{2}{*}{ Caso } & \multirow[b]{2}{*}{$\mathbf{n}$} & \multicolumn{2}{|c|}{ Cocaína } & \multicolumn{2}{|c|}{ Benzoilecgonina } & \multicolumn{2}{|c|}{ Cocaetileno } & \multicolumn{2}{|c|}{ AEME } & \multirow[b]{2}{*}{ Sexo } & \multirow[b]{2}{*}{ Idade } & \multirow[b]{2}{*}{ Ocorrência } \\
\hline & & $\begin{array}{l}\text { Primeira } \\
\text { análise } \\
\text { (ng/mL) }\end{array}$ & $\begin{array}{l}\text { Segunda } \\
\text { análise } \\
\text { (\% desvio) }\end{array}$ & $\begin{array}{l}\text { Primeira } \\
\text { análise } \\
\text { (ng/mL) }\end{array}$ & $\begin{array}{l}\text { Segunda } \\
\text { análise } \\
\text { (\% desvio) }\end{array}$ & $\begin{array}{l}\text { Primeira } \\
\text { análise } \\
\text { (ng/mL) }\end{array}$ & $\begin{array}{l}\text { Segunda } \\
\text { análise } \\
\text { (\% desvio) }\end{array}$ & $\begin{array}{l}\text { Primeira } \\
\text { análise } \\
\text { (ng/mL) }\end{array}$ & $\begin{array}{l}\text { Segunda } \\
\text { análise } \\
\text { (\% desvio) }\end{array}$ & & & \\
\hline 1 & 2 & ND & ND & 7,8 & -5 & ND & 10 & ND & ND & $\mathrm{M}$ & 33 & Morte suspeita \\
\hline 2 & 2 & ND & 6 & 11 & 2 & 1,0 & 5 & ND & ND & M & 48 & Morte suspeita \\
\hline 3 & 2 & 0,7 & 23 & 60 & 19 & ND & ND & ND & 5 & $M$ & 27 & Homicídio (FAF) \\
\hline 4 & 2 & 0,8 & -8 & 10 & 18 & ND & ND & ND & ND & $M$ & 20 & Morte suspeita \\
\hline 5 & 2 & 0,9 & -19 & 54 & 4 & ND & ND & ND & -6 & $\mathrm{~F}$ & 28 & Suicídio \\
\hline 6 & 2 & 5,1 & -3 & 91 & 8 & ND & ND & ND & -14 & $M$ & - & Morte suspeita \\
\hline 7 & 2 & 5,4 & -21 & 3440 & 1 & ND & ND & 1,9 & 8 & $\mathrm{M}$ & 51 & Morte suspeita \\
\hline 8 & 2 & 10 & 0 & 780 & -3 & ND & ND & ND & -8 & $M$ & 35 & Homicídio (FAB) \\
\hline 9 & 2 & 11 & -6 & 205 & 4 & 2,6 & 4 & 1,6 & 1 & $M$ & 19 & Morte suspeita \\
\hline 10 & 2 & 17 & -4 & 1397 & 7 & 1,5 & 0 & 1,5 & -5 & $M$ & 27 & Homicídio (FAF) \\
\hline 11 & 2 & 27 & 12 & 439 & 19 & 0,8 & 17 & 1,1 & -6 & $M$ & 20 & Morte suspeita \\
\hline 12 & 2 & 32 & -3 & 116 & 2 & 18 & -4 & ND & 4 & $\mathrm{M}$ & - & Homicídio (FAF) \\
\hline 13 & 2 & 55 & -15 & 727 & -4 & ND & -1 & 4,7 & -8 & $M$ & 45 & Morte suspeita \\
\hline 14 & 2 & 58 & -24 & 1262 & -1 & 60 & 12 & 2,8 & -5 & $M$ & 35 & Homicídio (FAF) \\
\hline 15 & 2 & 62 & 2 & 437 & -7 & 18 & 2 & ND & -6 & $\mathrm{M}$ & - & Homicídio (FAF) \\
\hline 17 & 2 & 84 & 11 & 201 & 12 & 4,3 & 2 & ND & -11 & $M$ & 28 & Acidente de trânsito \\
\hline 18 & 2 & 154 & 7 & 562 & 14 & ND & ND & 1,8 & -9 & $\mathrm{~F}$ & 57 & Morte suspeita \\
\hline 19 & 2 & 248 & 0 & 341 & 6 & 106 & -3 & 1,7 & 12 & $\mathrm{~F}$ & 36 & Homicídio (FAF) \\
\hline 20 & 2 & 341 & -11 & 2394 & 3 & ND & ND & 14 & 0 & $M$ & - & Atropelamento \\
\hline 21 & 2 & 488 & -8 & 910 & -2 & ND & 24 & 5,4 & -8 & $\mathrm{M}$ & - & Morte suspeita \\
\hline
\end{tabular}

Abreviações: $A E M E$ = anidroecgonina metil éster; $N D=$ não detectado (amostras cujas concentrações $<L Q$ ); $M=$ masculino; $F=$ feminino; $F A F=$ ferimento por arma de fogo; $F A B=$ ferimento por arma branca (objetos cortantes, perfurantes, perfurocortantes, contundentes, cortocontundentes, perfurocontundentes e perfurocortocontundentes) 


\subsubsection{Cromatogramas}

A Figura 3 representa os fragmentos monitorados e cromatogramas de uma amostra de sangue adicionada dos padrões na concentração de $1,0 \mathrm{ng} / \mathrm{mL}$ e submetida ao processo de extração conforme descrito no item 4.2.4. Os padrões internos foram adicionados na concentração de $100 \mathrm{ng} / \mathrm{mL}$.
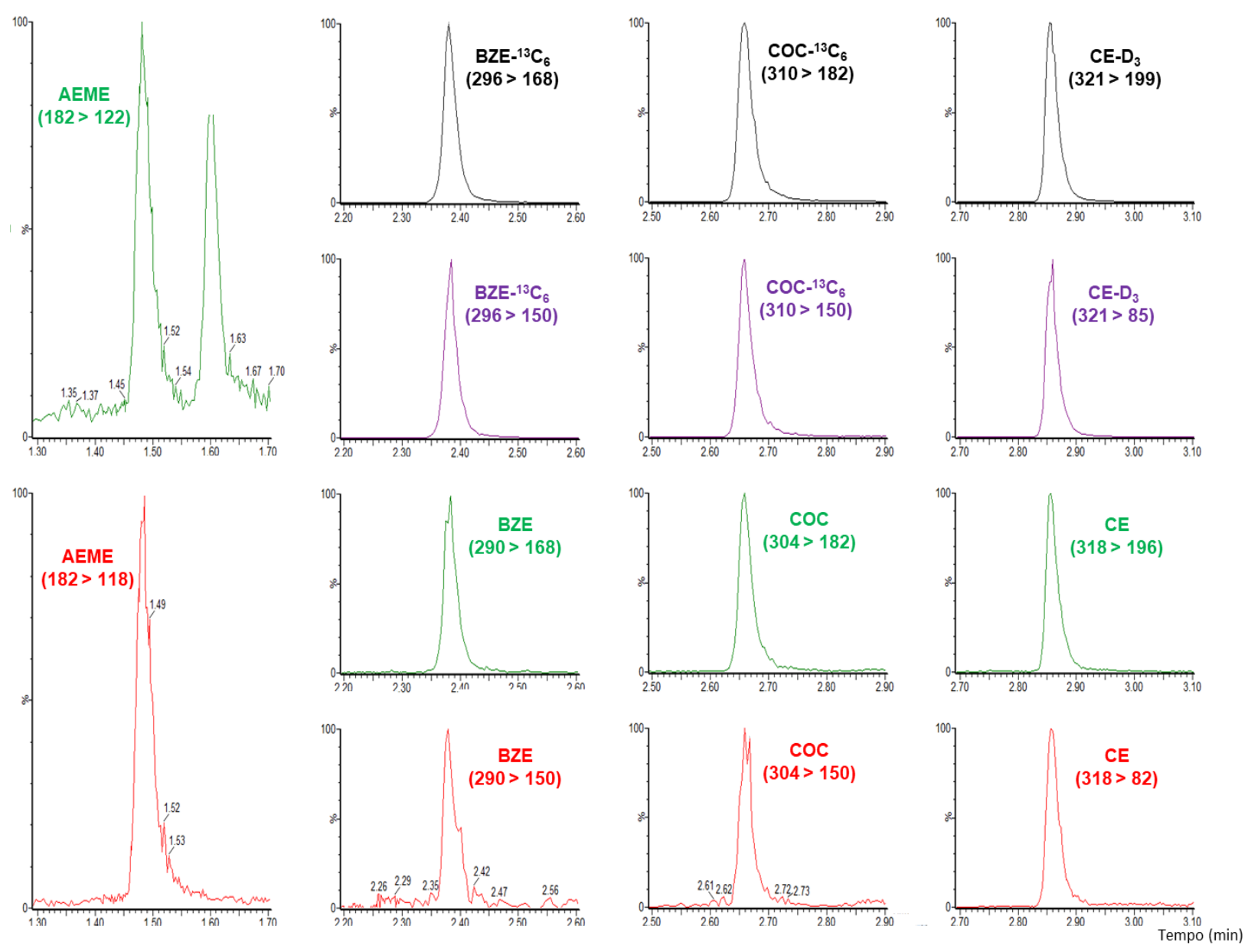

Figura 3 - Fragmentos monitorados e cromatogramas referentes a uma amostra adicionada dos padrões de drogas na concentração de $1,0 \mathrm{ng} / \mathrm{mL}$. Os respectivos padrões internos foram adicionados na concentração de $100 \mathrm{ng} / \mathrm{mL}$ 
A Tabela 13 apresenta o tempo de retenção e o tempo de retenção relativo para os quatro analitos pesquisados. Os dados basearam-se nos quatro ensaios realizados para a determinação da estabilidade dos analitos nas amostras de sangue postmortem. Cada ensaio incluiu seis calibradores, oito controles de qualidade, seis amostras "branco" e 10 a 12 amostras post-mortem (em duplicata), resultando no total de 170 injeções dentro de um período de aproximadamente 10 semanas.

Tabela 13 - Tempo de retenção e tempo de retenção relativo dos analitos em estudo

\begin{tabular}{lcccc}
\hline \multirow{2}{*}{ Analitos } & \multicolumn{4}{c}{ Tempos de Retenção (TR) } \\
\cline { 2 - 5 } & $\begin{array}{c}\text { TR dos } \\
\text { analitos (min) }\end{array}$ & $\begin{array}{c}\text { DPR TR } \\
(\%)\end{array}$ & $\begin{array}{c}\text { TRR dos } \\
\text { analitos (min) }\end{array}$ & $\begin{array}{c}\text { DPR TRR } \\
(\%)\end{array}$ \\
\hline Cocaína & 2.65 & 1,1 & 1,000 & 0,04 \\
Benzoilecgonina & 2.38 & 1,5 & 1,000 & 0,08 \\
Cocaetileno & 2.85 & 0,7 & 1,001 & 0,04 \\
AEME & 1.48 & 1,3 & 0,518 & 0,58 \\
\hline
\end{tabular}

Abreviações: TR = tempo de retenção; $\mathrm{DPR}=$ desvio padrão relativo; $\mathrm{AEME}=$ anidroecgonina metil éster; TRR = tempo de retenção relativo

A Figura 4 representa os cromatogramas e fragmentos monitorados de uma amostra de sangue postmortem submetida ao método desenvolvido e validado e que apresentou as seguintes concentrações para AEME, benzoilecgonina, cocaína e cocaetileno: $0,3 \mathrm{ng} / \mathrm{mL}, 11 \mathrm{ng} / \mathrm{mL}, 0,7 \mathrm{ng} / \mathrm{mL}$ e 1,1 $\mathrm{ng} / \mathrm{mL}$, respectivamente. Os padrões internos foram adicionados na concentração de $100 \mathrm{ng} / \mathrm{mL}$. 


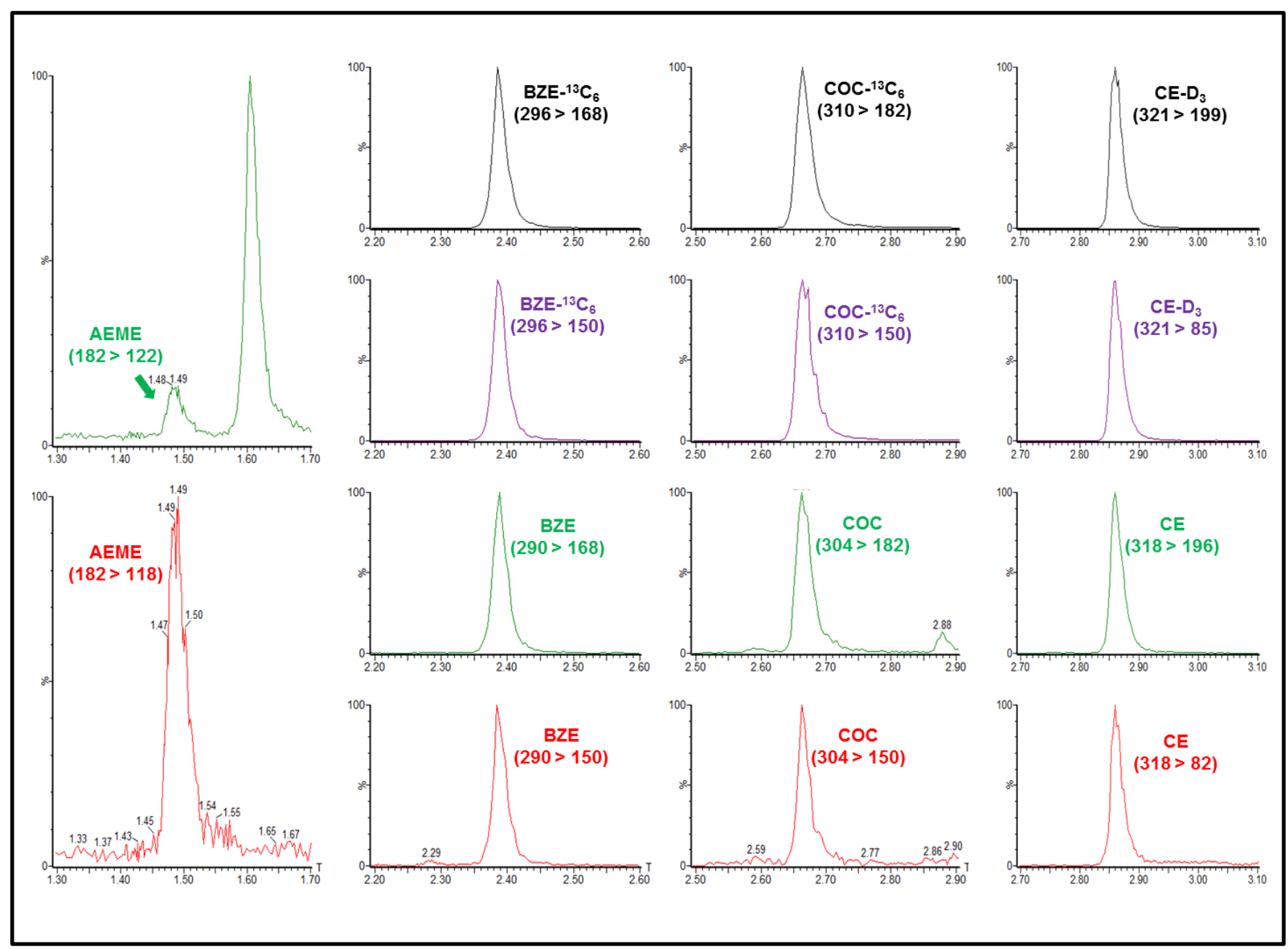

Figura 4 - Fragmentos monitorados e cromatogramas referentes a uma amostra de sangue postmortem submetida ao método desenvolvido. As concentrações obtidas respectivamente para AEME, benzoilecgonina, cocaína e cocaetileno foram: 0,3 ng/mL, $11 \mathrm{ng} / \mathrm{mL}, 0,7 \mathrm{ng} / \mathrm{mL}$ e $1,1 \mathrm{ng} / \mathrm{mL}$. Os respectivos padrões internos foram adicionados na concentração de $100 \mathrm{ng} / \mathrm{mL}$

A Figura 5 mostra uma amostra de sangue "branco", isenta dos analitos de interesse. Neste caso, não foram adicionados os padrões internos. 


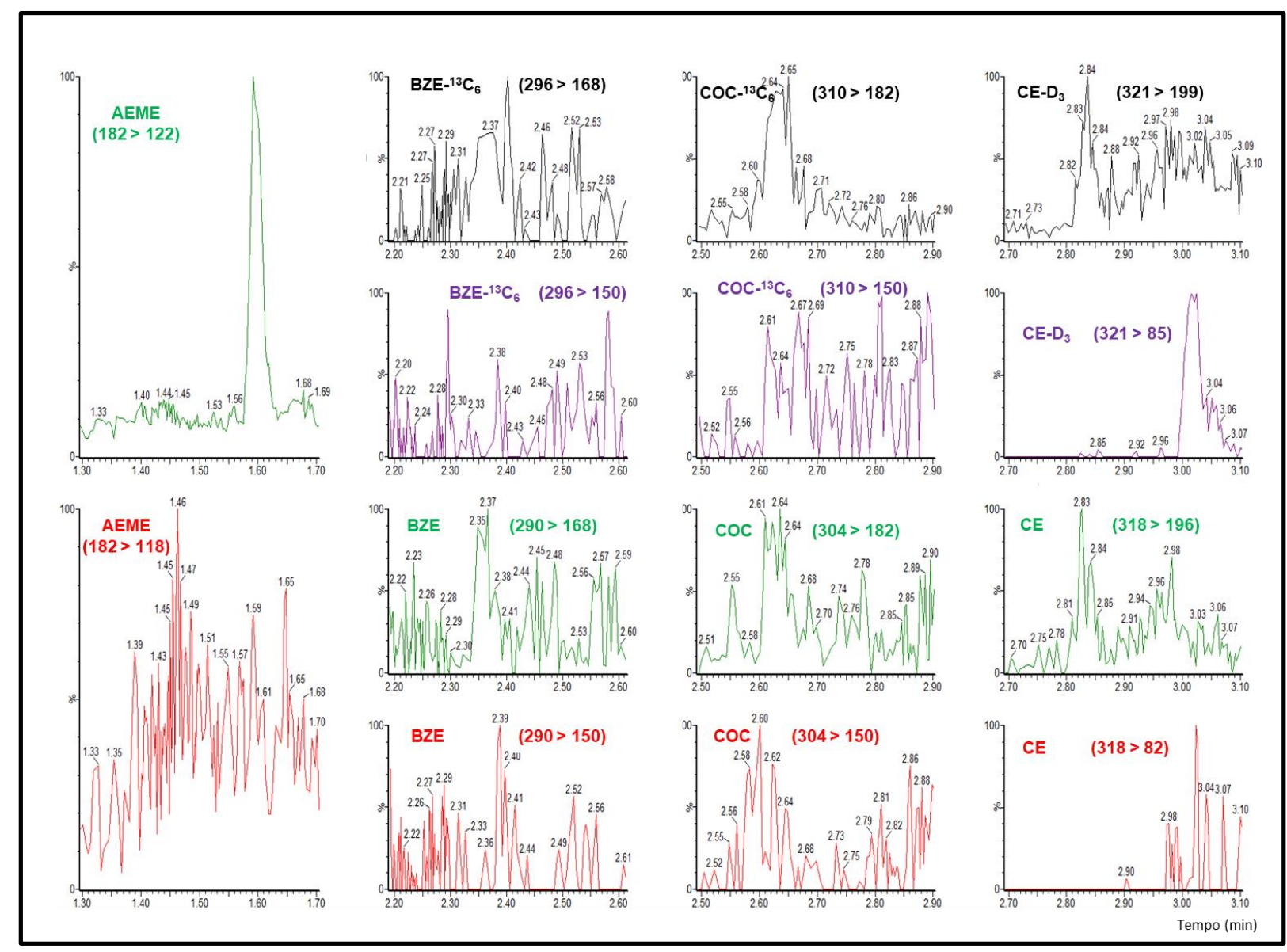

Figura 5 - Fragmentos monitorados e cromatogramas referentes a uma amostra de sangue "branco", isenta de quaisquer analitos pesquisados. Não foram adicionados padrões internos também 


\section{DISCUSSÃO}

Sabe-se que a ocorrência de lesões intencionais e não-intencionais é influenciada por uma série de fatores, os quais podem se relacionar ao próprio indivíduo (tomada de comportamentos de risco, uso de substâncias psicoativas, etc.) ou à comunidade no qual se insere (desigualdade social, insegurança, disponibilidade de estratégias de segurança, etc.) (Zinberg, 1984; Vitale \& van de Mheen, 2006; Rehm et al., 2017). Dentre os fatores individuais, o consumo de substâncias psicoativas exerce um importante papel nos casos com desfechos fatais (Wolfgang, 2002; Vitale \& van de Mheen, 2006; Darke, 2010).

Particularmente no Brasil, maconha e cocaína são as duas drogas ilícitas cujo consumo em algum momento da vida e também no ano de 2012, especificamente, foi o mais reportado entre adolescentes e adultos (Laranjeira, 2014). Diante deste cenário, optou-se por estudar, entre as vítimas fatais por causas externas, na cidade de São Paulo, a prevalência destas duas drogas ilícitas cujo consumo parece ser mais expressivo no país.

No Brasil, exames toxicológicos não são requeridos de todos os casos submetidos ao exame necroscópico, ficando tal decisão a cargo da autoridade policial competente e responsável por conduzir a investigação ou, então, como acontece no IML-SP, do médico legista no momento do exame, caso este julgue necessário. Uma vez que o intuito do presente trabalho foi verificar a prevalência do uso recente de cannabis e cocaína nos casos de morte por causas externas, todos os cadáveres (exceto os casos mencionados no item 4.1.1.1.2) que deram entrada nos dias programados para que houvesse coleta tiveram um exemplar 
de amostra de sangue colhido. O emprego da metodologia de amostragem probabilística assegurou que houvesse uma igual representação de todos os períodos de um dia (aqui denominado manhã, tarde, noite e madrugada) e de todos os dias da semana.

Sabe-se que para a quantificação de drogas em amostras de sangue postmortem o ideal é que sejam coletados espécimes de dois sítios distintos, sendo um periférico (veia femoral) e outro central (câmara cardíaca direita, preferencialmente), em virtude do fenômeno de redistribuição postmortem (Hepler \& Isenschmid, 2008). Para se obter o primeiro exemplar é recomendada punção direta da veia, sem dissecação dos tecidos adjacentes (Flanagan et al., 2005). Tal procedimento requer muita experiência, demanda grande investimento de tempo e fornece um pequeno volume de amostra. Além disso, no caso da pesquisa de fármacos/drogas e/ou praguicidas em amostras postmortem, nas normas do IML-SP não está especificado de qual sítio o material deverá ser coletado, sendo feita menção apenas para o caso da dosagem de álcool etílico, para o qual determina: "coletar $4 \mathrm{~mL}$ (quatro mililitros) de sangue da veia femoral ou da cavidade cardíaca em tubo contendo o conservante fluoreto de sódio e o anticoagulante EDTA (tubo de tampa cinza)" (São Paulo, 2012). Diante do exposto e considerando o elevado número de casos que são submetidos à necrópsia diariamente nos postos do IML-SP e, ainda, em respeito ao trabalho desenvolvido pelos médicos legistas e auxiliares de necrópsia, não foi solicitado a eles que modificassem a rotina diária por conta da pesquisa, com a inclusão da coleta de sangue da veia femoral. Assim sendo, os espécimes utilizados neste trabalho foram provenientes do mesmo sítio 
adotado pelo IML-SP, ou seja, da cavidade cardíaca e foram coletados em tubos tipo Vacutainer ${ }^{\circledR}$ contendo fluoreto de sódio (NaF) e EDTA, os quais permaneceram armazenados a -20 으 até 0 momento das análises toxicológicas, de acordo com procedimento sugerido em literatura para este tipo de análise (Baselt, 1983; Giorgi \& Meeker, 1995; Hepler \& Isenschmid, 2008; Kerrigan, 2011).

O intervalo de tempo decorrido entre a amostragem e as análises não foi superior a 12 semanas. Scheidweiler e colaboradores, em 2013, verificaram que analitos como $\Delta^{9}$-THC, THC-COOH e 11-OH-THC se mantiveram estáveis por até 26 semanas em amostras de sangue. Amostras de sangue de cavalo preservadas com $\mathrm{NaF}$ e armazenadas a $-18 \stackrel{\circ}{\circ} \mathrm{C}$ mantiveram $90 \%$ da concentração inicial de cocaína preservada ao final de 84 dias. Além disso, a concentração de benzoilecgonina detectada representou a quantidade total de cocaína perdida, indicando que houve uma efetiva inibição da hidrólise enzimática da cocaína (Rees et al., 2012).

As análises toxicológicas revelaram que quase um terço $(29,9 \%)$ das vítimas fatais por causas externas se encontravam sob influência, no momento do óbito, de pelo menos uma das substâncias ilícitas pesquisadas. Tal resultado representa uma prevalência acima daquela encontrada em outros estudos, a qual pode ser explicada pelo próprio padrão de consumo de drogas no país e pelos tipos de metodologias empregadas, tanto na seleção das amostras, como nas análises (Darke, 2010; Ahlner et al., 2014; Jones \& Holmgren, 2014). Foi constatado também que o consumo de cocaína foi maior $(21,9 \%)$ quando comparado ao consumo de cannabis (14\%). Os resultados de estudos prévios 
demonstraram a existência de uma correlação mais clara e evidente entre os óbitos por causas externas (acidentes e violência) e o uso de cocaína em comparação ao uso de cannabis, sendo os resultados para esta ainda controversos (Wintemute, 2015; McGinty et al., 2016; McGinty et al., 2017; Liakoni et al., 2018). Fonseca Pego e colaboradores, em 2018, encontraram uma positividade de 50,5\% para o uso recente de cocaína entre vítimas necropsiadas no Instituto Médico Legal de São Paulo. Os próprios autores atribuíram a elevada prevalência encontrada, em relação a outro estudo nacional, à seleção da amostra incluída, a qual procurou estudar mais detalhadamente o perfil dos agressores, e não das vítimas propriamente ditas (Campelo \& Caldas, 2010; Fonseca Pego et al., 2018).

No grupo estudado, os óbitos por causas externas vitimaram predominantemente indivíduos do sexo masculino, acima de 30 anos de idade (optou-se por esta categorização com base na pirâmide etária brasileira) e com grau de escolaridade primário (IBGE, 2018). Quanto à etnia, as vítimas foram classificadas em brancos e não-brancos, o que resultou em dois grupos com proporção bastante similar. De forma geral, os estudos mostram que os óbitos por causas externas vitimam predominantemente indivíduos do sexo masculino, com idade entre 20 e 39 anos e de cor parda. Pode-se atribuir esse perfil à maior exposição de homens jovens a situações de maior risco, como consumo de álcool, drogas, tráfico, comportamentos agressivos, violência urbana, atividades laborais e à direção perigosa de veículos automotores. A etnia não deve ser entendida como um fator de risco, mas sim deve-se considerar que uma provável relação exista entre inserção social e etnia e inserção social e óbito (Batista et 
al., 2004; Brasil, 2015). Na amostra estudada os homens jovens, não-brancos e com menor grau de escolaridade foram de fato os que apresentaram maior prevalência de consumo recente de cannabis e/ou cocaína.

Para a causa do óbito, o grupo denominado morte suspeita, por englobar uma variedade de causas muito grande, foi o que resultou no maior número de casos dentro da amostra total. Apesar disso, o homicídio e o acidente de trânsito como causas do óbito apresentaram proporções significativamente maiores para o consumo de pelo menos uma das substâncias pesquisadas e cocaína, no caso do homicídio, e cannabis, no caso do acidente de trânsito. Como já foi apontado, elevadas taxas de homicídio podem estar relacionadas aos efeitos diretos da droga (como, por exemplo, a desinibição causada pela ingestão de álcool, ou aos episódios de paranoia provocados pelo consumo de psicoestimulantes, como é o caso da cocaína) que podem levar à casos de violência e também às consequências secundárias, uma vez que atos de violência podem ser cometidos com a finalidade de sustentar tal prática ou para a proteção do tráfico de drogas (Goldstein, 1985; Room \& Rossow, 2001; Ousey \& Lee, 2002; Mann et al., 2006). Lee e colaboradores (2016) verificaram que o uso de estimulantes (anfetaminas e cocaína) esteve mais associado à ocorrência de mortes acidentais e homicídios, entre os anos de 2001 e 2013, nos Estados Unidos. Vítimas cuja análise toxicológica foi positiva para cocaína/benzoilecgonina tiveram maior probabilidade de serem mortas com o uso de arma de fogo e em locais públicos, cenário que no presente estudo também foi o local onde 0 consumo de substâncias ilícitas foi maior (Tardiff et al., 1995). Entrevistas realizadas com usuários de cocaína em seis diferentes clínicas de reabilitação 
na região Centro-Oeste do Brasil revelaram que o uso de cocaína esteve mais associado ao cometimento de homicídios, e o uso de crack, à prática de roubos (Guimarães et al., 2017).

Cannabis é a substância ilícita mais consumida mundialmente e também a mais prevalente entre motoristas que dirigem sob efeito de alguma droga (Hartman \& Huestis, 2013; UNODC, 2018). Apesar das diferenças metodológicas verificadas entre os diferentes trabalhos, evidências sugerem que o uso recente e/ou concentrações sanguíneas de THC entre 2-5 ng/mL estão associadas a um prejuízo importante na direção, especialmente em consumidores ocasionais, muito embora muitos motoristas ainda apresentam baixa percepção de risco quando do consumo de cannabis e condução de veículos (Hartman \& Huestis, 2013; Malhotra et al., 2017). Volkow e colaboradores, em 2014, reportaram que o uso de cannabis entre motoristas vítimas fatais de acidentes de trânsito foi maior quando comparado ao consumo de outras substâncias ilícitas, mesmo resultado observado em um estudo retrospectivo conduzido na Suécia entre os anos de 2008 a 2011 (Ahlner et al., 2014) e em outro estudo realizado na Nova Zelândia, o qual detectou uma positividade para cannabis quase similar àquela encontrada para o consumo de álcool (Poulsen et al., 2012). No Brasil, estudo realizado na cidade de Vitória/ES, analisou amostras de sangue de 391 vítimas fatais de acidentes de trânsito (incluindo-se motoristas, passageiros e pedestres) e encontrou, entre as substâncias ilícitas, uma positividade de 12\% para cocaína (sendo que 27,7\% destes haviam feito uso de crack), 4,3\% para cannabis e 4,1\% para anfetaminas (Pelição et al., 2016). 
De acordo com estudos prévios, usuários de drogas ilícitas apresentam chance maior de já terem sido presos quando comparados a não usuários, o que confirmam as altas taxas de problemas envolvendo questões legais nesta população (Vaughn et al., 2011; Bertoni et al., 2014; Halpern et al., 2017). Foram obtidos dados referentes ao registro de antecedentes criminais das vítimas (os principais observados foram tentativa de homicídio, homicídio, furto, roubo, lesão corporal dolosa), os quais revelaram maior prevalência de consumo de drogas ilícitas entre aqueles que possuíam algum registro, embora este grupo dentro da população geral amostrada tenha representado apenas $15,9 \%$ do total investigado.

Apesar de não terem sido observadas relações estatisticamente significativas entre o dia e o período das ocorrências que levaram ao desfecho fatal e o consumo de cocaína e/ou cannabis, um maior número de casos ocorreu durante a semana (provavelmente em virtude da própria distribuição naturalmente desigual entre dias da semana e finais de semana) e no período noturno (entre 18:00 e 23:59), embora o uso de pelo menos uma das substâncias pesquisadas tenha sido maior aos finais de semana e pelas vítimas que vieram a óbito durante a madrugada (entre 00:00 e 5:59), característica que está de acordo com estudos epidemiológicos sobre o consumo de drogas ilícitas (Institóris et al., 2013; Domingo-Salvany et al., 2017; Zeferino et al., 2017).

Deve-se ressaltar que todos os casos incluídos neste estudo foram considerados como sendo vítimas do evento lesivo por falta de informações adicionais, porém não se deve ignorar o fato de que aqueles que vieram a ser vítimas também podem ter atuado como agressores em determinadas situações. 
Além disso, não foram obtidas amostras dos agressores que não vieram a óbito. Não foi possível, portanto, fazer a distinção do uso de substâncias psicoativas entre vítimas e agressores, como alguns autores já propuseram (Darke, 2010). Com base nas informações disponíveis também seria temerário associar o consumo dessas duas drogas ilícitas (cannabis e cocaína) como causa única e exclusiva do evento fatal. Porém, acredita-se que principalmente em países de baixa e média rendas, como é o caso do Brasil, estudos tal como este fora desenvolvido e conduzido (ou seja, através da análise toxicológica em amostra de sangue, a qual reflete o consumo recente de determinada substância e fazendo-se a seleção de um número maior de casos a serem investigados, e não somente os rotineiramente incluídos) ainda são escassos e deveriam ser implementados em todo país para que um sistema nacional de vigilância em saúde e pesquisa de drogas fosse instituído, a exemplo do que já ocorre em países desenvolvidos (Romano et al., 2017; UNODC, 2017). As informações geradas servem como base para que estratégias de prevenção e fiscalização de combate às lesões relacionadas ao uso de drogas sejam delineadas de acordo com o tipo de substância, do cenário da ocorrência e do perfil da vítima.

O crack, droga estimulante produzida a partir da pasta-base de coca, surgiu no Brasil em meados de 1988, sendo as primeiras aparições reportadas no estado de São Paulo. Ao longo dos anos 1990, o consumo rapidamente se expandiu para todo o território nacional devido, principalmente, ao baixo custo da droga, sua crescente disponibilidade e seu efeito potente (Raup \& Adorno, 2011). Como já relatado por alguns autores, o perfil dos usuários de crack parece diferir daqueles que fazem uso de outras drogas ilícitas ou até mesmo dos que 
também consomem cocaína, porém através de outras vias de administração (aspirada e/ou injetada, por exemplo) (Duailibi et al., 2008; Chaves et al., 2011; Fischer et al., 2016).

Devido ao elevado poder de dependência e aos efeitos devastadores da droga, é importante que se tenham metodologias analíticas que permitam diferenciar entre o consumo recente de cloridrato de cocaína ou de crack. 0 sangue é uma das únicas matrizes biológicas que reflete a concentração de uma determinada droga no cérebro sendo considerada, portanto, ideal para o estudo dos prejuízos psicofarmacológicos atribuídos às substâncias psicoativas e também o mais recomendado para a análise da influência de drogas em vítimas fatais (Gjerde et al., 2011).

Embora o processo de aquecimento durante o consumo de crack rapidamente volatilize a droga, ele também produz grandes quantidades do produto de pirólise denominado anidroecgonina metil éster (AEME) (Fandino et al., 2002). Assim, a detecção em amostras biológicas de cocaína e do principal produto de biotransformação inativo benzoilecgonina indica que houve 0 consumo de cocaína, ao passo que a determinação de AEME é um marcador específico para o consumo de crack e a detecção do produto de biotransformação cocaetileno revela o uso concomitante de cocaína e álcool (etanol) (Hearn et al., 1991; Cone, 1995; Kolbrich et al., 2006).

Existem na literatura métodos analíticos descritos para a determinação simultânea de cocaína, benzoilecgonina e AEME, empregando-se as técnicas de GC-MS (Cone et al., 1994; Jenkins \& Goldberger, 1997; Kintz et al., 1997; Cardona et al., 2006; Valente et al., 2010; Fonseca Pego et al., 2017) e LC- 
MS/MS (Fandino et al., 2002b; Dams et al., 2003; Langman et al., 2009; Imbert et al., 2014; D’Avila et al., 2015; D'Avila et al., 2016; Dulaurent et al., 2016; Fiorentin et al., 2017a; Fiorentin et al., 2017b). Estes métodos geralmente utilizam técnicas de preparação de amostras baseadas na extração em fase sólida (SPE, do inglês "Solid Phase Extraction") ou na precipitação de proteínas (PPT, do inglês "Protein Precipitation Technique"), as quais envolvem várias etapas e podem ser encarecidas pelo custo dos cartuchos, como é o caso da SPE, ou não são capazes de remover completamente os fosfolipídios e componentes endógenos da matriz, como ocorre principalmente com a PPT (Kraemer \& Paul, 2007; Barroso et al., 2009; Ismaiel et al., 2010; Jemal et al., 2010; Kole et al., 2011; Barroso \& Gallardo, 2015). A extração líquido-líquido e a extração sólido-líquido (SLE, do inglês "Solid Liquid Extraction") são outros exemplos de técnicas utilizadas com sucesso na análise de drogas em amostras biológicas (Ismaiel et al., 2010; Kole et al., 2011; Novakova, 2013; Bylda et al., 2014), porém a baixa taxa de recuperação de compostos hidrofílicos/ionizados deve ser uma questão a ser considerada, fato que foi observado quando as técnicas de SLE e PALME ("Parallel Artificial Liquid Membrane Extraction”) foram testadas. A cocaína é uma base fraca (pKa $8,7 \pm 0,6$ ) e pode ser facilmente extraída por LLE, porém a benzoilecgonina é um analito anfotérico (pKa1 13,2 \pm 0,6 e pKa2 10,1 \pm 0,6) e, por esta razão, encontra-se ionizada em toda faixa de pH, o que pode dificultar a extração (Hezinova et al., 2012). Oiestad et al. (2007), Oiestad et al. (2011), Zancanaro et al. (2012) e Vanstechelman et al. (2012) desenvolveram métodos por LC-MS/MS de detecção de diferentes drogas em amostras de sangue ou fluído oral utilizando-se LLE e a mistura de acetato de etila/heptano ou acetato de etila/hexano como solventes orgânicos, porém todos 
eles obtiveram baixas taxas de recuperação para benzoilecgonina $(<5 \%)$. Outros autores, por outro lado, atingiram resultados satisfatórios de recuperação, também com LLE, para cocaína e benzoilecgonina, utilizando-se solventes clorados (Kintz et al., 1997; Gergov et al., 2003; Strano-Rossi et al., 2008; Bystrowska et al., 2012; Thibert et al., 2014). Apesar disso, devido aos riscos ambientais e aos possíveis efeitos carcinogênicos em humanos, optou-se por utilizar no presente estudo apenas solventes não-clorados (Guha et al., 2012; Benbrahim-Tallaa et al., 2014). Por esta razão e pelos resultados apresentados no item 5.2.1 e na Tabela 6, o método de extração escolhido foi a LLE com o emprego da solução MTBE/2-propanol (70:30, v:v) como solventes orgânicos e ajuste de pH com solução tampão de carbonato de amônio $0.2 \mathrm{M}$ (pH 9.3), o qual forneceu valores de recuperação de aproximadamente $80 \%$ para cocaína, cocaetileno e AEME e de aproximadamente $40 \%$ para benzoilecgonina, valor que se mostrou superior ao obtido em outros métodos utilizando-se LLE e apenas solventes não-clorados.

Estudos prévios demonstraram que padrões internos marcados com isótopos apresentam maior similaridade com seus respectivos analitos, quando comparados aos padrões internos deuterados, e, portanto, fornecem uma correção das eventuais variações no preparo de amostras e efeitos de supressão/acréscimo iônico mais precisa (Wieling, 2002; Wang et al., 2007; Berg \& Strand, 2011; Berg et al., 2014). Neste estudo, cocaína- ${ }^{13} \mathrm{C}_{6}$, benzoilecgonina${ }^{13} \mathrm{C}_{6}$ e cocaetileno- $\mathrm{D}_{3}$ foram utilizados como padrões internos, sendo o último também empregado como padrão interno para o analito $A E M E$, já que este não possuía o seu correspondente comercialmente disponível. Apesar disso, verificou-se que não houve prejuízos às análises, uma vez que o composto 
apresentou boa separação cromatográfica dos demais analitos pesquisados (Figura 2).

Os resultados obtidos com a validação do método estão de acordo com o preconizado por guias internacionais de validação em Toxicologia e demonstraram que o método apresenta a precisão, a exatidão, a robustez e a sensibilidade requeridas (UNODC, 2009; SWGTOX, 2013). A aplicação do método em 21 amostras de sangue postmortem, positivas na etapa de triagem por ELISA para a classe da cocaína, foi realizada em duplicata e a análise foi repetida após um intervalo de tempo de 63 dias, período no qual as alíquotas permaneceram armazenadas a $-20^{\circ} \mathrm{C}$ em tubos tipo Vacutainer ${ }^{\circledR} \operatorname{com~NaF~e~}$ EDTA. As concentrações calculadas na reanálise variaram cerca de $\pm 20 \%$ para benzoilecgonina, cocaetileno e AEME e aproximadamente $\pm 30 \%$ para cocaína. De maneira geral, verificou-se um decréscimo nas concentrações de cocaína decorridos os 63 dias, ao passo que as concentrações de benzoilecgonina foram ligeiramente maiores, o que provavelmente indica uma conversão da cocaína em benzoilecgonina.

O tempo de meia vida para a eliminação da cocaína é bastante curto $(0,5-$ $1,5 \mathrm{~h})$ se comparado ao do seu principal produto de biotransformação benzoilecgonina (6-10h); apesar disso, somente duas amostras (casos número 1 e número 2 - Tabela 12) tiveram valor abaixo do limite de quantificação para cocaína, o que pode sugerir que houve um consumo relativamente recente da droga nos 19 casos restantes, embora os dados não permitam com que se façam afirmações referentes à quantidade de cocaína administrada ou ao momento em que se deu o último consumo (Cone, 1995; Moolchan et al., 2000). 
Ao contrário do que ocorre com indivíduos vivos, nos quais a mensuração de uma droga no sangue pode fornecer informações sobre a quantidade administrada (após o consumo de uma dose única, por exemplo, e levando-se em conta características farmacocinéticas) o mesmo não pode ser observado nos casos postmortem (Pelissier-Alicot et al., 2003). A principal razão para tal é que as concentrações obtidas dessas amostras não refletem necessariamente a concentração do sangue no momento da morte, devido a fenômenos e mecanismos diversos que ocorrem no intervalo de tempo decorrido entre o óbito e a amostragem, modificando as concentrações e, assim, dificultando a interpretação dos resultados (Pelissier-Alicot et al., 2003). Certas propriedades físico-químicas inerentes a algumas drogas e que influenciam nesta disparidade são: volume de distribuição $(V d)$, lipofilicidade, ligação a proteínas e pKa, sendo que compostos com elevado $\mathrm{Vd}$ e características alcalinas parecem ser mais suscetíveis às variações (Yarema \& Becker, 2005). A interpretação das concentrações de drogas obtidas de amostras de sangue e tecidos postmortem pode ser dificultada também pela instabilidade de algumas substâncias, tolerância, variação interindividual na resposta farmacológica, interações entre drogas, presença de certas patologias e circunstâncias nas quais a morte ocorreu (Morgan \& McLean, 1995; Wong et al., 2000; Karch, 2001; Drummer, 2004; Jones, 2008; Drummer \& Karch, 2011).

Alguns órgãos e tecidos, tais como o trato gastrointestinal, fígado, pulmões, miocárdio e tecido adiposo funcionam como verdadeiros "reservatórios" de drogas ante mortem; após a morte, mudanças no pH provocam autólise das células e devido a diferenças de gradiente, essas substâncias são redistribuídas aos tecidos adjacentes por difusão através dos 
vasos sanguíneos e pela própria parede em direção a outros órgãos circundantes (Pelissier-Alicot et al., 2003). Em virtude da proximidade desses "reservatórios" com vasos de grande calibre e o coração, o sangue coletado deste sítio central tende a apresentar concentrações mais elevadas, que podem chegar a uma diferença até dez vezes maior quando comparado a uma amostra de sangue periférico, como é o caso daquele coletado da veia femoral, por exemplo, e já mencionado anteriormente (Jones, 2011). Além disso, o processo de putrefação, por ação de bactérias, pode levar à síntese ou à decomposição de xenobióticos; e, mesmo após a morte, muitas enzimas importantes na metabolização de fármacos continuam atuando por algum tempo, resultando na degradação destes e assim dificultando a correlação com as concentrações ante mortem (Gerostamoulos et al., 2012). Por estas razões, não foram feitas quaisquer inferências acerca das concentrações obtidas e a causa provável do óbito.

Por fim, a determinação do produto de biotransformação cocaetileno em dez das 21 amostras testadas indica que, além do consumo de cocaína, as vítimas fizeram uso concomitante de álcool, uma vez que tal analito funciona como marcador para o uso associado dessas substâncias, o qual já se demonstrou ser bastante comum entre vítimas de causas externas, podendo agravar a precipitação de episódios de violência (Macdonald et al., 2014; EMCDDA, 2015; Herbst et al., 2011; Houwing et al., 2011). Anidroecgonina metil éster (AEME) é um produto obtido exclusivamente da pirólise da cocaína e utilizado como marcador nas análises toxicológicas forenses para a determinação do consumo de crack (Martin et al., 1989; Jacob et al., 1990; Kintz et al., 1995; Toennes et al., 1999; Toennes et al., 2003). Dez amostras foram 
positivas (concentração determinada > LQ) para AEME; apesar do número de amostras testadas ter sido relativamente pequeno, os resultados indicam que o consumo de crack entre vítimas de causas externas é comum e, portanto, precisa de fato ser estudado.

O uso de álcool e outras drogas pode ser associado a episódios de violência com vítimas ou não. Assim, acredita-se que estudos que tenham por objetivo estimar a prevalência desse uso em uma determinada localidade são de grande importância, pois fornecem dados que poderão ser utilizados para a elaboração de estratégias que visem a redução desses desfechos desfavoráveis. 


\section{CONCLUSÕES}

- Dentre as vítimas incluídas ( $n=365)$, quase um terço $(29,9 \%)$ havia feito uso recente de pelo menos uma das substâncias pesquisadas. Cocaína e cannabis, por meio de seus produtos de biotransformação, foram detectadas em $21,9 \%$ e $14 \%$ das amostras de sangue postmortem analisadas, respectivamente.

- Uma nova metodologia analítica para identificação e quantificação de cocaína, benzoilecgonina, cocaetileno e anidroecgonina metil éster (AEME) em sangue total foi desenvolvida e validada. A metodologia envolveu a extração dos analitos pela técnica de extração líquido-líquido com o uso de solventes não clorados e análise por UHPLC-MS/MS. A aplicação em amostras de sangue postmortem revelou o consumo concomitante de cocaína e álcool por dez vítimas e também indicou que houve o consumo de crack por dez vítimas. 


\section{ANEXOS}

\section{ANEXO A}

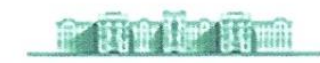 \\ MEDICINA \\ TSP \\ COMITÊ DE ÉTICA EM PESQUISA}

Ao

Prof. Dr. Heráclito Barbosa de Carvalho

Departamento de Medicina Preventiva

O Comitê de Ética em Pesquisa da Faculdade de Medicina da Universidade de São Paulo, em o8.12.2014 tomou conhecimento que o Protocolo de Pesquisa intitulado: "Determinação de lesões relacionadas ao uso de drogas: unindo achados toxicológicos e dados criminais", contempla o sub-projeto intitulado: "Vítimas de morte violenta e a relação com o uso de drogas no município de São Paulo, que será Tese de Doutorado da(o) aluna(o) Juliana Takitane, tendo como orientador(a) Prof. Dra. Vilma Leyton.

CEP-FMUSP, o8 de Dezembro de 2014.

$$
\text { Plhemm. }
$$

Prof. Dr.Roger Chammas Coordenador

Comitê de Ética em Pesquisa 
ANEXO B

\section{Aitilidifili: MEDICINA \\ TSP \\ COMITÊ DE ÉTICA EM PESQUISA}

\section{APROVAÇÃo}

o Vice-Coordenador do Comitê de Ética em Pesquisa da Faculdade de Medicina da Universidade de São Paulo, em 22/04/2014, após atendimento a diligência encaminhada APROVOU ad-referendum o Protocolo de Pesquisa $\mathrm{n}^{\circ}$ 096/14 intitulado: "DETERMINAÇÃo DE LESÕES RELACIONADAS AO USO DE DROGAS: UNINDO ACHADOS TOXICOLÓGICOS E DADOS CRIMINAIS" apresentado pelo Departamento de MEDICINA PREVENTIVA

Cabe ao pesquisador elaborar e apresentar ao CEPFMUSP, os relatórios parciais e final sobre a pesquisa (Resolução do Conselho Nacional de Saúde $n^{\circ}$ 466/12).

Pesquisador (a) Responsável: Prof. Dr. Heráclito Barbosa de Carvalho Pesquisador (a) Executante: Gabriel Andreuccetti

CEP-FMUSP, 22 de Abril de 2014.

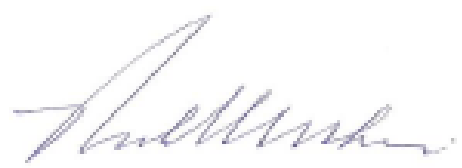

Prof. Dr. Paulo Eurípedes Marchiori Vice-Coordenador Comitê de Ética em Pesquisa 


\section{ANEXO C}

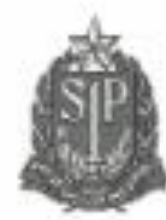

\section{SECRETARIA DA SEGURANCCA PÚBLICA SUPERINTENDENCIA DA POLICIA TÉCNIOO-CIENTIFCA INSTITUTO MEDICO LEGAL}

\section{OF. Comissdo Cientifice - IML Ne 005/2014}

Referència: Oficio $5 / a^{\circ}$ datada de 28 de Janeiro de 2014.

Interessado: Prof. Dr. Ivan D. Miziara - Médico Legista - Assessor Técnico - IML.

Assunto: Projeto de estudo "Determinaçĩo de lesões relacionadas ao uso de dropas: unidos achados toxicológjcos e dados criminais".

Så Paulo, 18 de Marco de 2014.

Prezado Doutor,

A Comissăo Clentifica do IML/SP analisou e aprovou o projeto de pesquisa "Determinaçẫo de lesōes relacionadas ao uso de drogas: unidos achados toxicológicos e dados criminais"

Aguardamos o parecer da Consultoria Juridica para o inicio da sua execuç̄a.

Atenciosamente.

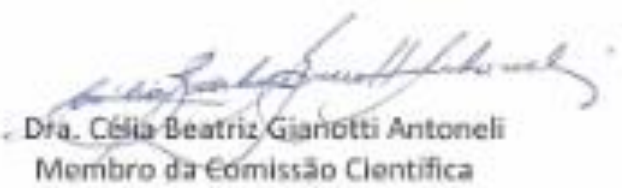

Senhor

Dr. Gabriel Andreuccetti

Departamento de Medicina Legal, Ética Médica e Medicina Social do Trabalho 


\section{REFERÊNCIAS BIBLIOGRÁFICAS}

Abdalla RR, Madruga CS, Ribeiro M, Pinsky I, Caetano R, Laranjeira R. Prevalence of Cocaine Use in Brazil: Data from the II Brazilian National Alcohol and Drugs Survey (BNADS). Addictive Behaviors. 2014; 39 (2014):297-301.

Abdalla RR, Massaro L, Miguel AQC, Laranjeira R, Caetano R, Madruga CS. Association between drug use and urban violence: Data from the II Brazilian National Alcohol and Drugs Survey (BNADS). Addictive Behaviors Reports. 2018;7:8-13.

Ahlner J, Holmgren A, Jones AW. Prevalence of alcohol and other drugs and the concentrations in blood of drivers killed in road traffic crashes in Sweden. Scandinavian Journal of Public Health. 2014;42:177-83.

Alves VS, Lima IMSO. Atenção à saúde de usuários de álcool e outras drogas no Brasil: convergência entre a saúde pública e os direitos humanos. Revista De Direito Sanitário. 2013;13(3):9-32.

Anderson PD, Bokor G. Forensic aspects of drug-induced violence. Journal of Pharmacy Practice. 2012;25(1):41-9.

Andrews P. Cocaethylene toxicity. J Addict Dis. 1997;16:75-84.

Anthony JC. The epidemiology of cannabis dependence. In: Roffman RA, Stephens RS. Cannabis dependence: its nature, consequences and treatment. Cambridge: Cambridge University Press; 2006. 58-105.

Arendt M, Munk-Jørgensen $\mathrm{P}$, Sher $\mathrm{L}$, Jensen SO. Mortality among individuals with cannabis, cocaine, amphetamine, MDMA, and opioid use disorders: a nationwide follow-up study of Danish substance users in treatment. Drug Alcohol Depend. 2011;114:134-9.

Azorlosa JL, Greenwald MK, Stitzer ML. Marijuana smoking: effects of varying puff volume and breathhold duration. J Pharmacol Exp Ther. 1995;272(2):5609.

Azorlosa JL, Heishman SJ, Stitzer ML, Mahaffey JM. Marijuana smoking: Effect of varying delta-9-tetrahydrocannabinol content and number of puffs. $J$ Pharmacol Exp Ther. 1992;261(1):114-22.

Bansal S. Controversial São Paulo project offers jobs to crack addicts in Cracolândia. Guardian, London, 29 October 2014. [Internet]. [citado em 20 fev 2019]. Disponível em: http://www.theguardian.com/globaldevelopment/2014/oct/29/sao-paulo-brazil-crack-addicts-drugs. 
Barcellos C, Zaluar A. Homicídios e disputas territoriais nas favelas do Rio de Janeiro. Rev Saúde Pública. 2014;48(1):94-102.

Barroso M, Gallardo E, Queiroz JA. Bioanalytical methods for the determination of cocaine and metabolites in human biological samples. Bioanalysis. 2009;1(5):977-1000.

Barroso M, Gallardo E. Assessing cocaine abuse using LC-MS/MS measurements in biological specimens. Bioanalysis. 2015;7(12):1497-1525.

Baselt RC. Stability of cocaine in biological fluids. $J$ Chromatogr. 1983;268(3):502-5.

Bastos FI, Bertoni N. Pesquisa nacional sobre o uso de crack: quem são os usuários de crack e/ou similares do Brasil? Quantos são nas capitais brasileiras? Rio de Janeiro: Instituto de Comunicação e Informação Científica e Tecnológica em Saúde, Fundação Oswaldo Cruz. 2014.

Batista LE, Escuder MML, Pereira JCR. A cor da morte: causas de óbito segundo características de raça no Estado de São Paulo, 1999 a 2001. Rev Saúde Pública. 2004;38(5):630-6.

Beato Filho CC, Marinho FC. Padrões regionais de homicídios no Brasil. In: Cruz MUG, Batitucci ECO, eds. Homicídios no Brasil. Rio de Janeiro: FGV. 2007: 177190.

Benbrahim-Tallaa L, Lauby-Secretan B, Loomis D, Guyton KZ, Grosse Y, El Ghissassi F, Bouvard V, Guha N, Mattock H, Straif K. International Agency for Research on Cancer Monograph Working Group, Carcinogenicity of perfluorooctanoic acid, tetrafluoroethylene, dichloromethane, 1,2-dichloropropane, and 1,3-propane sultone. Lancet Oncol. 2014;15(9):924-5.

Berg T, Strand DH. (1)(3)C labelled internal standards-a solution to minimize ion suppression effects in liquid chromatography-tandem mass spectrometry analyses of drugs in biological samples? J Chromatogr A. 2011;1218(52):936674.

Berg T, Karlsen M, Oiestad AM, Johansen JE, Liu H, Strand DH. Evaluation of (1)(3)C- and (2) H-labeled internal standards for the determination of amphetamines in biological samples, by reversed-phase ultra-high performance liquid chromatography-tandem mass spectrometry. $J$ Chromatogr $A$. 2014;1344:83-90.

Bertoni N, Burnett C, Cruz MS, Andrade T, Bastos FI, Leal E, $\quad$ Fischer, B. Exploring sex differences in drug use, health and service use characteristics among young urban crack users in Brazil. International Journal for Equity in Health. 2014;13(1):70. 
Boghdadi MS, Henning RJ. Cocaine: pathophysiology and clinical toxicology. Heart Lung. 1997;26(6):466-83.

Bosron WF, Dean RA, Brzezinski MR, Pindel EV. Human liver cocaine carboxylesterases. NIDA Res. Monogr. 1997;173:27-34.

Brasil. Ministério da Saúde, 2018. Secretaria de Vigilância em Saúde/MS Saúde Brasil 2017: uma análise da situação de saúde e os desafios para o alcance dos Objetivos de Desenvolvimento Sustentável. Brasília, DF: MS. 2018. 426 p. Disponível http://bvsms.saude.gov.br/bvs/publicacoes/saude_brasil_2017.pdf

em:

Brasil. Ministério da Saúde. Manual de Instruções para o preenchimento da Declaração de Óbito. Brasília (DF): Ministério da Saúde; 2011.

Brasil. Ministério da Saúde. Saúde Brasil 2014: uma análise da situação de saúde e das causas externas. Brasília (DF): Ministério da Saúde; 2015, p.462.

Brasil. Ministério da Saúde. Secretaria de Vigilância em Saúde. Departamento de Vigilância de Doenças e Agravos não Transmissíveis e Promoção da Saúde. Saúde Brasil 2017: uma análise da situação de saúde e os desafios para o alcance dos objetivos de desenvolvimento sustentável [recurso eletrônico] / Ministério da Saúde, Secretaria de Vigilância em Saúde, Departamento de Vigilância de Doenças e Agravos não Transmissíveis e Promoção da Saúde. Brasília: Ministério da Saúde. 2018b.426p.

Brasil. Ministério da Saúde. Sistema de Vigilância em Saúde. CoordenaçãoGeral de Informações e Análises Epidemiológicas. Sistema de Informações sobre Mortalidade - SIM [Internet]. [Acessado em Dez 2018a]. Disponível em: http://tabnet.datasus.gov.br/cgi/tabcgi.exe?sim/cnv/ext10uf.def

Bylda C, Thiele R, Kobold U, Volmer DA. Recent advances in sample preparation techniques to overcome difficulties encountered during quantitative analysis of small molecules from biofluids using LC-MS/MS. Analyst. 2014;139(10):226576.

Bystrowska B, Adamczyk P, Moniczewski A, Zaniewska M, Fuxe K, Filip M. LC/MS/MS evaluation of cocaine and its metabolites in different brain areas, peripheral organs and plasma in cocaine self-administering rats. Pharmacol. Rep. 2012;64(6):1337-49.

Camara P. O risco de acidentes entre motoristas profissionais em função de estresse e fadiga. Revista ABRAMET. 1999;30:31-5.

Campelo ELC, Caldas ED. Postmortem data related to drug and toxic substance use in the federal district, Brazil, from 2006 to 2008. Forensic Sci Int. 2010;200:136-40. 
Cano I, Ribeiro E. Homicídios no Rio de Janeiro e no Brasil: dados, políticas públicas e perspectivas. In: Cruz MUG, Batitucci ECO, editors. Homicídios no Brasil. Rio de Janeiro: FGV; 2007. p. 51-78.

Cardona PS, Chaturvedi AK, Soper JW, Canfield DV. Simultaneous analyses of cocaine, cocaethylene, and their possible metabolic and pyrolytic products. Forensic Sci Int. 2006;157(1):46-56.

Carlini EA, Galduróz JC, Noto AR, Nappo SA. I Levantamento domiciliar nacional sobre uso de drogas psicotrópicas no Brasil (2001). São Paulo: Secretaria Nacional Antidrogas/Centro Brasileiro de Informações sobre Drogas Psicotrópicas; 2002.

Carrera MRC, Meijler MM, Janda KD. Cocaine pharmacology and current pharmacotherapies for its abuse. Bioorganic \& Medicinal Chemistry. 2004;12:5019-30.

Carvalho HB, Seibel SD. Crack cocaine use and its relationship with violence and HIV. Clinics. 2009;64:857-66.

Carvalho JCA. Farmacologia dos Anestésicos Locais. Rev Bras Anestesiol. 1994;44(1):75-82.

Cerro JCL. Cannabis. In: Lorenzo P, Ladero JM, Leza JC, Lizasoain I. Drogodependencias. Madri: Panamericana; 1998. 191-214.

Chaves TV, Sanchez ZM, Ribeiro LA, Nappo AS. Crack cocaine craving: behaviors and coping strategies among current and former users. Rev Saude Publica. 2011;45:1168-75.

Cherpitel, C. J. Methods of Epidemiological Studies in the Emergency Department. In: C. J. Cherpitel, G. Borges, N. Giesbrecht, D. Hungerford, M. Peden, V. Poznyak et al., editors. Emergency Department Studies in an International Perspective, Emergency Department Studies in an International Perspective. Geneva, Switzerland: WHO; 2010, pp. 107- 114.

Cone EJ, Hiilsgrove M, Darwin WD. Simultaneous Measurement of Cocaine, Cocaethylene, Their Metabolites, and "Crack" Pyrolysis Products by Gas Chromatography-Mass Spectrometry. Drug Monitoring and Toxicology. 1994;40(7):1299.

Cone EJ. Pharmacokinetics and pharmacodynamics of cocaine. J Anal Toxicol. 1995;19:459-78.

Crane NA, Schuster RM, Fusar-Poli P, Gonzales, R. Effects of cannabis on neurocognitive functioning: recent advances, neurodevelopmental influences, and sex differences. Neuropsychol Rev. 2013;23(2):117-37. 
Dams R, Murphy CM, Lambert WE, Huestis MA. Urine drug testing for opioids, cocaine, and metabolites by direct injection liquid chromatography/ tandem mass spectrometry. Rapid Commun Mass Spectrom. 2003;17(14):1665-70.

Darke S. The toxicology of homicide offenders and victims: a review. Drug Alcohol Rev. 2010;29:202-15.

D’Avila FB, Ferreira PC, Salazar FR, Pereira AG, Santos MK, Pechansky F, Limberger RP, Froehlich PE. Analysis of cocaine/crack biomarkers in meconium by LC-MS. J Chromatogr B Anal Technol Biomed Life Sci. 2016;1012-1013:1137.

D'Avila FB, Pereira AG, Salazar FR, Ferreira PL, Salazar CR, Limberger RP, Froehlich PE. Determination of cocaine/crack biomarkers in colostrum by LC-MS following protein precipitation. J Pharm Biomed Anal. 2015;103:67-72.

Dias AC, Araújo MR, Dunn J, Sesso RC, de Castro V, Laranjeira R. Mortality rate among crack/cocaine-dependent patients: A 12-year prospective cohort study conducted in Brazil. Journal of Substance Abuse Treatment. 2011;41:273-8.

Domingo-Salvany A, Herrero MJ, Fernandez B, Perez J, Del Real P, GonzálezLuque JC, de la Torre R. Prevalence of psychoactive substances, alcohol and illicit drugs, in Spanish drivers: A roadside study in 2015. Forensic Sci Int. 2017;278:253-9.

Drummer $\mathrm{OH}$. Postmortem toxicology of drugs of abuse. Forensic Sci Int. 2004;142:101-13.

Drummer $\mathrm{OH}$, Karch S. Interpretation of Toxicological Data. In: Moffat AC, Osselton MD, Widdop B. Clarke's analysis of drugs and poisons. London: Pharmaceutical Press; 2011. 417-28.

Duailibi LB, Ribeiro M, Laranjeira R. Profile of cocaine and crack users in Brazil. Cad Saude Publica 2008; 24: 547-57.

Dulaurent S, El Balkhi S, Poncelet L, Gaulier JM, Marquet P, Saint-Marcoux F. QuEChERS sample preparation prior to LC-MS/MS determination of opiates, amphetamines, and cocaine metabolites in whole blood. Anal Bioanal Chem. 2016;8(5):1467-74.

Dunn J, Laranjeira R. Cocaine--profiles, drug histories, and patterns of use of patients from Brazil. Substance Use \& Misuse. 1999;34(11):1527-48.

European Monitoring Centre for Drugs and Drug Addiction (EMCDDA). European Drug Report 2015. p.86.

Engström A, Adamsson C, Allebeck P, Rydberg U. Mortality in patients with substance abuse: a follow-up in Stockholm County, 1973-1984. Int J Addict. $1991 ; 26: 91-106$. 
European Monitoring Centre for Drugs and Drug Addiction (EMCDDA). Mortality related to drug use in Europe: public health implications. Luxembourge: Publications Office of the European Union. 2011.

Fandino AS, Toennes SW, Kauert GF. Studies on in vitro degradation of anhydroecgonine methyl ester (methylecgonidine) in human plasma. J Anal Toxicol. 2002a;26(8):567-70.

Fandino AS, Karas M, Toennes SW, Kauert G. Identification of anhydroecgonine methyl ester $\mathrm{N}$-oxide, a new metabolite of anhydroecgonine methyl ester, using electrospray mass spectrometry. J Mass Spectrom. 2002b;37(5):525-32.

Ferreira Filho OF, Turchi MD, Laranjeira R, Castelo A. Epidemiological profile of cocaine users on treatment in psychiatrics hospitals, Brazil. Rev Saúde Pública. 2003;37:751-9.

Fiorentin TR, D'Avila FB, Comiran E, Zamboni A, Scherer JN, Pechansky F, Borges PEM, Froehlich PE, Limberger RP. Simultaneous determination of cocaine/crack and its metabolites in oral fluid, urine and plasma by liquid chromatography-mass spectrometry and its application in drug users. $J$ Pharmacol Toxicol Methods. 2017a;86:60-6.

Fiorentin TR, Scherer JN, Marcelo MCA, Sousa TRV, Pechansky F, Ferrao MF, Limberger RP. Comparison of cocaine/crack biomarkers concentra-tions in oral fluid, urine and plasma simultaneously collected from drug users. J Anal Toxicol. 2017b:1-8.

Fischer B, Cruz MS, Bastos FI, Tyndall M. Crack across the Americas - A massive problem in continued search of viable answers: Exemplary views from the North (Canada) and the South (Brazil). International Journal of Drug Policy. 2013;24:631-3.

Fischer B, Kuganesan S, Burnett C, Gallassi A, Werb D. 'Crack': global epidemiology, key characteristics and consequences of use, and existent interventions. In: Fielding, A. (Ed.) Roadmaps to Regulation: Coca, Cocaine, and Derivatives - A Report Commissioned by the Beckley Foundation's Global Initiative for Drug Policy Reform. The Beckley Foundation, Oxford. 2016.

Flanagan RJ, Connally G, Evans JM. Analytical Toxicology: Guidelines for Sample Collection Postmortem. Toxicol Rev. 2005;24(1):63-71.

Fonseca Pego AM, Roveri FL, Kuninari RY, Leyton V, Miziara ID, Yonamine M. Determination of cocaine and its derivatives in hair samples by liquid phase microextraction (LPME) and gas chromatography-mass spectrometry (GC-MS), Forensic Sci Int. 2017;274:83-90. 
Fonseca Pego AM, de Oliveira SCWSEF, de Oliveira TF, Leyton V, Miziara ID, Mauricio Yonamine M. Cocaine toxicological findings in cases of violent death in Sao Paulo city - Brazil. Journal of Forensic and Legal Medicine. 2018;60:3-8.

França EB, Passos VMA, Malta DC, Duncan BB, Ribeiro ALP, Guimarães MDC, Abreu DMX, Vasconcelos ANM, Carneiro M, Teixeira R, Camargos P, Melo APS, Queiroz BL, Schmidt MI, Ishitani L, Ladeira RM, Morais-Neto OL, BustamanteTeixeira MT, Guerra MR, Bensenor I, Lotufo P, Mooney M, Naghavi M. Causespecific mortality for 249 causes in Brazil and states during 1990-2015: a systematic analysis for the global burden of disease study 2015. Population Health Metrics. 2017;15:39.

Galduróz JC, Noto AR, Nappo SA, Carlini EA. I Levantamento domiciliar nacional sobre uso de drogas psicotrópicas - Parte A: estudo envolvendo as 24 maiores cidades do estado de São Paulo (1999). São Paulo: Fundação de Amparo à Pesquisa do Estado de São Paulo/Centro Brasileiro de Informações sobre Drogas Psicotrópicas; 2000.

Garry A, Rigourd V, Amirouche A, Fauroux V, Aubry S, Serreau R. Cannabis and breastfeeding. J Toxicol. 2009;2009:1-5.

Gergov M, Ojanpera I, Vuori E. Simultaneous screening for 238 drugs in blood by liquid chromatography-ion spray tandem mass spectrometry with multiplereaction monitoring. $J$ Chromatogr $B$ Anal Technol Biomed Life Sci. 2003;795(1):41-53.

Gerostamoulos D, Beyer J, Staikos V, Tayler P, Woodford N, Drummer OH. The effect of the postmortem interval on the redistribution of drugs: a comparison of mortuary admission and autopsy blood specimens. Forensic Sci Med Pathol. 2012;8:373-9.

Giorgi SN, Meeker JE. A 5-year stability study of common illicit drugs in blood. $J$ Anal Toxicol. 1995;19(6):392-8.

Gjerde $H$, Øiestad EL, Christophersen AS. Using biological samples in epidemiological research on drugs of abuse. Nor Epidemiol. 2011;21:5-14.

Gloss D. An overview of products and bias in research. Neurotherapeutics. 2015;12(4):731-4.

Gold MS. Cocaine. New York: Plenum Medical Book Company; 1993.

Goldstein PJ, Johnson BD. Robbery among Heroin Users. Presented at annual meetings of the Society for the Study of Social Problems. 1983.

Goldstein PJ. The drugs/violence nexus: a tripartite conceptual framework. J Drug Issues. 1985;14:493-506. 
Goldstein RA, DesLauriers C, Burda AM. Cocaine: History, Social Implications, and Toxicity-A Review. Dis Mon. 2009;55:6-38.

Gossop M, Stewart D, Treacy S, Marsden J. A prospective study of mortality among drug misusers during a 4-year period after seeking treatment. Addiction. 2002;97:39-47.

Grant I, Gonzalez R, Carey CL, Natarajan L, Wolfson T. Non-acute (residual) neurocognitive effects of cannabis use: a meta-analytic study. J Int Neuropsychol Soc. 2003;9(5):679-89.

Grinshteyn E, Hemenway D. Violent death rates: the US compared with other high-income OECD countries, 2010. Am J Med. 2016;129:266-73.

Guha N, Loomis D, Grosse Y, Lauby-Secretan B, El Ghissassi F, Bouvard V, Benbrahim-Tallaa L, Baan R, Mattock H, Straif K. International Agency for Research on Cancer Monograph Working Group, Carcinogenicity of trichloroethylene, tetrachloroethylene, some other chlorinated solvents, and their metabolites. Lancet Oncol. 2012;13(12):1192-3.

Guimarães RA, Mesquita NS, Lopes RS, Lucchese R, Felipe RL, Vera I, Fernandes IL, Castro PA, Monteiro LHB, Silva GC. Prevalence and Factors Associated With Criminal Behavior Among Illicit Drug Users: A Cross-Sectional Study, Substance. Use \& Misuse. 2017;52:(11):1393-9.

Guindalini C, Vallada H, Gerome Breen G, Laranjeira R. Concurrent crack and powder cocaine users from Sao Paulo: Do they represent a different group? BMC Public Health. 2006;6(10).

Halpern SC, Scherer JN, Roglio V, Faller S, Sordi A, Ornell F, Dalbosco C, Pechansky F, Kessler F, von Diemen L. Vulnerabilidades clínicas e sociais em usuários de crack de acordo com a situação de moradia: um estudo multicêntrico em seis capitais brasileiras. Cad. Saúde Pública. 2017;33(6):e00037517.

Haggerty GC, Deskin R, Kurtz PJ, Fentiman AF, Leighty EG. The pharmacological activity of the fatty acid conjugate 11-palmitoyloxy-delta 9tetrahydrocannabinol. Toxicol Appl Pharmacol. 1986;84:599-606.

Hartman RL, Huestis MA. Cannabis Effects on Driving Skills. Clinical Chemistry. 2013;59(3):478-92.

Hatsukami DK, Fischman MW. Crack cocaine and cocaine hydrochloride. Are the differences myth or reality? JAMA. 1996;276:1580-8.

Heard K, Palmer R, Zahniser NR. Mechanisms of acute cocaine toxicity. Open Pharmacol J. 2008;2(9):70-8. 
Hearn WL, Flynn DD, Hime GW, Rose S, Cofino JC, Mantero-Atienza E, Wetli $\mathrm{CV}$, Mash DC. Cocaethylene: a unique cocaine metabolite displays high affinity for the dopamine transporter. J. Neurochem. 1991;56(2):698-701.

Hearn WL, Walls HC. Introduction to Postmortem Toxicology. In: Karch SB. Postmortem Toxicology of Abused Drugs. Boca Raton: CRC Press Taylor \& Francis Group; 2008. 1-11.

Hepler BR, Isenschmid DS. Specimen Selection, Collection, Preservation, and Security. In: Karch SB. Postmortem Toxicology of Abused Drugs. Boca Raton: CRC Press Taylor \& Francis Group; 2008. 13-30

Herbst ED, Harris DS, Everhart ET, Mendelson J, Jacob P, Jones RT. Cocaethylene Formation Following Ethanol and Cocaine Administration by Different Routes. Experimental and Clinical Psychopharmacology. 2011;19(2):95-104.

Hezinova V, Aturki Z, Kleparnik K, D'Orazio G, Foret F, Fanali S. Simultaneous analysis of cocaine and its metabolites in urine by capillary electrophoresiselectrospray mass spectrometry using a pressurized liquid junction nanoflow interface. Electrophoresis. 2012;33(4):653-60.

Hickman M, Carnwath Z, Madden P, Farrell M, Rooney C, Ashcroft R, et al. Drugrelated mortality and fatal overdose risk: pilot cohort study of heroin users recruited from specialist drug treatment sites in London. J Urban Health. 2003;80:274-87.

Hoaken PN, Stewart SH. Drugs of abuse and the elicitation of human aggressive behavior. Addictive Behaviors. 2003;28(9):1533-54.

Hoffman RS. Cocaine. In: Flomenbaum NE, Goldfrank LR, Hoffman RS, et al., editors. Goldfrank's Toxicologic Emergencies. New York: McGraw Hill; 2006. 1133-46.

Houwing S, Hagenzieker M, Mathijssen R, Bernhoft IM, Hels T, Janstrup K, et al. Prevalence of alcohol and other psychoactive substances in drivers in general traffic. Part I: general results. 2011. 173p.

Hu SS, Mackie K. Distribution of the endocannabinoid system in the central nervous system. In: Pertwee RG. Handbook of Experimental Pharmacology. New York: Springer; 2015. 59-93.

Huestis MA. Pharmacokinetics and metabolism of the plant cannabinoids, delta9tetrahydrocannabinol, cannabidiol and cannabinol. Handb Exp Pharmacol. 2005:657-90.

IBGE (2010). Censo 2010. Brasília: Instituto Brasileiro de Geografia e Estatística. 
IBGE (2018). Projeções e estimativas da população do Brasil e das Unidades da Federação. [Internet]. [citado em 5 mar 2019]. Disponível em: https://www.ibge.gov.br/apps/populacao/projecao/

Imbert L, Dulaurent S, Mercerolle M, Morichon J, Lachatre G, Gaulier JM. Development and validation of a single LC-MS/MS assay following SPE for simultaneous hair analysis of amphetamines, opiates, cocaine and metabolites, Forensic Sci Int. 2014;234:132-8.

Institóris L, Tóth AR, Molnár A, Arok Z, Kereszty E, Varga T. The frequency of alcohol, illicit and licit drug consumption in the general driving population in SouthEast Hungary. Forensic Sci Int. 2013;224(1-3):37-43.

Ismaiel OA, Zhang T, Jenkins RG, Karnes HT. Investigation of endogenous blood plasma phospholipids, cholesterol and glycerides that contribute to matrix effects in bioanalysis by liquid chromatography/mass spectrometry. J Chromatogr B Anal Technol Biomed Life Sci. 2010;878(31):3303-16.

Iversen L. How cannabis works in the human brain. In: Castle D, Murray R, D'Souza DC. Marijuana and madness. Cambridge: Cambridge University Press; 2012. 1-11.

Izzo AA, Borrelli F, Capasso R, Di Marzo V, Mechoulam R. Non-psychotropic plant cannabinoids: new therapeutic opportunities from an ancient herb. Trends Pharmacol Sci. 2009;30(10):515-27.

Jacob P, Lewis ER, Elias-Baker BA, Jones RT. A pyrolysis product, anhydroecgonine methyl ester (methylecgonidine), is in the urine of cocaine smokers. J Anal Toxicol. 1990;14:353-7.

Jatlow P. Cocaethylene: pharmacologic activity and clinical significance. Ther Drug Monit. 1993;15(6):533-6.

Jemal M, Ouyang Z, Xia YQ. Systematic LC-MS/MS bioanalytical method development that incorporates plasma phospholipids risk avoidance, usage of incurred sample and well thought-out chromatography. Biomed Chromatogr. 2010;24(1):2-19.

Jenkins AJ, Goldberger, BA. Identification of unique cocaine metabolites and smoking by-products in postmortem blood and urine specimens. J Forensic Sci. 1997;42(5):824-7.

Johnson BD, Goldstein PJ, Preble E, Schmeidler, Lipton JDS, Spunt B, Miller T. Taking Care of Business: The Economics of Crime by Heroin Abusers. Lexington: Lexington Books. 1985.

Jones GR. Interpretation of Postmortem Drug Levels. In: Karch SB. Postmortem Toxicology of Abused Drugs. Boca Raton: CRC Press Taylor \& Francis Group; 2008. 113-30. 
Jones G. Postmortem Toxicology. In: Moffat AC, Osselton MD, Widdop B. Clarke's analysis of drugs and poisons. London: Pharmaceutical Press; 2011. 176-89.

Jones AW, Holmgren A. Concentrations of Cocaine and Benzoylecgonine in Femoral Blood from Cocaine-Related Deaths Compared with Venous Blood from Impaired Drivers. J Anal Toxicol. 2014;38:46-51.

Kaplan MS, Giesbrecht N, Caetano R, Conner KR, Huguet N, McFarland BH, Nolte KB. Acute alcohol consumption as a contributing factor to suicidal behavior. Am J Public Health. 2013;103(e2-e3).

Karch SB. Alternate strategies for post mortem drug testing. J Anal Toxicol. 2001;25(5):393-5.

Kerrigan S. Sampling, Storage and Stability. In: Moffat AC, Osselton MD, Widdop B. Clarke's analysis of drugs and poisons. London: Pharmaceutical Press; 2011. 445-57.

Kessler FHP, Terra MB, Faller S, Stolf AR, Peuker CA, Benzano D, et al. Crack users show high rates of antisocial personality disorder, engagement in illegal activities and other psychosocial problems. Am J Addicti. 2012;21:370-80.

Kintz P, Cirimele V, Sengler C, Mangin P. Testing human hair and urine for anhydroecgonine methyl ester, a pyrolysis product of cocaine. J Anal Toxicol. 1995;19:479-82.

Kintz P, Sengler C, Cirimele V, Mangin P. Evidence of crack use by anhydroecgonine methylester identification. Hum Exp Toxicol. 1997;16 (2):1237.

Kolbrich EA, Barnes AJ, Gorelick DA, Boyd SJ, Cone EJ, Huestis MA. Major and minor metabolites of cocaine in human plasma following controlled subcutaneous cocaine administration. J Anal Toxicol. 2006;30(8):501-10.

Kole PL, Venkatesh G, Kotecha J, Sheshala R. Recent advances in sample preparation techniques for effective bioanalytical methods. Biomed Chromatogr. 2011;25(1-2):199-217.

Kraemer T, Paul LD. Bioanalytical procedures for determination of drugs of abuse in blood. Anal Bioanal Chem. 2007;388(7):1415-35.

Kuhns JB, Exum ML, Clodfelter TA, Bottia MC. The prevalence of alcoholinvolved homicide offending: A meta-analytic review. Homicide Studies. 2014;18:251-70.

Kuhns JB, Maguire ER. Drug and alcohol use by homicide victims in Trinidad and Tobago, 2001-2007. Forensic Sci Med Pathol. 2012;8(3):243-51. 
Kuhns JB, Wilson DB, Clodfelter TA, Maguire ER, Ainsworth SA. A meta-analysis of alcohol toxicology study findings among homicide victims. Addiction. 2011;106:62-72.

Langman LJ, Bjergum MW, Williamson CL, Crow FW. Sensitive method for detection of cocaine and associated analytes by liquid chromatography- tandem mass spectrometry in urine. J Anal Toxicol. 2009;33(8);447-55.

Laranjeira R, supervisor. II Levantamento Nacional de Álcool e Drogas (LENAD) - 2012. São Paulo: INPAD/UNIFESP; 2014.

Lee D, Delcher C, Maldonado-Molina MM, Thogmartin JR, Goldberger BA. Manners of Death in Drug-Related Fatalities in Florida. J Forensic Sci. 2016;61(3).

Leite MC, Andrade AC, et al. Cocaína e crack: dos fundamentos ao tratamento. Porto Alegre: Editora Artes Médicas Sul; 1999.

Liakoni E, Gartwyl F, Ricklin M, Exadaktylos AK, Krähenbühl S. Psychoactive substances and violent offences: A retrospective analysis of presentations to an urban emergency department in Switzerland. PLoS ONE. 2018;13(3):e0195234.

Licata A, Taylor S, Berman M, Cranston J. Effects of cocaine on human aggression. Pharmacol Biochem Behav. 1993;45:549-52.

Lima D, Garcia A. A ingestão de álcool e o ato de dirigir: medição e consequências. Revista ABRAMET. 2001;37:44-47.

Lorenzetti V, Lubman DI, Fornito A, Whittle S, Takagi MJ, Solowij N, et al. The impact of regular cannabis use on the human brain: a review of structural neuroimaging studies. In: Miller PM. Biological research on addiction. San Diego: Academic Press; 2013. 711-28.

MacDonald S, Anglin-Bodrug K, Mann RE, Erickson P, Hathaway A, Chipman M, Rylett M. Injury risk associated with cannabis and cocaine use. Drug Alcohol Depend. 2003;72:99-115.

MacDonald S, Erickson P, Wells S, Hathaway A, Pakula B. Predicting violence among cocaine, cannabis, and alcohol treatment clients. Addict Behav. 2008;33:201-5.

Macdonald S, Pakula B, Martin G, Wells S, Borges G, Roth E, Salmon A, Stockwell T, Callaghan RC. Health Profiles of Clients in Substance Abuse Treatment: A Comparison of Clients Dependent on Alcohol or Cocaine With Those Concurrently Dependent. Substance Use \& Misuse. 2014;49(14).

Madras BK (2015). Update of cannabis and its medical use. Report to the WHO Expert Committee on Drug Dependence. [citado 28 novembro 2016]. Disponível 
em:

http://www.who.int/medicines/access/controlledsubstances/6_2_cannabis_upda te.pdf?ua=1

Malhotra N, Starkey NJ, Charlton SG. Driving under the influence of drugs: Perceptions and attitudes of New Zealand drivers. Accident Anal. Prev. 2017;106:44-52.

Mann RE, Zalcman RF, Smart R, Rush BR, Suurvali H. Alcohol consumption, Alcoholics Anonymous membership and homicide mortality rates in Ontario, 1968 to 1991. Alcohol Clin Exp Res. 2006;30:1743-51.

Matielo F, Maniglia FT, Senaga KI, et al. Atenção: estrabismo e direção veicular. Revista ABRAMET. 2002;20:14-9.

Matuszewski BK, Constanzer ML, Chavez-Eng CM. Strategies for the assessment of matrix effect in quantitative bioanalytical methods based on HPLC-MS/MS. Anal. Chem. 2003;75(13):3019-30.

McEllistren JE. Affective and predatory violence: a bimodal classification system of aggression and violence. Aggress Viol Behav. 2004;10:1-30.

McGinty EE, Choksy S, Wintemute GJ. The Relationship Between Controlled Substances and Violence. Epidemiol Rev. 2016;38:5-31.

McGinty EE, Webster DW. The Roles of Alcohol and Drugs in Firearm Violence. JAMA Internal Medicine. 2017;177(3).

Mechoulam R, Hanus L. Other cannabinoids. In: Castle D, Murray RM, D'Souza DC. Marijuana and madness. Cambridge: Cambridge University Press; 2012. 1722.

Moffat AC, Osselton MD, Widdop B. Clarke's analysis of drugs and poisons. 4 ${ }^{\text {a }}$ ed. London: Pharmaceutical Press; 2011. 2609 p.

Moolchan ET, Cone EJ, Wstadik A, Huestis MA, Preston KL. Cocaine and metabolite elimination patterns in chronic cocaine users during cessation: plasma and saliva analysis. J Anal Toxicol. 2000;24:458-66.

Moreira MM, Laranjeira R, Mitsuhiro SS Uso de crack no Brasil e factores psicossociais que antecedem esta tomada de decisão. Salud \& Sociedad. 2017;8(3):254 - 61 .

Moreira MR, Fernandes FMB, Ribeiro JM, Neto TLF. A review of Brazilian scientific output on crack-contributions to the political agenda. Ciênc Saúde Coletiva. 2015;20:1047-62. 
Moreno C, Pasqua I, Cristofoletti M. Turnos irregulares de trabalho e sua influência nos hábitos alimentares e de sono: o caso dos motoristas de caminhão. Revista ABRAMET. 2001;36:17-24.

Morgan DJ, McLean AJ. Clinical pharmacokinetic and pharmacodynamics considerations in patients with liver disease: an update. Clin Pharmacokinet. 1995;29:370-91.

Narvaez JC, Jansen K, Pinheiro RT, Kapczinski F, Silva RA, Pechansky F, Magalhaes PV. Psychiatric and substance-use comorbidities associated with lifetime crack cocaine use in young adults in the general population. Comprehensive Psychiatry. 2014;55(6):1369-76.

National Institute on Drug Abuse (NIDA). Cocaine. Source: National Institute on Drug Abuse; National Institutes of Health; U.S. Department of Health and Human Services. [citado 30 novembro 2016]. Disponível em: https://www.drugabuse.gov

North Carolina Office of the Chief Medical Examiner (NC-OCME). Toxicology. [Internet]. [citado 15 fev 2019]. Disponível em: https://www.ocme.dhhs.nc.gov/toxicology/index.shtml

Novakova L. Challenges in the development of bioanalytical liquid chromatography-mass spectrometry method with emphasis on fast analysis. $J$ Chromatogr A. 2013;1292:25-37.

Oiestad EL, Johansen U, Christophersen AS. Drug screening of preserved oral fluid by liquid chromatography-tandem mass spectrometry. Clin Chem. 2007;53(2):300-9.

Oiestad EL, Johansen U, Oiestad AM, Christophersen AS. Drug screening of whole blood by ultra-performance liquid chromatography-tandem mass spectrometry. J Anal Toxicol. 2011;35(5):280-93.

Ousey GC, Lee MR. Examining the conditional nature of the illicit drug markethomicide relationship: a partial test of the theory of contingent causation. Criminology. 2002;40:73-101.

Pelição FS, Peres MD, Pissinate JF, de Paula DML, de Faria MGC, NakamuraPalacios EM, De Martinis BS. Predominance of alcohol and illicit drugs among traffic accidents fatalities in an urban area of Brazil. Traffic Injury Prevention. 2016;17(7):663-7.

Pelissier-Alicot $A L$, et al. Mechanisms underlying postmortem redistribution of drugs: a review. J Anal Toxicol. 2003;27:533-44.

Perez-Reyes M, Wall ME. Presence of delta9-tetrahydrocannabinol in human milk. N Engl J Med. 1982;307:819-20. 
Perri CP, Dunn J. Overdose por cocaína - uma revisão crítica. Rev Bras Clin terap. 1999;25(5).

Phillips JP. Construct Validity of a Laboratory Aggression Paradigm: A MultitraitMultimethod Approach, College of Arts and Sciences. University of Kentucky, Lexington, Kentucky. 2011. p.60.

Potter DJ. A review of the cultivation and processing of cannabis (Cannabis sativa L.) for production of prescription medicines in the UK. Drug Test Anal. 2014;6:318.

Poulsen $\mathrm{H}$, Moar R, Troncoso $\mathrm{C}$. The incidence of alcohol and other drugs in drivers killed in New Zealand road crashes 2004-2009. Forensic Sci Int. 2012;223:364-70.

Radwan MM, EISohly MA, El-Alfy AT, Ahmed SA, Slade D, Husni AS, et al. Isolation and pharmacological evaluation of minor cannabinoids from high potency Cannabis sativa. J Nat Prod. 2015;78(6):1271-6.

Raup LM, Adorno RCF. Jovens em situação de rua e usos de crack: um estudo etnográfico em duas cidades. Rev. Bras. Adolescência e Conflitualidade. 2011(4):52-67.

Rees KA, Jones NS, McLaughlin PA, Seulin S, Leyton V, Yonamine M, Osselton MD. The effect of sodium fluoride preservative and storage temperature on the stability of cocaine in horse blood, sheep vitreous and deer muscle. Forensic Sci Int. 2012;217(1-3):182-8.

Rehm J, Gmel GE, Gmel G, Hasan OSM, Imtiaz S, Popova S, et al. The relationship between different dimensions of alcohol use and the burden of disease-an update. Addiction. 2017;112:968-1001.

Reichenheim ME, Souza ER, Moraes CL, Mello Jorge MHP, Silva CMFP, Minayo MCS. Violence and injuries in Brazil: the eff ect, progress made, and challenges ahead. Lancet. 2011;377:1962-75.

Ribeiro M, Duailibi S, Frajzinger R, Alonso ALS, Marchetti L, Williams A, Strang $\mathrm{J}$, Laranjeira R. The Brazilian 'Cracolândia' open drug scene and the challenge of implementing a comprehensive and effective drug policy. Addiction. 2016;111:571-3.

Ribeiro M, Dunn J, Laranjeira R, Sesso R. High mortality among young crack cocaine users in Brazil: a 5-year follow-up study. Addiction. 2004;99(9):1133-35.

Romano M; Ribeiro M, Marques ACPR. Abuso e Dependência da Cocaína (Projeto Diretrizes). Associação Brasileira de Psiquiatria; 2002. 
Romano E, Torres-Saavedra P, Voas RB, Lacey JH. Marijuana and the risk of fatal car crashes: what can we learn from FARS and NRS data? J Prim Prev. 2017;38:315-28.

Room R, Rossow I. The share of violence attributable to drinking. J Subst Use. $2001 ; 6: 218-28$.

Santos Cruz M, Andrade T, Bastos FI, Leal E, Bertoni N, Villar LM, Fischer B. Key drug use, health and socio-economic characteristics of young crack users in two Brazilian cities. International Journal of Drug Policy. 2013;24(5):432-8.

São Paulo (Estado). Superintendência da Polícia Técnico-Científica. Instituto Médico Legal. Portaria do Diretor Técnico de Departamento, de 04-07-2012. Dispõe sobre normas e procedimentos para envio de materiais biológicos para análise ao Núcleo de Toxicologia Forense. Diário Oficial do Estado, São Paulo. Poder Executivo - Seção I. 201207 jul.;122(127):11.

São Paulo. São Paulo State Government Restart Program - the state program for coping with crack and other drugs. [Internet]. [citado em 20 fev 2019]. São Paulo, SP. 2014. Disponível em: http://www.programarecomeco.sp.gov.br.

Schreiner A, Dunne ME. Residual effects of cannabis use on neurocognitive performance after prolonged abstinence: a meta-analysis. Exp Clin Psychopharmacol. 2012;20:420-9.

Sharma P, Murthy P, Bharath MMS. Chemistry, Metabolism, and Toxicology of Cannabis: Clinical Implications. Iran J Psychiatry. 2012;7(4):149-156.

Scheidweiler KB, Schwope DM, Karschner EL, Desrosiers NA, Gorelick DA, Huestis MA. In Vitro Stability of Free and Glucuronidated Cannabinoids in Blood and Plasma Following Controlled Smoked Cannabis. Clinical Chemistry. 2013;59(7):1108-17

Sokolov BP, Cadet JL. Methamphetamine causes alteration in the MAP kinaserelated pathways in the brains of mice that display increased aggression. Neuropsychopharmacology. 2006;31:956-66.

Sokolov BP, Schlinder CW, Cadet JL. Chronic methamphetamine increases fighting in mice. Pharmacol Biochem Behav. 2004;77:319-26.

Solowij N, Battisti R. The chronic effects of cannabis on memory in humans: a review. Curr Drug Abuse Rev. 2008;1(1):81-98.

Souza ER, Minayo MCS. Violência no transito: expressão da violência social. In: Ministério da Saúde, ed. Impacto da violência na saúde dos brasileiros. Brasília: MS. 2005:279-312. 
Strano-Rossi S, Colamonici C, Botre F. Parallel analysis of stimulants in saliva and urine by gas chromatography/mass spectrometry: perspectives for "in competition" anti-doping analysis. Anal Chim Acta. 2008;606(2):217-22.

Scientific Working Group for Forensic Toxicology (SWGTOX). Standard Practices for Method Validation in Forensic Toxicology. J Anal Toxicol. 2013;37(7):452-74.

Tardiff K, Marzuk PM, Leon AC, Hirsch CS, Stajić M, Portera L, Hartwell N. Cocaine, opiates, and ethanol in homicides in New York City: 1990 and 1991. J Forensic Sci. 1995;40(3):387-90.

Thibert V, Legeay P, Chapuis-Hugon F, Pichon V. Molecularly imprinted polymer for the selective extraction of cocaine and its metabolites, benzoylecgonine and ecgonine methyl ester, from biological fluids before LC-MS analysis. J Chromatogr B Anal Technol Biomed Life Sci. 2014;949-950:16-23.

Toennes SW, Fandino AS, Kauert G. Gas chromatographic-mass spectrometric detection of anhydroecgonine methyl ester (methylecgonidine) in human serum as evidence of recent smoking of crack. Journal of Chromatography $B$. 1999;735:127-32.

Toennes SW, Fandino AS, Hesse FJ, Kauert GF. Artifact production in the assay of anhydroecgonine methyl ester in serum using gas chromatography-mass spectrometry. J Chromatogr B Analyt Technol Biomed Life Sci. 2003;792:34551.

Toledo L, Góngora A, Bastos FIPM. À margem: uso de crack, desvio, criminalização e exclusão social - uma revisão narrativa. Ciênc Saúde Coletiva. 2017;22:31-42.

Tunving K. Fatal outcome in drug addiction. Acta Psychiatr Scand. 1988;77:55166.

United Nations Office on Drugs and Crime (UNODC). Terminology and information on drugs. New York: UNODC; 2003.

United Nations Office on Drugs and Crime. Guidance for the Validation of Analytical Methodology and Calibration of Equipment used for Testing of Illicit Drugs in Seized Materials and Biological Specimens: A commitment to quality and continuous improvement. Vienna:UNODC;2009.

United Nations Office on Drugs and Crime (UNODC). World Drug Report 2013. Vienna: UNODC; 2013.

United Nations Office on Drugs and Crime (UNODC). Colombia Coca Cultivation Survey 2014. Vienna: UNODC; 2015. 
United Nations Office on Drugs and Crime (UNODC). World Drug Report 2016. New York: UNODC; 2016.

United Nations Office on Drugs and Crime (UNODC). World drug report 2017. Vienna: UNODC; 2017.

United Nations Office on Drugs and Crime (UNODC). World Drug Report 2018. Sales No. E.18.XI.9. Vienna: UNODC; 2018.

Valente MJ, Carvalho F, Bastos ML, Carvalho M, de Pinho PG. Development and validation of a gas chromatography/ion trap-mass spectrometry method for simultaneous quantification of cocaine and its metabolites benzoylecgonine and norcocaine: application to the study of cocaine metabolism in human primary cultured renal cells. J Chromatogr B Anal Technol Biomed Life Sci. 2010;878(30):3083-8.

van der Pol P, Liebregts N, de Graaf R, Korf DJ, van den Brink W, van Laar M. Predicting the transition from frequent cannabis use to cannabis dependence: a three-year prospective study. Drug Alcohol Depend. 2013;133(2):352-9.

Vanstechelman S, Isalberti C, Van der Linden T, Pil K, Legrand SA, Verstraete AG. Analytical evaluation of four on-site oral fluid drug testing devices. J Anal Toxicol. 2012;36(2):136-40.

Vaughn MG, Shook JJ, Perron BE, Abdon, A, Ahmedani B. Patterns and correlates of illicit drug selling among youth in the USA. Substance Abuse and Rehabilitation. 2011;2:102-11.

Vearrier D, Vearrier L, McKeever R, Okaneku J, et al. Issues in driving impairment. Disease-a-Month. 2016;62:72-116.

Vitale S, van de Mheen D. Illicit drug use and injuries: a review of emergency room studies. Drug Alcohol Depend. 2006;82:1-9.

Volkow ND, Baler RD, Compton WM, Weiss SRB. Adverse Health Effects of Marijuana Use. N Engl J Med. 2014;370(23):2219-27.

Wang S, Cyronak M, Yang E. Does a stable isotopically labeled internal standard always correct analyte response? A matrix effect study on a LC/MS/ MS method for the determination of carvedilol enantiomers in human plasma. J Pharma Biomed Anal. 2007;43(2):701-7.

Watts J. Cracolândia: the crack capital of Brazil where addicts are forced to seek help. Guardian, London, 9 maio 2013. [Internet]. [citado em 9 jan 2019]. Disponível em: http://www.theguardian.com/world/2013/may/09/cracolandiacrack-capital-brazil.

Wieling J. LC-MS-MS experiences with internal standards. Chromatographia. 2002;55:107-13. 
Wintemute GJ. Alcohol misuse, firearm violence perpetration, and public policy in the United States. Prev Med. 2015;79:15-21.

Wolfgang ME. Victim precipitated criminal homicide. In: Silverman RA, Thornberry TP, Cohen B, Krisberg B, eds. Crime and justice at the millennium. New York: Springer US. 2002. p.293-306.

Wong JY, Seah ES, Lee EJ. Pharmacogenetics: the molecular genetics of CYP2D6 dependent drug metabolism. Ann Acad Med Singapore. 2000;29:4016.

World Health Organization (WHO). Global Health Estimates 2016: Deaths by Cause, Age, Sex, by Country and by Region, 2000-2016. Geneva: WHO; 2018a.

World Health Organization (WHO). Injuries and violence: the facts 2014. Geneva: WHO; 2014.

World Health Organization (WHO). The health and social effects of nonmedical cannabis use. Geneva: WHO; 2016.

World Health Organization (WHO). World health statistics 2018: monitoring health for the SDGs, sustainable development goals. Geneva: WHO; 2018.

Yarema MC, Becker CE. Key concepts in postmortem drug redistribution. Clin Toxicol (Phila). 2005;43: 235-41

Yucel M, Solowij N, Respondek C, Whittle S, Fornito A, Pantellis C, et al. Regional brain abnormalities associated with long-term heavy cannabis use. Arch Gen Psychiatry. 2008; 65:694-701.

Zancanaro I, Limberger RP, Bohel PO, dos Santos MK, De Boni BR, Pechansky F, Caldas ED. Prescription and illicit psychoactive drugs in oral fluid-LC-MS/MS method development and analysis of samples from Brazilian drivers. Forensic Sci Int. 2012;223(1-3):208-16.

Zeferino MT, Fermo VC, Fialho MB, Bastos FI. Semelhanças e contrastes nos padrões de uso de crack em Santa Catarina, Brasil: capital vs Meio Oeste. Ciência \& Saúde Coletiva. 2017;22(1):97-106.

Zinberg NE. Drug, set, and setting. The basis for controlled intoxicant use. New Haven, CT: Yale University Press. 1984. 